ANL-5733

Reactors - Power (TID-4500, 14th Ed.)

AEC Research and

Development Report

\author{
ARGONNE NATIONAL LABORATORY \\ P. O. Box 299 \\ Lemont, Illinois
}

\title{
REACTIVITY TRANSIENTS AND STEADY-STATE OPERATION OF A THORIA-URANIA-FUELED DIRECT-CYCLE LIGHT \\ WATER-BOILING REACTOR (BORAX-IV)
}

\section{by}

B. S. Maxon, O. A. Schulze and J. A. Thie

Reactor Engineering Division

Work performed by:
J. Boland
M. Novick
G. Brunson
O. A. Schulze*
J. D. Cerchione
A. Solbrig
R. N. Curran
R. W. Thiel
F. Kirn
R. Wallin
B. S. Maxon*
G. K. Whitham
F. D. McGinnis
*Loaned Employee from American Machine and Foundry Co.

February, 1959
Operated by The University of Chicago under Contract W-31-109-eng-38




\section{DISCLAIMER}

This report was prepared as an account of work sponsored by an agency of the United States Government. Neither the United States Government nor any agency Thereof, nor any of their employees, makes any warranty, express or implied, or assumes any legal liability or responsibility for the accuracy, completeness, or usefulness of any information, apparatus, product, or process disclosed, or represents that its use would not infringe privately owned rights. Reference herein to any specific commercial product, process, or service by trade name, trademark, manufacturer, or otherwise does not necessarily constitute or imply its endorsement, recommendation, or favoring by the United States Government or any agency thereof. The views and opinions of authors expressed herein do not necessarily state or reflect those of the United States Government or any agency thereof. 


\section{DISCLAIMER}

Portions of this document may be illegible in electronic image products. Images are produced from the best available original document. 
TABLE OF CONTENTS

$\underline{\text { Page }}$

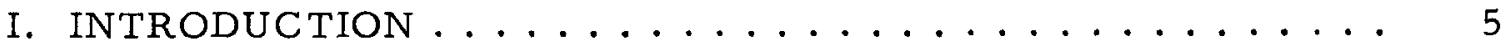

II. DESCRIPTION OF FACILITY ................. 6

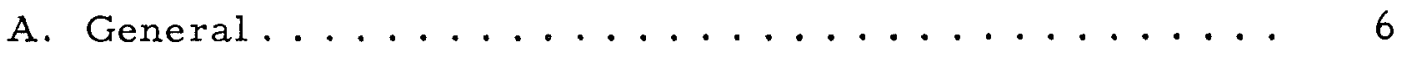

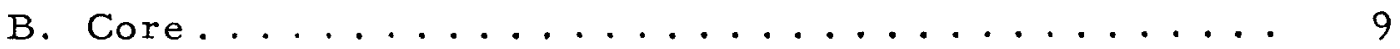

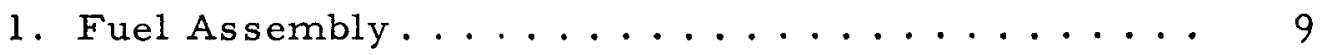

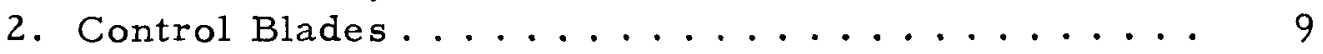

III. PHYSICS STATICS EXPERIMENTS. ............. 13

A. Approach to Criticality................. 13

B. Calibration of Shim and Center Blade(s) ......... 14

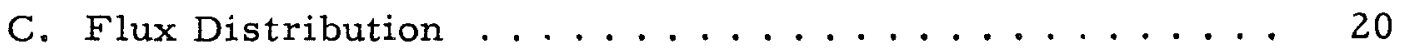

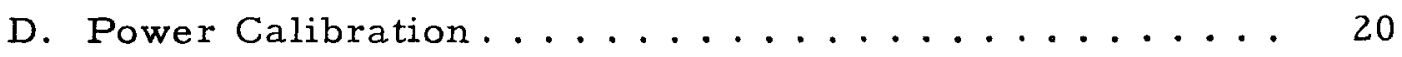

E. Temperature Coefficient of Reactivity.......... 22

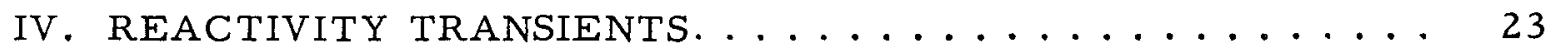

A. Experimental Procedure ................... 23

B. Transients with Water at Atmospheric Boiling

Temperature ..................... 24

C. Transients with Water Initially Subcooled ........ 26

D. Summary of Transient Behavior ............ 30

V. ATMOSPHERIC PRESSURE BOILING . . . . . . . . . . 33

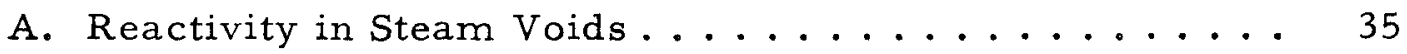

B. Central Fuel and Clad Temperatures ......... 35

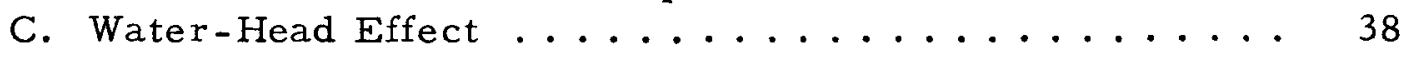

D. Self-Induced Oscillations .............. 40

VI. PRESSURIZED BOILING. . . . . . . . . . . . . . . 43

A. Reactivity in Steam Voids ................ 43

B. Self-Induced Oscillations .................. 43

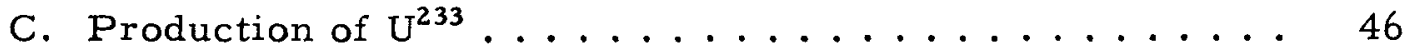

VII. TRANSFER FUNCTION MEASUREMENTS . . . . . . . . . 47

A. Rod Oscillator Experiments ............. 47

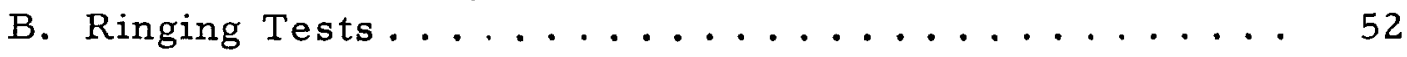

C. Power Frequency Spectrum............. 55 


\section{TABLE OF CONTENTS}

$\underline{\text { Page }}$

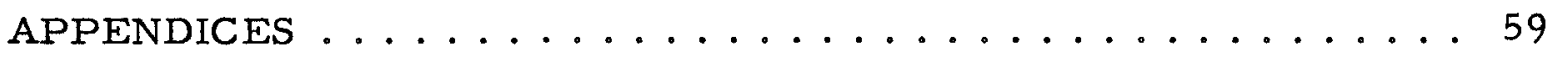

Appendix A: REACTOR CORE PHYSICS. . . . . . . . 59

Appendix B: TRANSFER FUNCTION ANALYSIS ....... 65

Appendix C: ANALYSIS OF INHERENT MECHANISMS OF

REACTIVITY COMPENSATION DURING

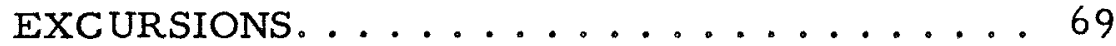

Appendix D: CORE HYDRAULICS................ 73

Appendix E: STEADY-STATE REACTIVITY IN VOIDS . . . . 75

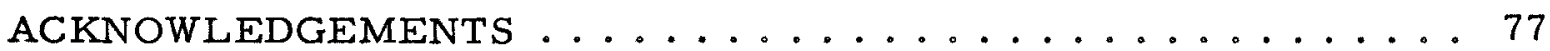

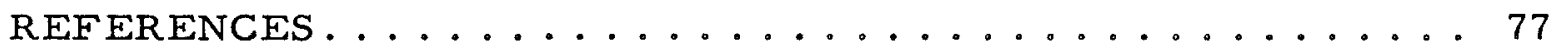




\title{
REACTIVITY TRANSIENTS AND STEADY-STATE OPERATION \\ OF A THORIA-URANIA-FUELED DIRECT-CYCLE LIGHT WATER-BOILING REACTOR SYSTEM (BORAX-IV)
}

\author{
B. S. Maxon, O. A. Schulze and J. A. Thie
}

\begin{abstract}
A series of experiments involving rapid ejections of a control blade from low power levels were done at room temperature and $207^{\circ} \mathrm{F}$ to obtain information about the inherent self-limiting capabilities of light water-boiling reactor systems. Periods down to 83 milliseconds were self-terminated without core damage. Theoretical analysis showed that the power excursion data could be correlated by a single energy coefficient of reactivity: $0.029 \pm 0.001 \%$ reactivity $/ \mathrm{Mw}-\mathrm{sec}$.

Steady-state boiling experiments at pressures ranging from atmospheric pressure to 322 psig gave powers up to $4.6 \mathrm{Mw}$ for the former, and $20.5 \mathrm{Mw}$ for the latter, pressure. A reactivity in steam voids of $6.9 \%$ was achieved at 322 psig; the corresponding power density was $45 \mathrm{kw} / 1$ iter of core.
\end{abstract}

Information on reactor stability was obtained from measurements of transfer function using a rod oscillator. A sharp resonance was observed, and values of the resonant transfer function obtained were as much as seven times higher than the mid-frequency zero-powertransfer function. Theoretical analysis revealed the resonating transfer functions were due to a feedback whose magnitude was of the order of reactivity in steam voids, and whose phase was determined by time constants of the same order as that of the fuel and the steam bubbles.

Computations based on the theoretical initial conversion ratio for $\mathrm{U}^{233}$ show that $71 \mathrm{gm} \mathrm{U}^{233}$ were produced as a result of intermittent experimental operation for one year, equivalent to $300 \mathrm{MWD}$.

\section{INTRODUCTION}

As of 1956, the series of BORAX experiments (carried out in the reactors BOR AX-I, -II, - III $(1-4)$ had provided virtually all existing knowledge pertinent to the safety and operating characteristics of boiling reactors. However, it was realized the thin aluminum-plate fuel elements used in 
the respective cores were not typical of the elements to be employed in, for example, central station boiling power reactors. It was expected the latter type would have appreciably longer thermal time constants. Thus early in 1956 it was decided to design and fabricate a core (designated BORAX-IV) of thoria-urania fuel elements for evaluation in the existing BORAX facility. (5)

The desirable features which led to the selection of the fuel element were: (1) time constants typical of oxide-fueled power reactors (see Appendix B); (2) chemical inertness of an oxide fuel in water; (3) metallurgical simplicity and economy in the use of aluminum tube sheets loaded with oxide pellets; and (4) potential economic advantages associated with conversion of thorium to $\mathrm{U}^{233}$.

The philosophy involved in designing the core was based on having a reactor available for intermittent experimental operation for a year or longer. The balance of the system remained as for BORAX-III, $(3,4)$ characterized by natural circulation, direct cycle, boiling light water with an electrical power capability of $2 \mathrm{Mw}$. The simplicity of the core was demonstrated by the completion of its design and fabrication in less than a year: the reactor was first brought to criticality on December 3, 1956.

The scope of the experimental program was designed to obtain the maximum information on the safety and stability of urania-thoria-fueled boiling reactors consistent with the limited budget allocated this relatively low-cost experiment. The "ringing" and rod oscillator experiments performed represent "firsts" in boiling reactors. Also incidental to $300 \mathrm{MWD}$ of experimental operation during 1957, a quantity of $\mathrm{U}^{233}$ was generated, again a "first" for electric generating nuclear power plants.

\section{DESCRIPTION OF FACILITY}

\section{A. General}

With the exception that a new design of the fuel elements was required, the BORAX-IV system comprised the same components and instrumentation used in BORAX-III. Consequently, the BORAX-IV experimentation was hindered to some extent by (1) residual radioactivity from high-power level runs performed less than a year before, and (2) natural deterioration of components, including control-rod drives and instrument cables, originally intended for short-term use.

The reactor and turbine buildings are shown in Fig. 1. Referring to the simplified plant flow diagram (Fig. 2), the power circuit consists of a feed-water pump that discharges either condensate from the condenser or freshly de-ionized water from the make-up system into the annular downcomer of the reactor. Steam from the reactor vessel flows through a sixinch line to either the turbine or to a vent to the atmosphere. The pressure 


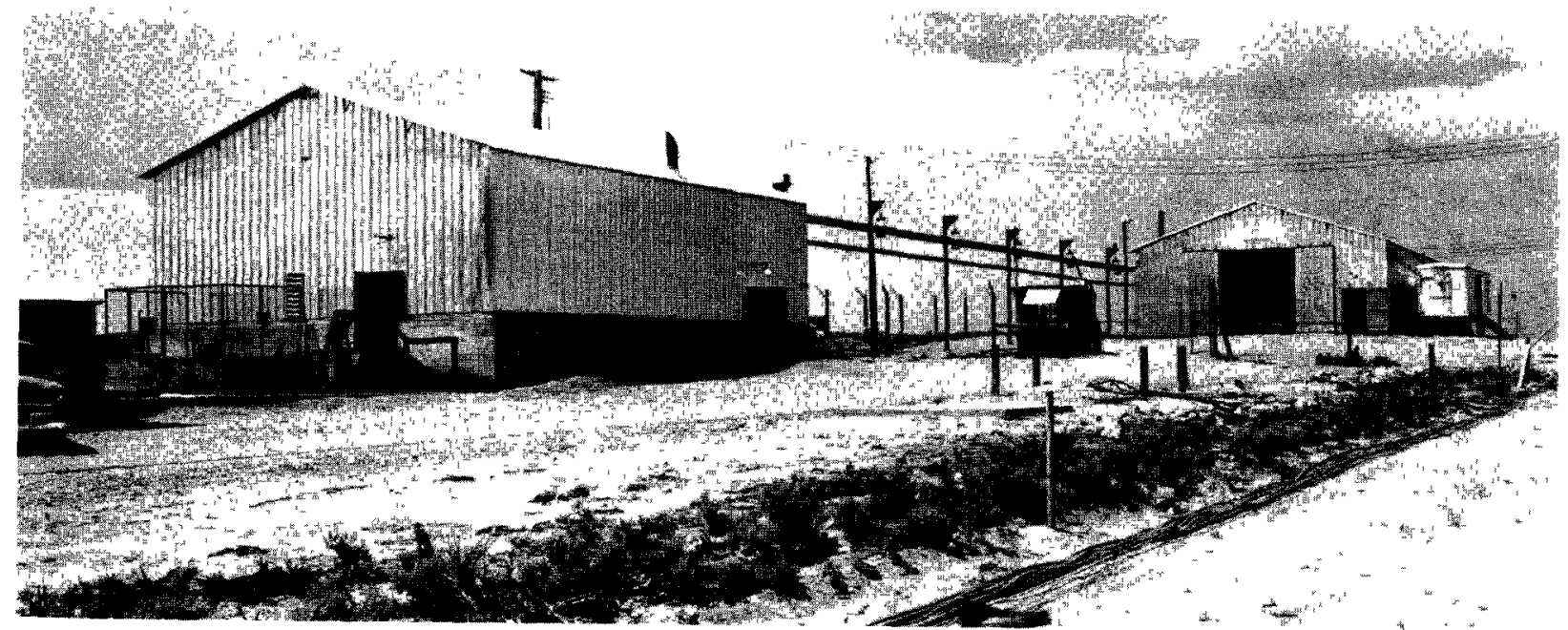

TURBINE (LEFT) AND REACTOR (RIGHT) BUILDINGS

CABLES IN FOREGROUND LEAD TO CONTROL TRAILER ONE-HALF MILE DISTANT

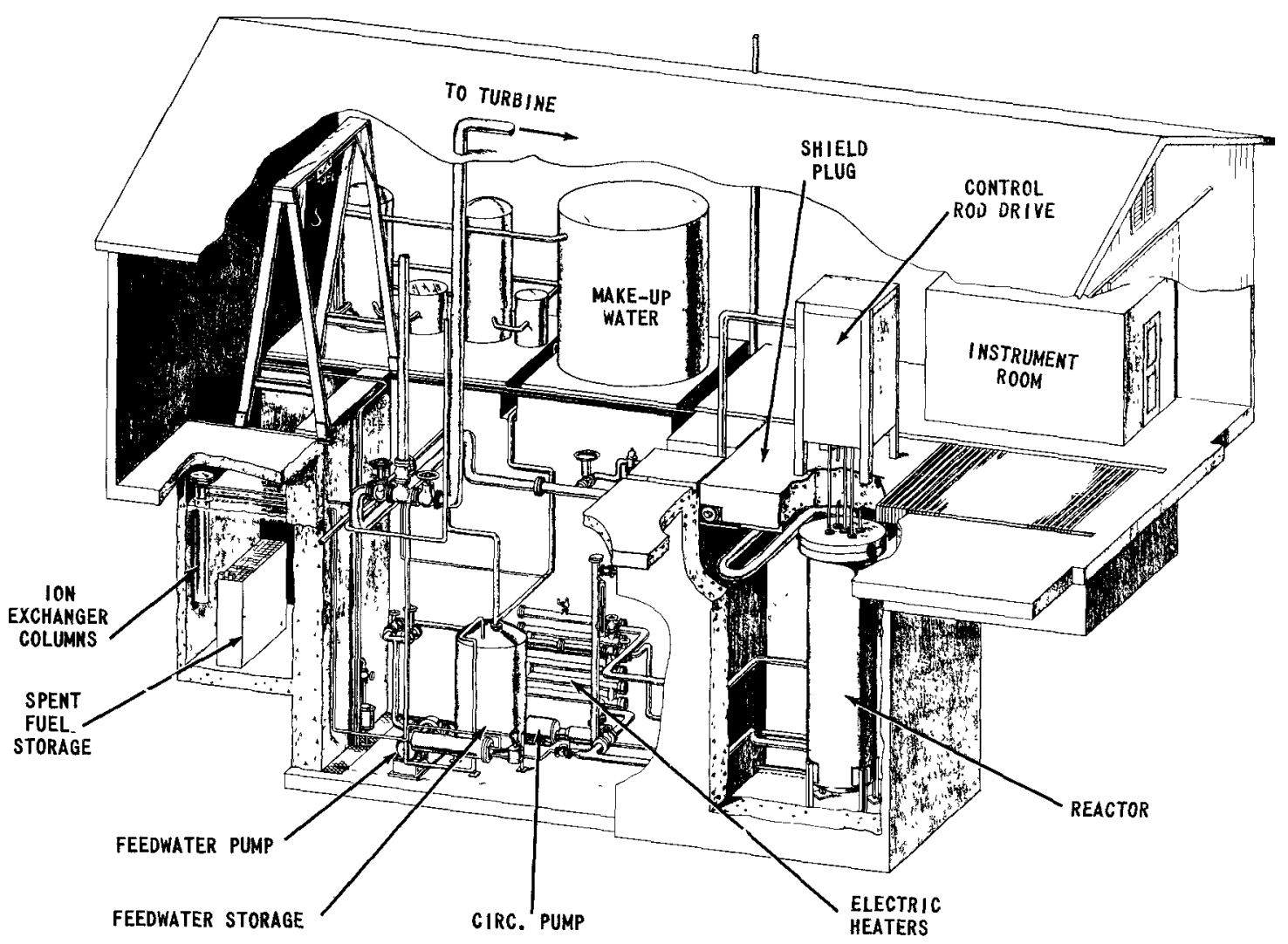

FIG. I

REACTOR AND TURBINE BUILDINGS 

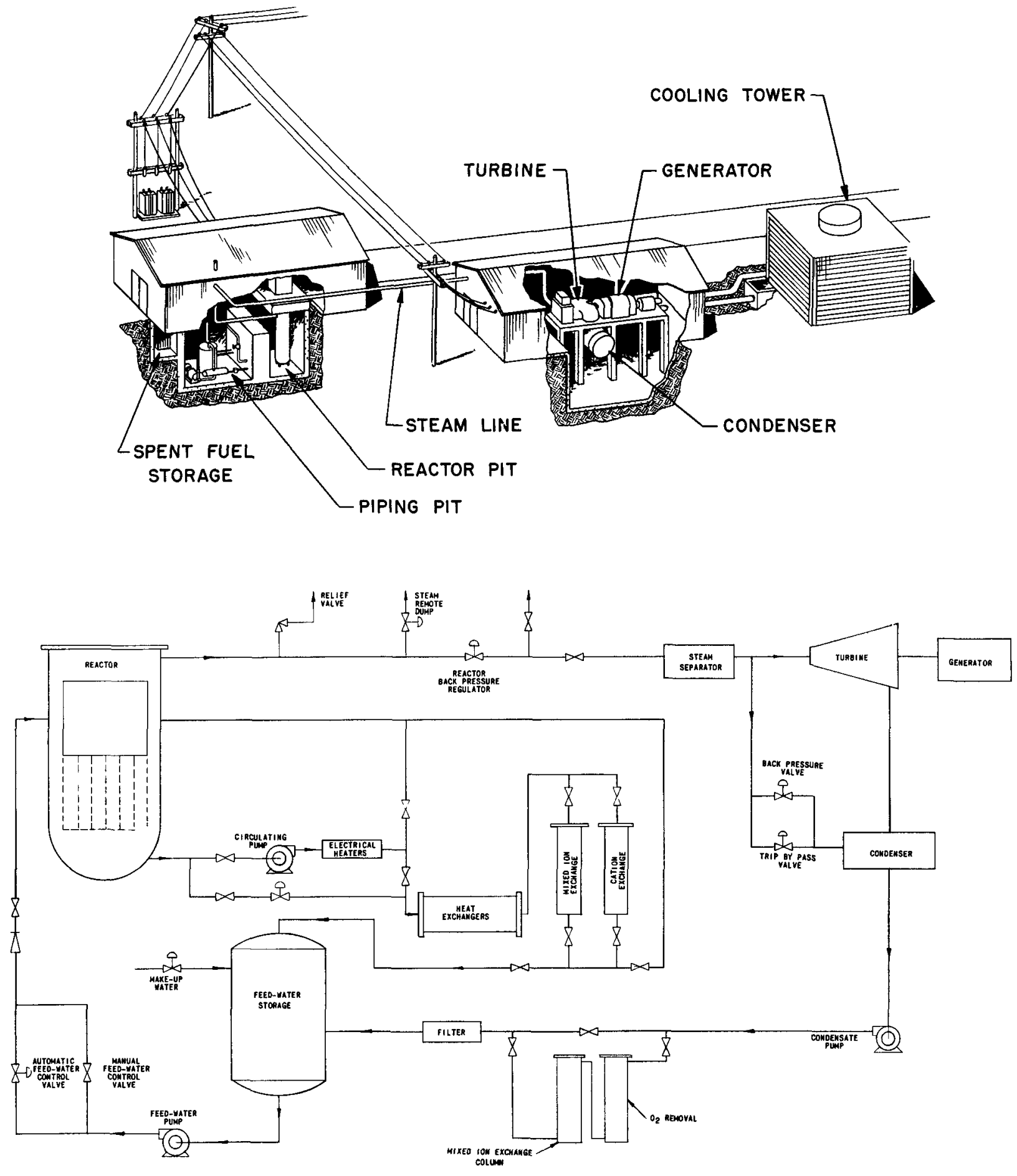

FIG. 2

SIMPLIFIED FLOW DIAGRAM 
vessel may be opened and the steam released to building atmosphere for short-term tests. The second circuit, which features a circulating pump and electric heaters, permits pressurizing the reactor vessel independently of reactor operation. It is also useful in performing low-power calibration of the nuclear instruments. The third circuit consists of filters and ionexchange columns for cleanup of the reactor water.

Fig. 3.

The instrumentation and circuitry is shown schematically in

B. Core

\section{Fuel Assembly}

The BORAX-IV fuel assembly, pioneered by the Argonne Metallurgy Division, utilizes urania-thoria $\left(\mathrm{UO}_{2}-\mathrm{ThO}_{2}\right)$ pellets fired in air. $(6,7)$ The uranium is enriched in $\mathrm{U}^{235}$ to the extent of $93 \%$. The finished pellets have an outer diameter of $0.230 \mathrm{in}$. and vary in length from about 0.375 in. to $0.75 \mathrm{in}$. The density is about $9.1 \mathrm{gm} / \mathrm{cc}$, with $0.0559 \mathrm{gm} \mathrm{U} \mathrm{gm}^{235} / \mathrm{gm}$ $\mathrm{ThO}_{2}$. The pellets are inserted into extruded $\mathrm{M}-388$ aluminum (Al $-1 \% \mathrm{Ni}$ ) tube-plates, a mechanical bond being made by filling in the spaces with lead.

Each fuel assembly (Fig. 4) contains six tube plates ( 8 tubes per plate) or a total of 47 active tubes with one tube available for the insertion of a boron-steel rod. Each as sembly contains about $5425 \mathrm{gm} \mathrm{UO}_{2}-\mathrm{ThO}_{2}$, or about $283 \mathrm{gm} \mathrm{U}^{235}$, with an active length of about $24 \mathrm{in}$.

\section{Control Blades}

Figure 5 is a cutaway view of the reactor pressure vessel, showing the core assembly and location of the control blades. The pressure vessel is a stainless steel tank, $15 \mathrm{ft}-11 \frac{1}{4} \mathrm{in}$. high with an internal diameter of $52 \frac{1}{2}$ in., and a wall thickness of $3 / 4$ in.

The reactor is controlled by four boron-steel shim blades (12 $\frac{1}{2}$ in. wide $\times 3 / 8$ in. thick) with 8 -in. long hafnium tips. These blades operate upward out of the core in channels which divide the core into four quadrants. Two center blade designs are available. One 3-in. wide blade can be used as an excursion blade, i.e., it can be pneumatically ejected downward out of the core for transient tests. The second blade, 5 in. wide, operates in the same manner as the shim blades during normal operation. All of the blades have aluminum followers.

The core grid plate can accommodate up to 88 fuel assemblies, each with cell dimensions of $3.888 \times 4.000$ in. The assemblies are held in place by a hold-down grid. 


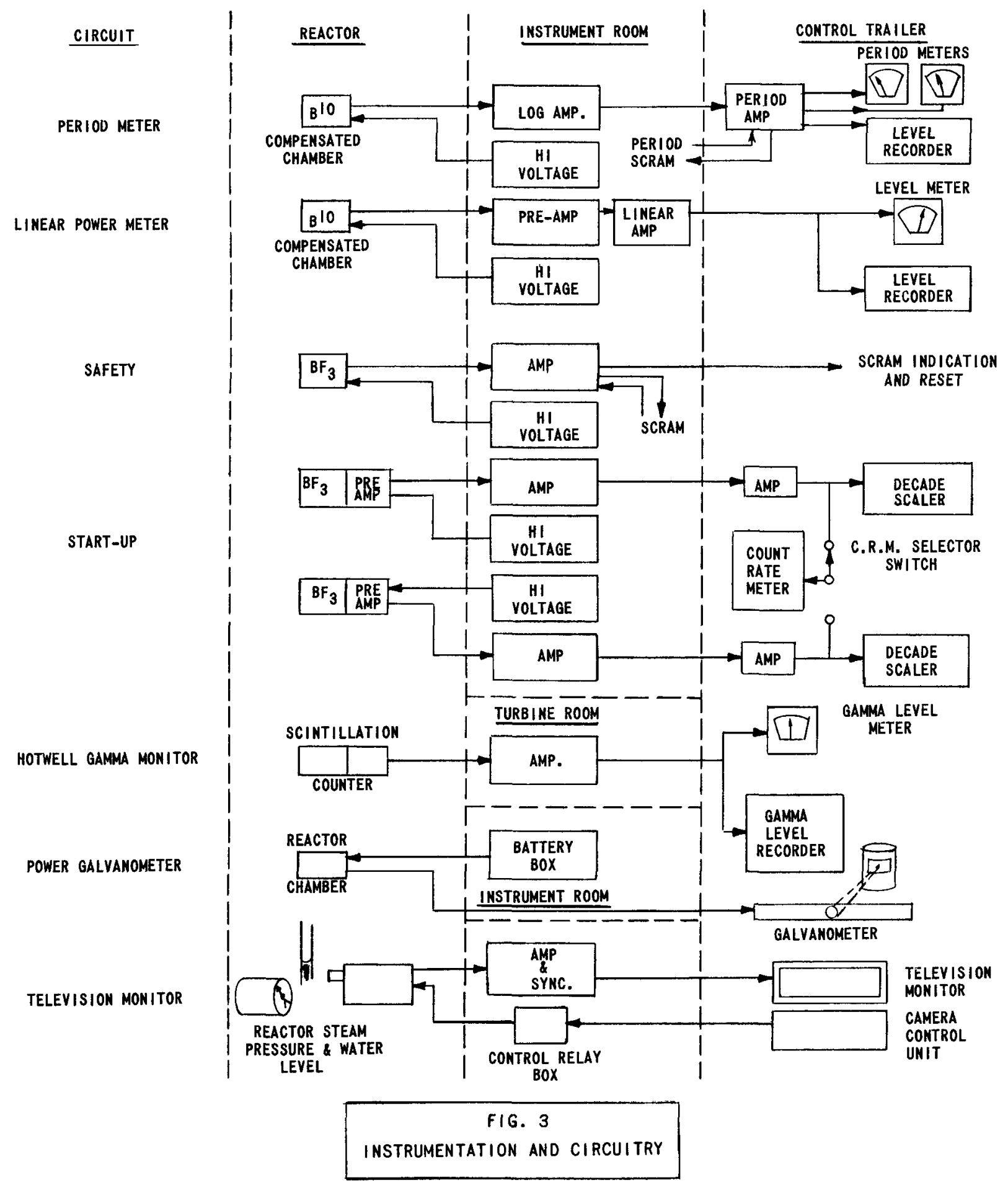



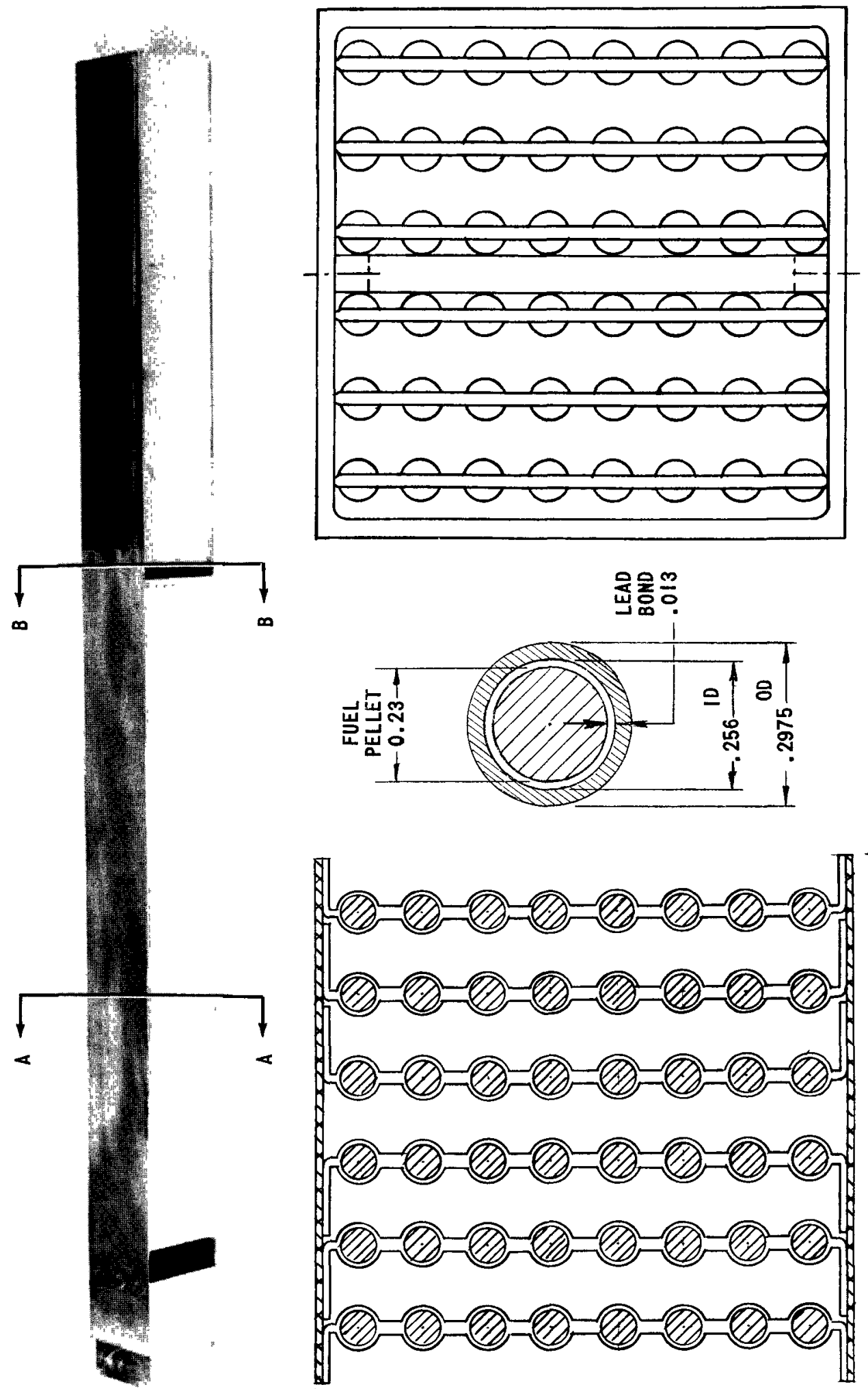

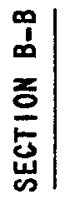

웝웅응
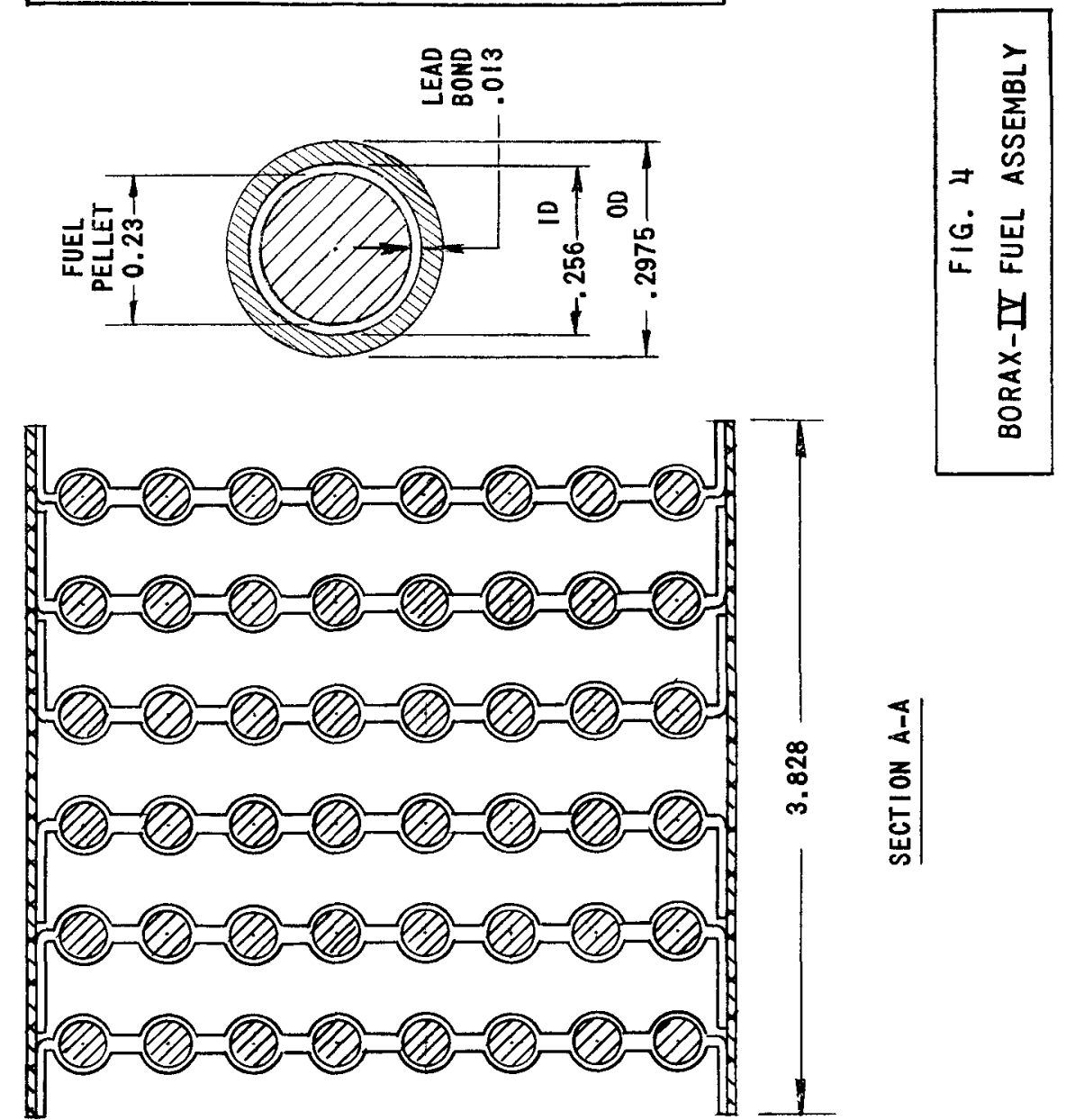

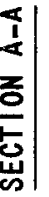

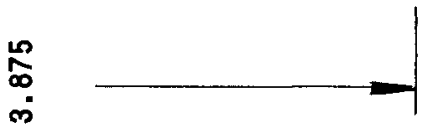




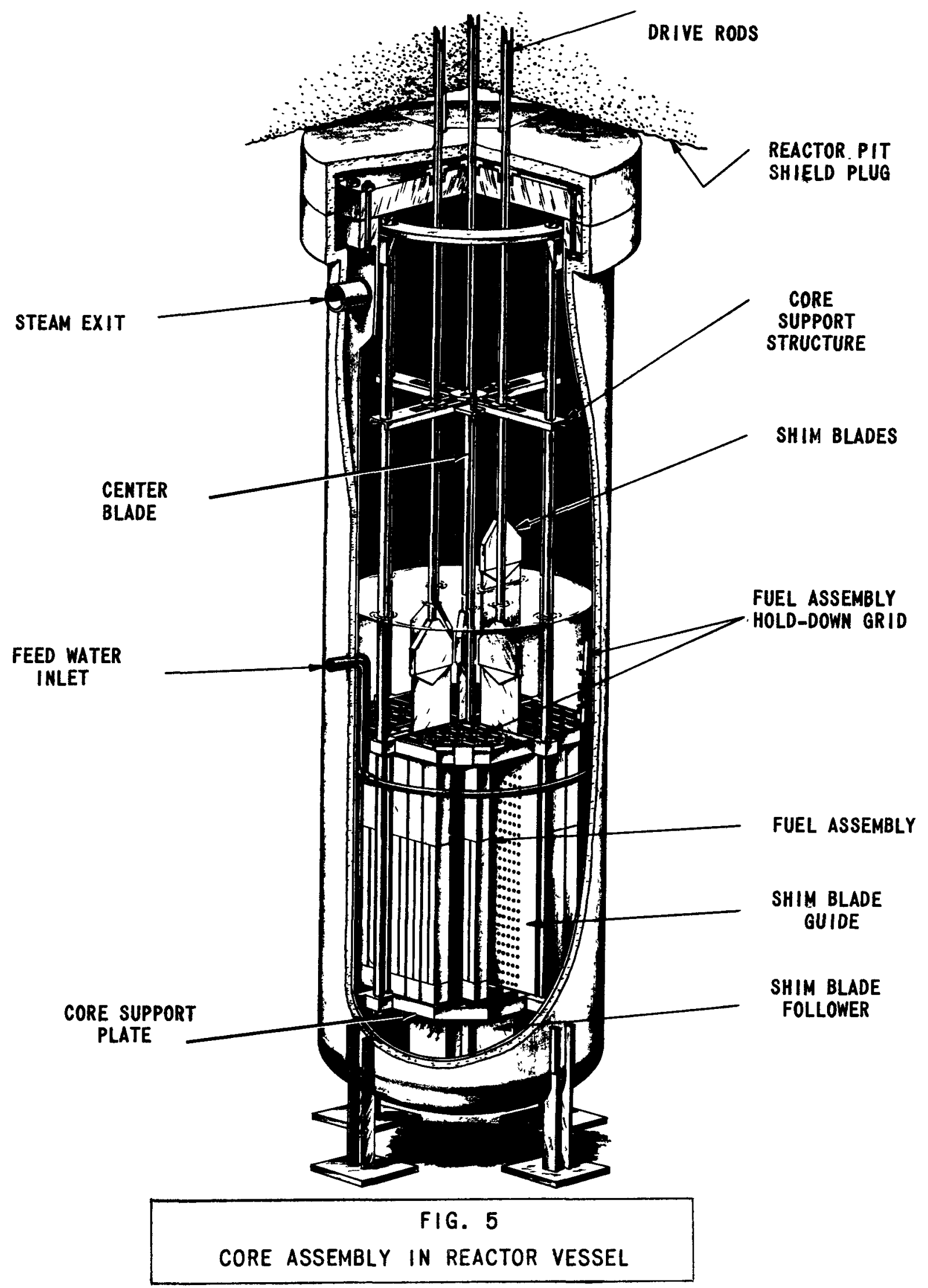


A more detailed description of the design and physics characteristics of the core is given in Appendix $\mathrm{A}$.

\section{PHYSICS ST ATIC EXPERIMENTS}

\section{A. Approach to Criticality}

The approach to criticality was made by adding one fuel assembly at a time to the water-filled reactor pressure vessel. As the loading progressed, the count rates from two Westinghouse fission counters were measured with all shim blades inserted in the core. The shim blades were then removed slowly, one at a time, and the count rates measured again. This procedure was repeated after each fuel assembly addition, with repositioning of the source as required, until criticality was reached.

Criticality was obtained with a core loading of 28 fuel assemblies $\left(7.92 \mathrm{~kg} \mathrm{\textrm {U } ^ { 2 3 5 }}\right.$ ) in the pattern diagrammed in Fig. 6. With all the shim blades in their maximum out-position, this loading had an as ymptotic period of $18 \mathrm{~min}$. As more excess reactivity was required for the later experiments, fuel assemblies were added to the periphery of the core. The worth of these assemblies is also shown in Fig. 6.

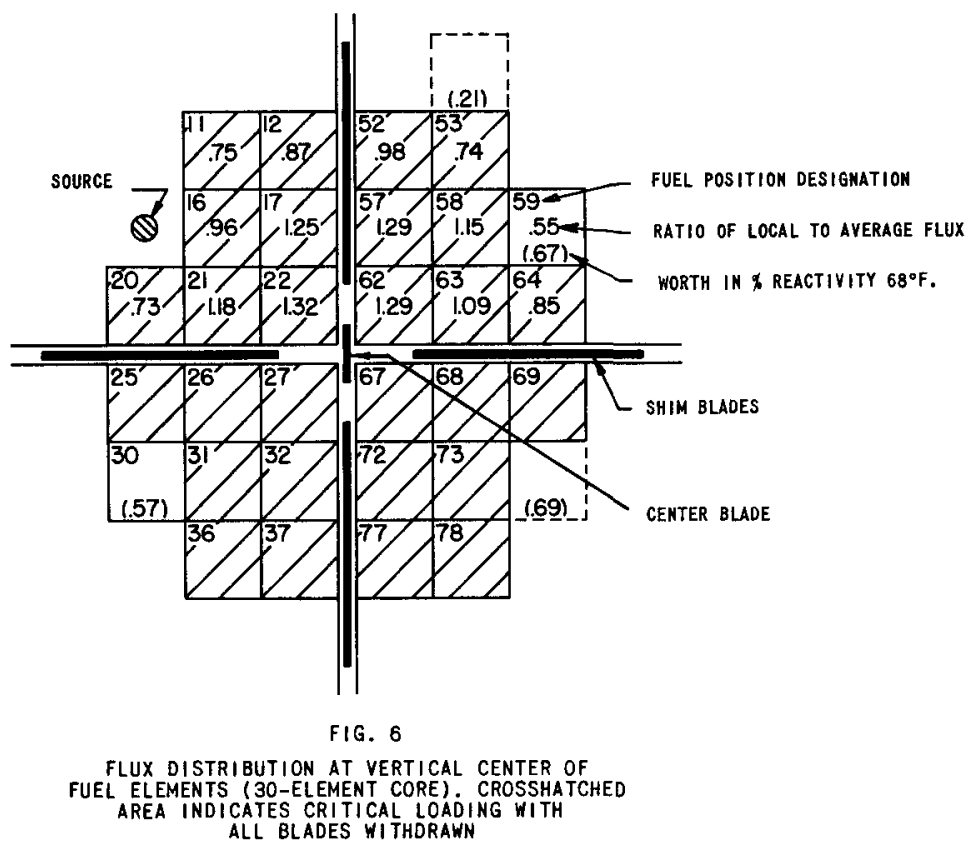




\section{B. Calibration of Shim and Center Blade(s)}

A differential worth calibration of the four shim blades was performed by the usual method of measuring the asymptotic period after withdrawing the shim blades as a "bank" a short distance from their critical positions. The critical position was varied by adjustment of the center blade, by the addition of fuel assemblies to the periphery of the core or by addition of boric acid to the reactor water.

The initial calibration of the shim blades was performed at room temperature $\left(68^{\circ} \mathrm{F}\right)$ and at saturation $\left(207^{\circ} \mathrm{F}\right)$ in a core consisting of between 29 and 31 fuel assemblies. The differential worths as a function of position for these two temperature conditions are given in Fig. 7 . The integral worth as a function of position is shown in Fig. 8 .

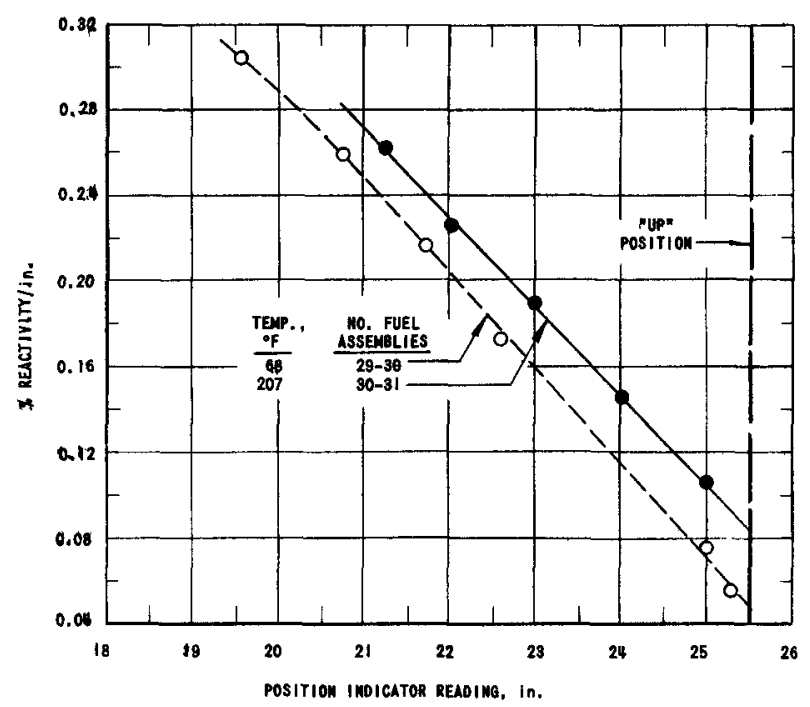

FIG. 7

DIFFERENTIAL WORTH OF FOUR SHIM BLADES

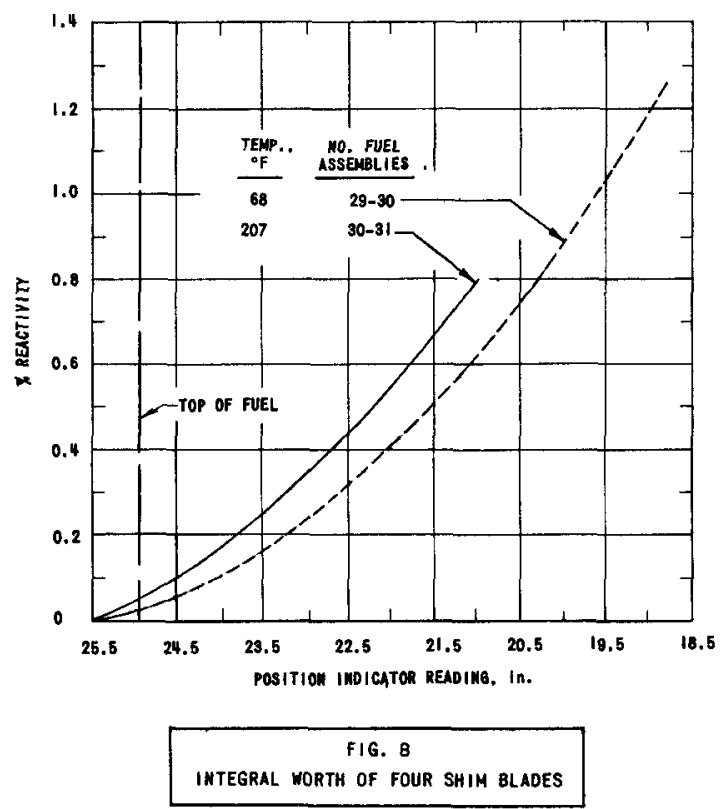


The calibration of the center blade was made by the same method employed for the shim blades. The differential worth and integral worth as a function of position are shown in Figs. 9 and 10. In Fig. 10, the worth of the excursion blade as obtained from the transient tests is also given for comparison. In both figures the position indicator reading is the number of inches the blade has been lifted from its fully "out " position below the core. It is to be noted that within experimental error, the worth of the excursion blade did not change with temperature up to $207^{\circ} \mathrm{F}$.
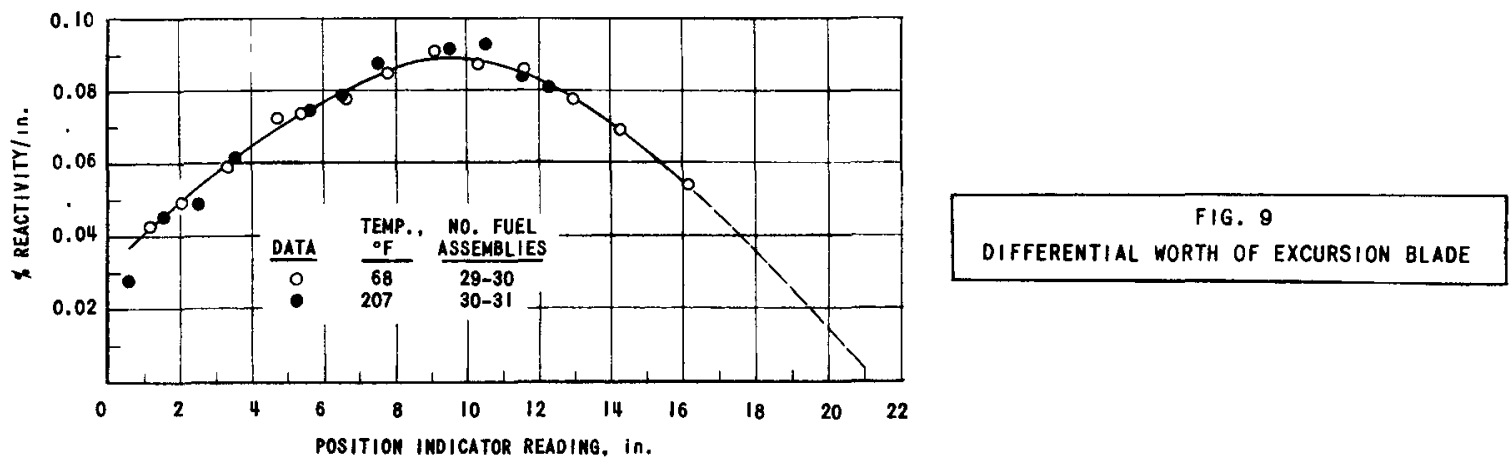

FIG. 10

INTEGRAL WORTH OF EXCURSION BLADE

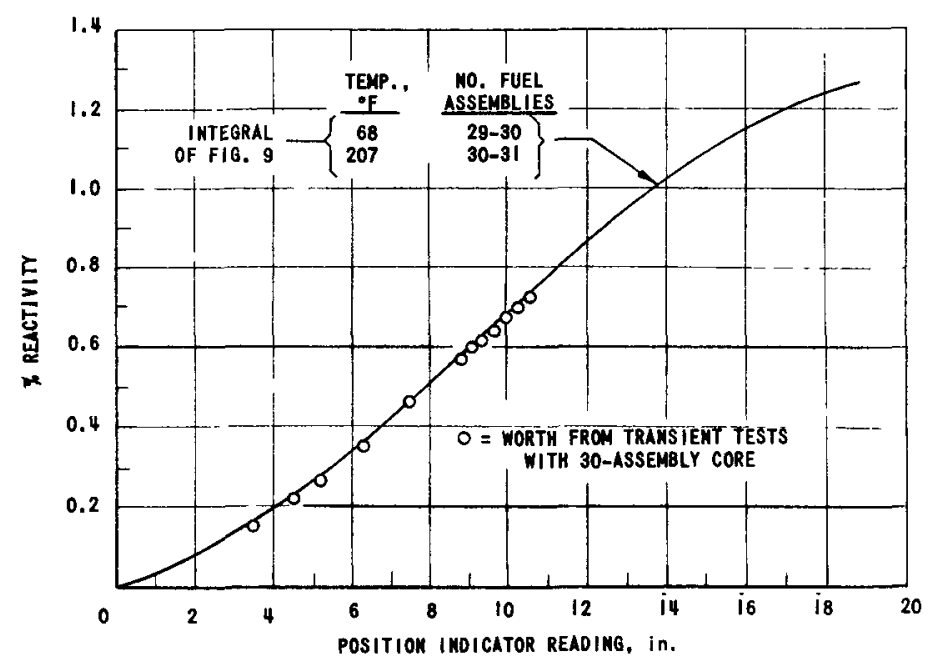

The shim blades were re-calibrated prior to the measurement of the excess reactivity held down by steam voids in larger sized cores during oscillator experiments at saturation temperature (atmospheric pressure). Figure 11 shows the differential worth as a function of position in cores consisting of 39 and 42 fuel assemblies. The loading arrangement of the 42-assembly core is shown in Fig. 12. The integral worths for these cores are plotted in Fig. 13; the worth in a 30-31 as sembly core is also plotted for comparison. For the transfer function tests, the differential worth of the oscillator rod was measured with the results shown in Fig. I4. The tip of the oscillator rod was not necessarily at the same level as that of a blade for a given position-indicator reading. The rod consisted of a cadmium tube, 12 in. long, which occupied the lower half of the core in its "in" position. 


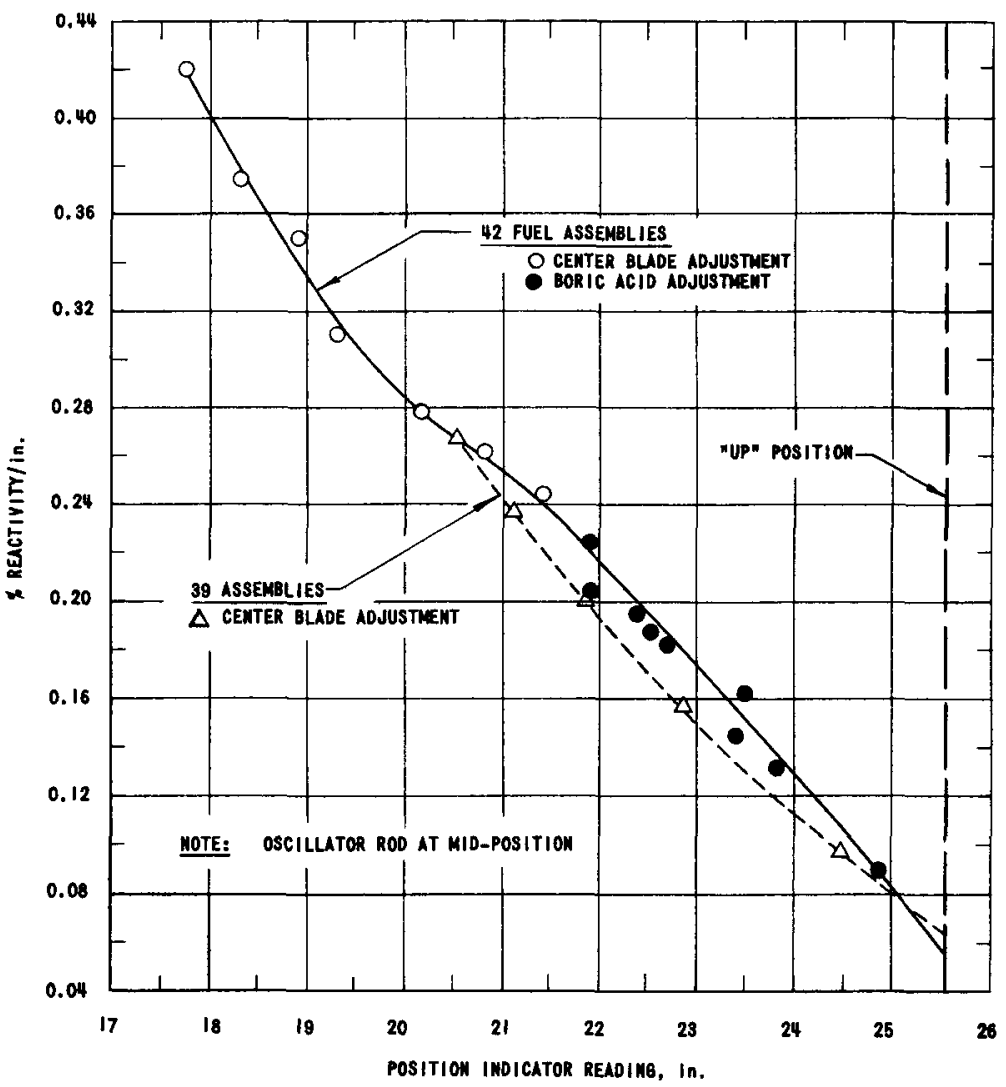

FIG. II

DIFFERENTIAL WORTH OF FOUR SHIM BLADES AT $207^{\circ} \mathrm{F}$ (SATURATION TEMPERATURE, ATMOSPHERIC PRESSURE)

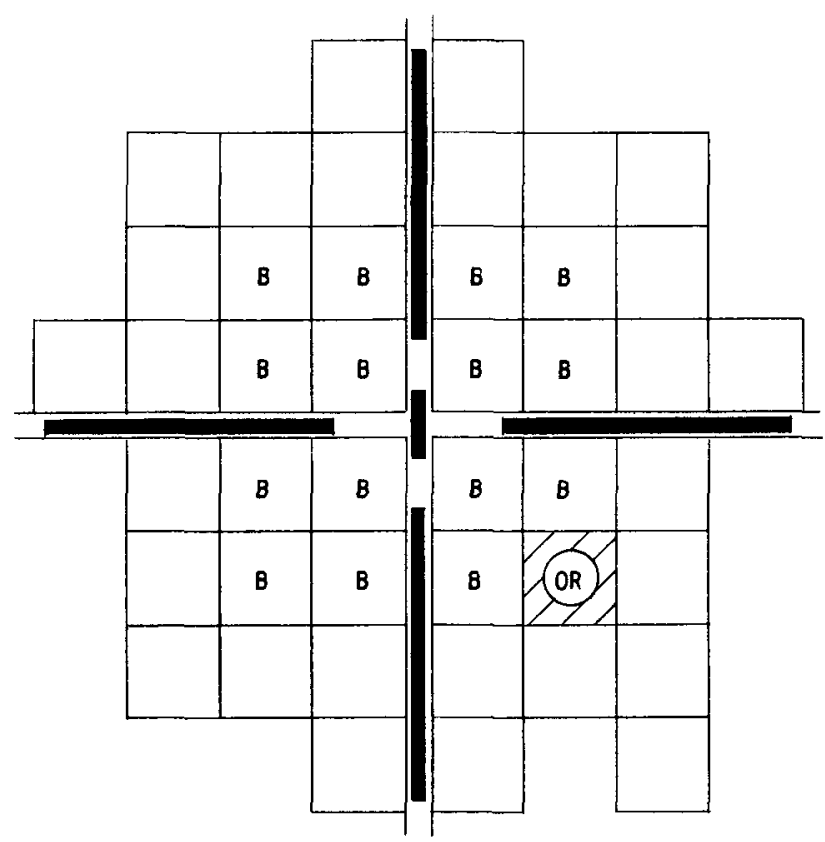

FIG. 12

42-ASSEMBLY LOADING ARRAHGEMENT FOR OSCILLATOR EXPERIMENTS

HOTE: $B=$ ASSEMBLY CONTAINING 0.18 in. DIA. BORON-STAINLESS STEEL ROD.

$O R=$ OSCILLATOR ROD 


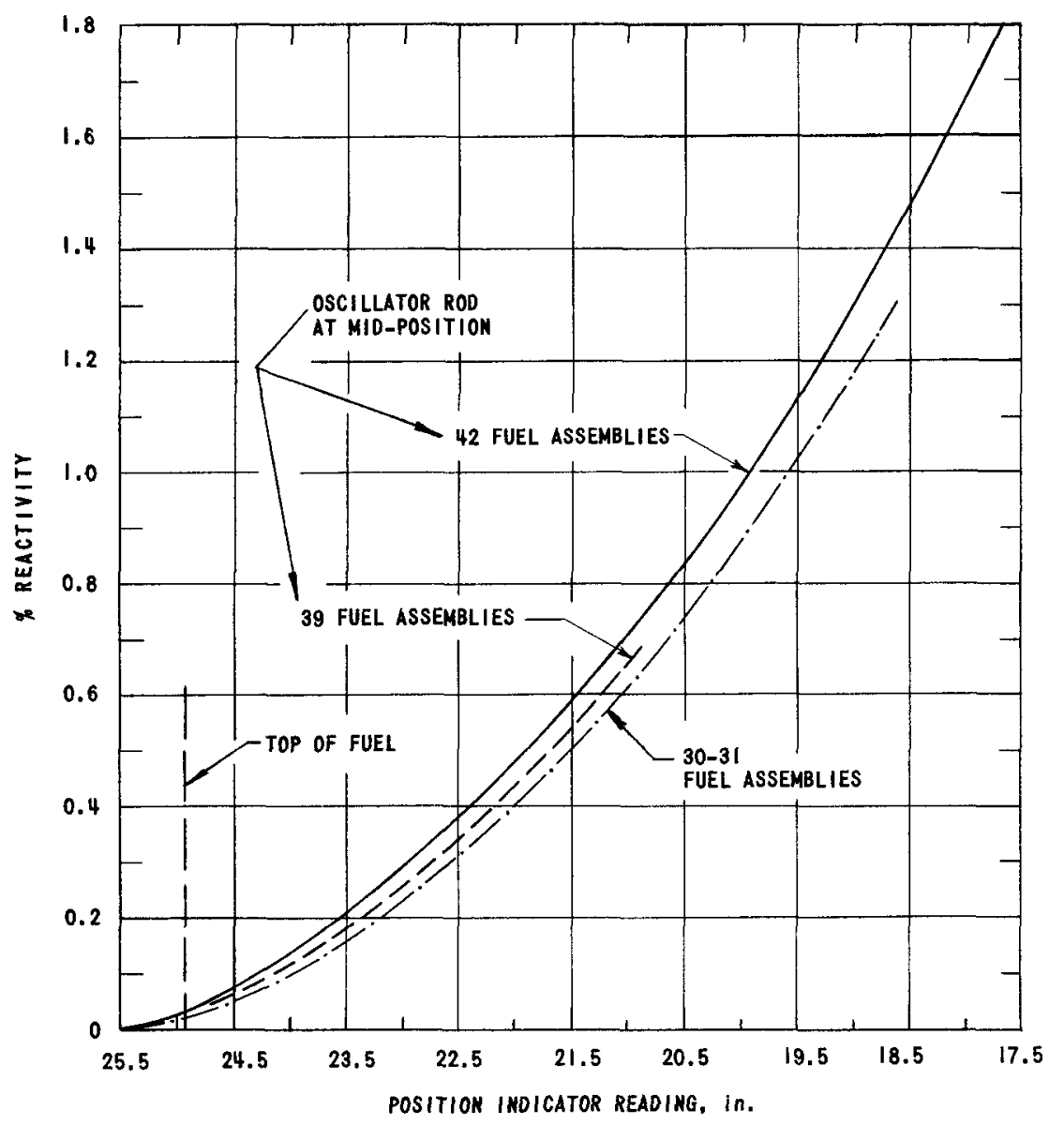

FIG. I3

INTEGRAL WORTH OF FOUR SHIM BLADES AT $207^{\circ} \mathrm{F}$ (SATURATION TEMPERATURE, ATMOSPHERIC PRESSURE)

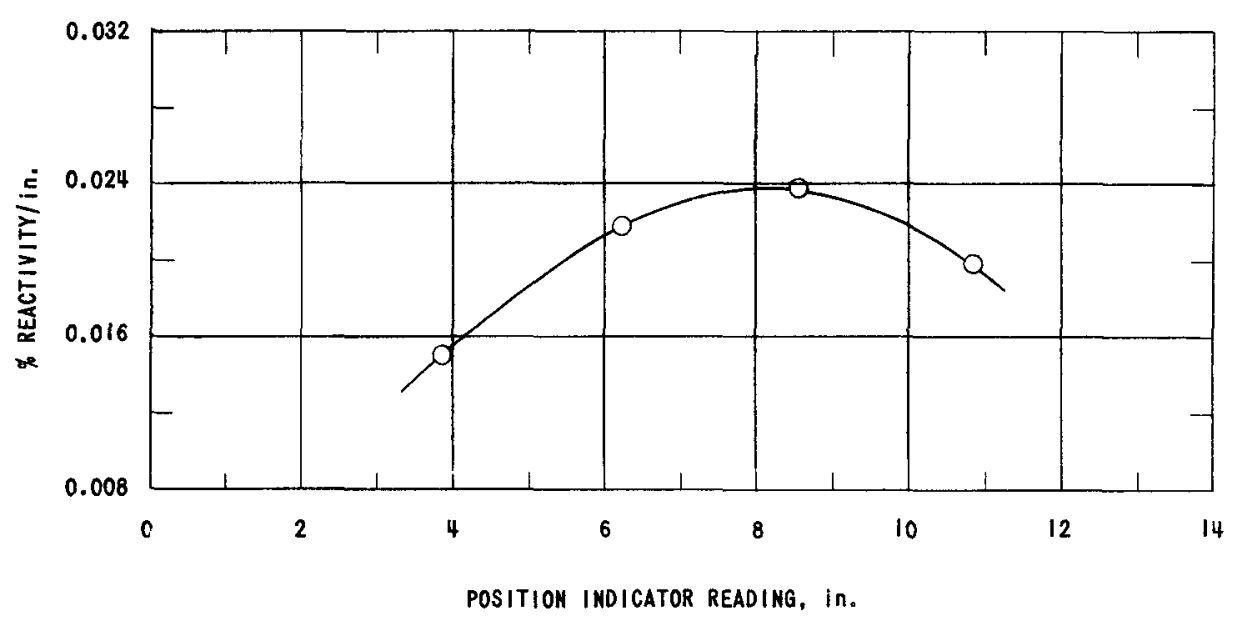

FIG. 14

DIFFERENTIAL WORTH OF OSCILLATOR ROD IN 42-ASSEMBLY CORE AT $207^{\circ} \mathrm{F}$ (SATURATION TEMPERATURE, ATMOSPHERIC PRESSURE) 
At reactor pressures above atmospheric, the shim blades were calibrated in a core consisting of 59 fuel assemblies, as shown in Fig. 15.

Each of the center 16 assemblies con-

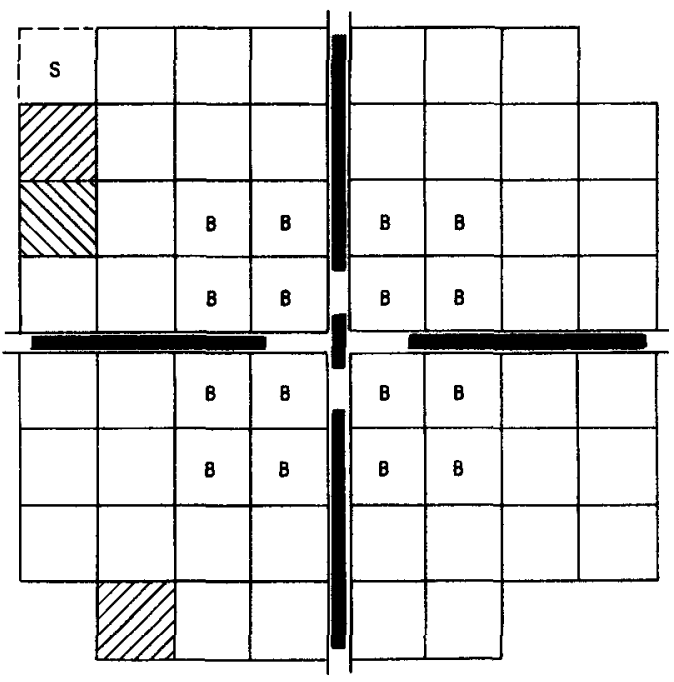

HOTE: CROSSHATCHED ASSEMBLIES REMOVED DURING FLUX DISTRIBUTIOH MEASUREMENTS.

$S=$ SOURCE FIG. 15 59-FUEL ASSEMBLY LOADING ARRANGEMENT tained a boron-stainless steel poison rod. The shim blades were calibrated at various temperatures in the range from $100^{\circ} \mathrm{F}$ to $420^{\circ} \mathrm{F}$ ( $300 \mathrm{psig}$ ). The critical position was varied by addition of boric acid to the reactor water. The differential worth of the blades as a function of position for these temperatures is given in Fig. 16. The integral worth at $100^{\circ} \mathrm{F}$ and $420^{\circ} \mathrm{F}$ is given in Fig. 17.

The inhour curve (Fig. 18) used in these calibrations is based on a neutron lifetime of $5 \times 10^{-5} \mathrm{sec}$. For the range of periods covered in the blade(s) calibration and transient tests, this curve is insensitive to the neutron lifetime.

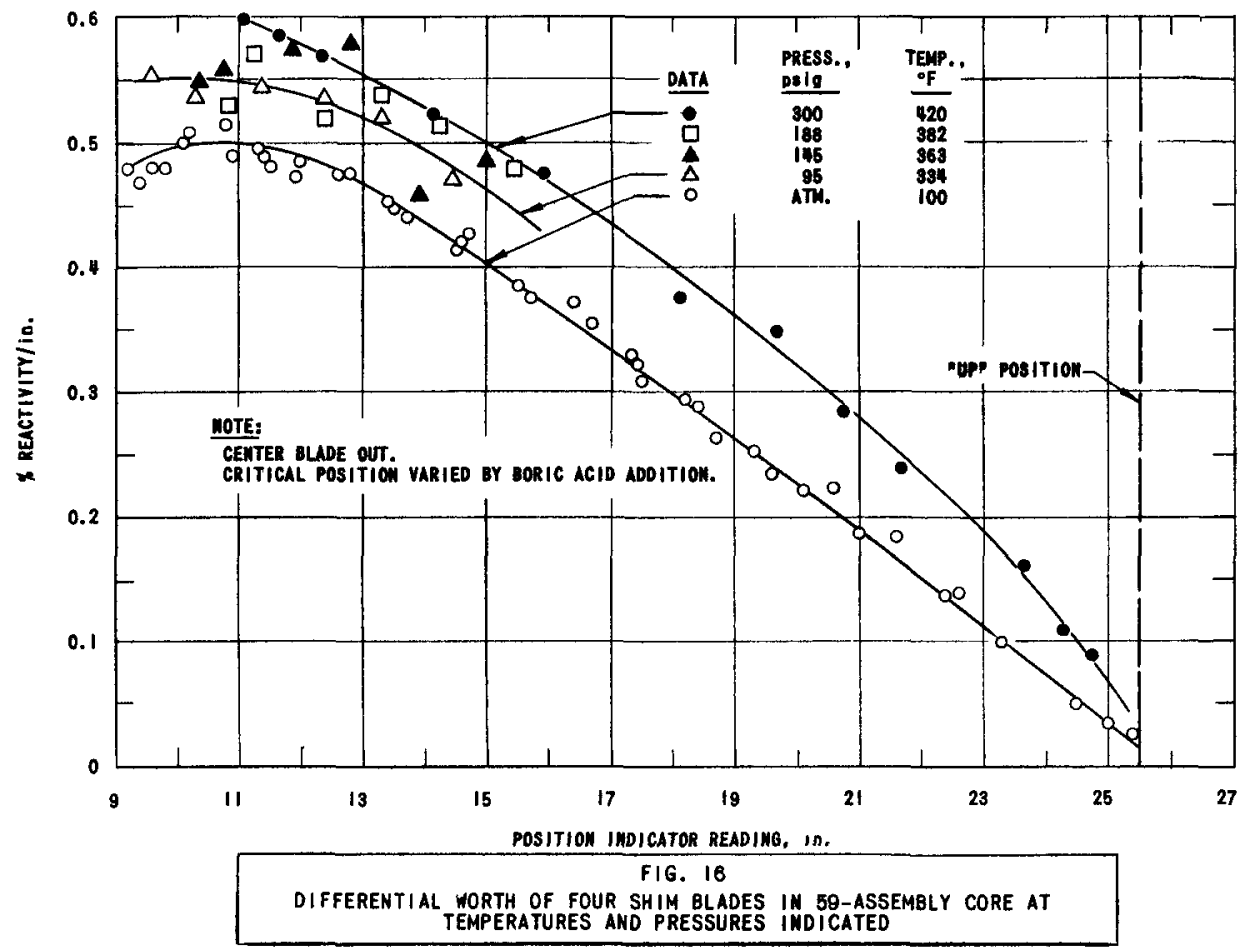


FIG. 17

INTEGRAL WORTH OF FOUR SHIM BLADES IN 59-ASSEMBLY CORE AT $100^{\circ} \mathrm{F}$ AND $420^{\circ} \mathrm{F}$
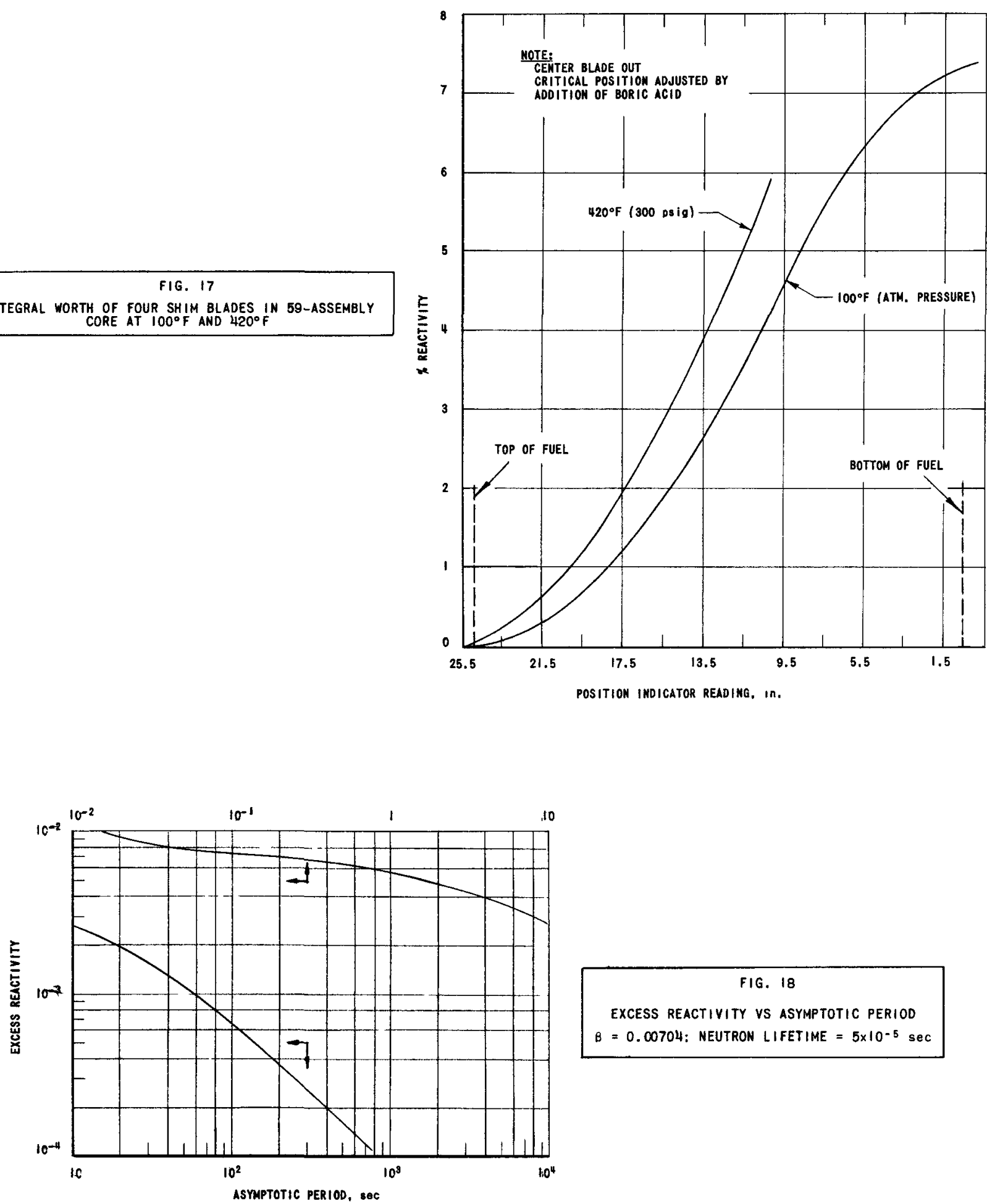

FIG. 18

EXCESS REACTIVITY VS ASYMPTOTIC PERIOD

$B=0.00704:$ NEUTRON LIFETIME $=5 \times 10^{-5} \mathrm{seC}$ 


\section{Flux Distribution}

The neutron flux distribution at room temperature $\left(68^{\circ} \mathrm{F}\right)$ was measured for two core loadings by activations of bare gold foils attached to foil holders that were suspended between the fuel tube-plates at various positions in the core. The gold foils were covered with aluminium foil to prevent contamination by impurities in the reactor water.

The initial measurement of neutron flux distribution was made for a core consisting of 30 fuel assemblies (Fig. 6). The ratio of local to average flux in the radial positions for this loading is given in this figure. The neutron flux distributions parallel to the core axis for two fuel positions are indicated in Fig. 19 in terms of the saturated foil activity. It is to be noted that the excursion and shim blades are partially inserted in the core. The maximum to average flux for this loading was about 1.8 .

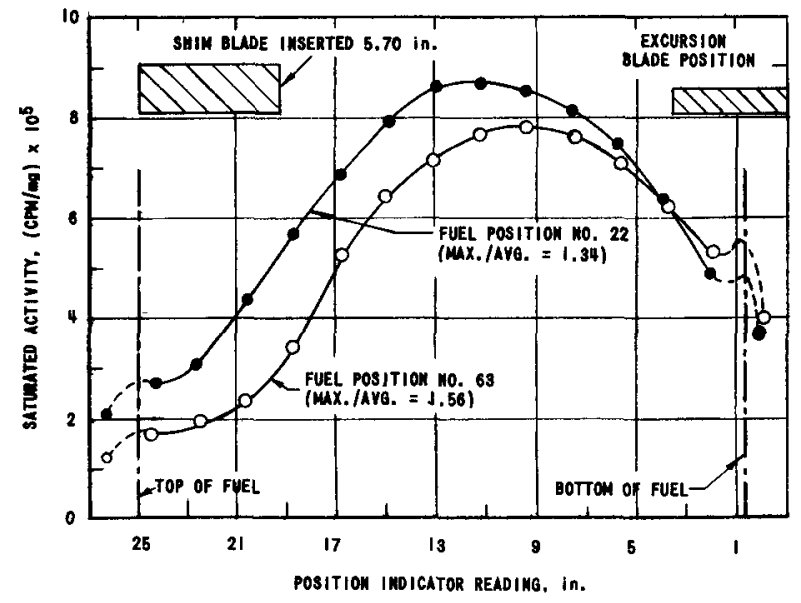

F.I G. 19

AXIAL NEUTRON FLUX DISTRIBUTION AT TWO FUEL POSITIONS

The measurements of neutron flux distribution were repeated when the core had been built up to 56 fuel assemblies (see Fig. 15). Each of the central 16 fuel assemblies contained a boron-stainless steel rod, and the water was poisoned with boric acid. The neutron flux distributions for the radial and axial positions are shown in Fig. 20. The maximum to average flux for this loading was about 1.95 .

\section{Power Calibration}

Calibrations of the nucleonic instruments were performed by various methods, depending on the power level. During initial start-up of the reactor, measurements of the power level were made by activation of gold foils and from the responses of an absolute fission counter. For calibration at low power (i.e., 100 watts), the reactor power was taken above the source level and both bare and cadmium-covered gold foils were 


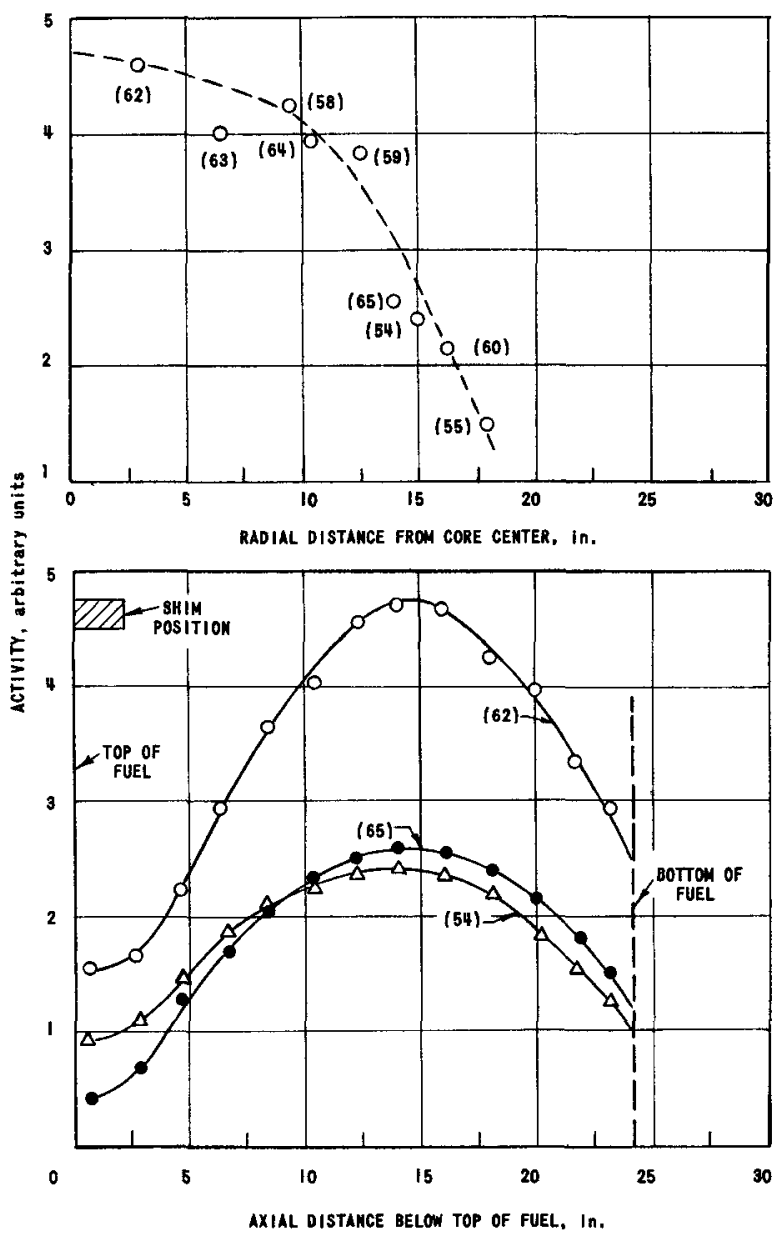

FIG. 20 RADIAL AND AXIAL NEUTRON FLUX DISTRIBUTION
IN SB-ASSEMBLY CORE AT $68^{\circ} \mathrm{F}$.

(PARENTHESIZED MUMERALS INDICATE FUEL POSITIOMS)

activated for a known period of time. The count rate on the absolute fission counter was also taken. The gold foils were counted with a calibrated counter. The relative average thermal neutron flux between the absolute fission counter and the core was measured by gold foils. The power level was then calculated from these measurements and the $\mathrm{U}^{235}$ content in the core and fission counter. The values measured by both methods agreed within $40 \%$.

More reliable power calibrations were made in the kilowatt range by comparison of the total heating and cooling rates between the reactor and electrical heaters. With the reactor shut down, the heating and cooling rates of the reactor water were measured with the electrical heaters $(55 \mathrm{kw})$ turned on, and then off. The reactor was then taken to about the same power level as the electrical heaters had been, and the measurements were repeated. In both instances the reactor water was circulated continuously through the electric heater circuit and the reactor tank. The power calibration by this method was used for the transient test measurements. 
During steady-state boiling operations at atmospheric pressure the reactor power level was calibrated by the rate of change in the water level with zero feed-water flow, or by the measurement of the feedwater flow required to attain a constant water level.

For the pressurized power runs, the reactor power was calibrated by measuring the pressure drop across an orifice delivering steam either to the turbine or to the atmosphere. The feed-water flow required to maintain constant water level served as a check on this method.

\section{E. Temperature Coefficient of Reactivity}

The change of reactivity with temperature was measured for core loadings of 30 and 59 fuel assemblies. These measurements were performed by noting the positions of the shim blades and by thermocouple readings as the reactor was heated stepwise with the electrical heaters. The change of reactivity with position of the shim blades was taken from the integral worth curves measured at either $68^{\circ} \mathrm{F}$ (30 elements) or $100^{\circ} \mathrm{F}$ (59 elements).

Figure 21 shows the temperature coefficient as a function of water temperature for the two loadings. The average temperature coefficient for the range between $68^{\circ} \mathrm{F}$ and $200^{\circ} \mathrm{F}$ in the 30 -element core was $-2.47 \times 10^{-5}(\Delta \mathrm{k} / \mathrm{k}) /{ }^{\circ} \mathrm{F}$.

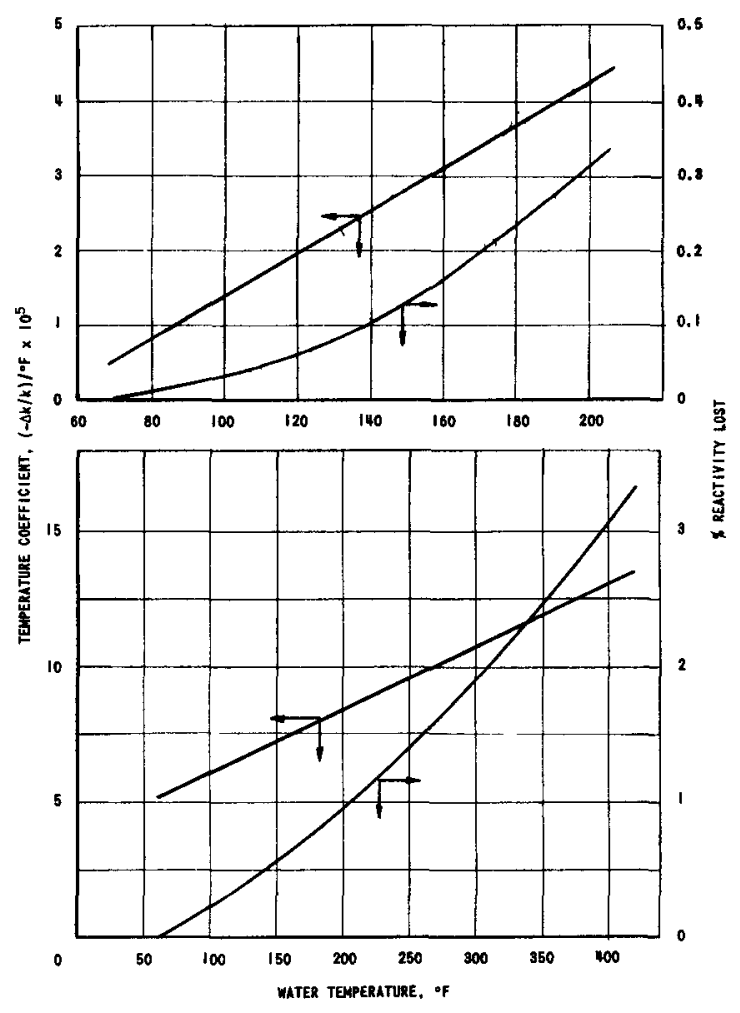


IV. REACTIVITY TRANSIENTS

A. Experimental Procedure

The responses of the reactor power and temperatures to step inputs of reactivity were investigated to determine the self-limiting characteristics of the reactor over a range of initial periods from a few seconds to slightly below 100 milliseconds. It was not intended to cover completely and exhaustively the range of interest for this reactor, but rather to explore the transient behavior so that operation at steady power could proceed with greater confidence. The transient behavior at atmospheric pressure was investigated with the reactor water initially at saturation temperature $\left(207^{\circ} \mathrm{F}\right.$ at $5,000 \mathrm{ft}$ elevation) and initially subcooled $\left(120-160^{\circ} \mathrm{F}\right)$.

Prior to each transient (1) the reactor was heated to the desired temperature with the electrical heaters, (2) the reactor was made critical at a low power (i.e., 100 watts) with the excursion blade holding down a known amount of excess reactivity, and (3) the maximum power trips and excursion timer were normally adjusted to allow the excursion to continue through the peak power level using the inherent reactor shutdown mechanisms, before the shim blades would scram the reactor. When these conditions were met, the air-loaded central excursion blade was ejected downward and out of core. The excursion was recorded on variable-speed Brush and Heiland recorders.

The three major types of information recorded during the transient tests were reactor power and the surface and fuel center temperatures of a few fuel "bayonets." A fuel "bayonet" was essentially an aluminum and lead-encased fuel rod minus the tube sheet for convenience in frequent removal and insertion. Chromel-alumel thermocouples were spot welded to the clad surface of the bayonet. The center fuel thermocouple was inserted through a hole drilled axially in a fuel pellet and held in place by silicate cement. As pointed out in Appendix $C$, this method of measurement of the temperature of the fuel center proved reliable during steady-state power tests, but was subject to errors during transient tests.

Special fuel "bayonets" were used as a precaution against core damage as the excursion period was reduced. These bayonets contained fuel pellets enriched 2 and 4 times ( $2 X$ and $4 X$ ) the normal enrichment and were inserted in the core between two fuel plates. Since the heat generated in a pellet is approximately proportional to the enrichment, the $4 \mathrm{X}$ pellets in a position of maximum flux should give advance warning, by reason of noticeable damage, of conditions which could inflict serious damage to the whole core. The special fuel "bayonets" were inspected after each transient with a period shorter than in any previous test. 
Reactor power and the thermocouple response were recorded on a single strip of photographic paper by a Heiland oscillograph employing high-speed galvanometers. Power was normally measured by various ion chambers located at different positions around the core. The ionchamber currents were fed to the Heiland galvanometers through either logarithmic or linear amplifiers.

B. Transients with Water at Atmospheric Boiling Temperature

Reactor transients, with periods ranging from a few seconds to 83 milliseconds, were made with the reactor water at the atmospheric boiling temperature. A typical recording of an excursion is depicted in Fig. 22 .

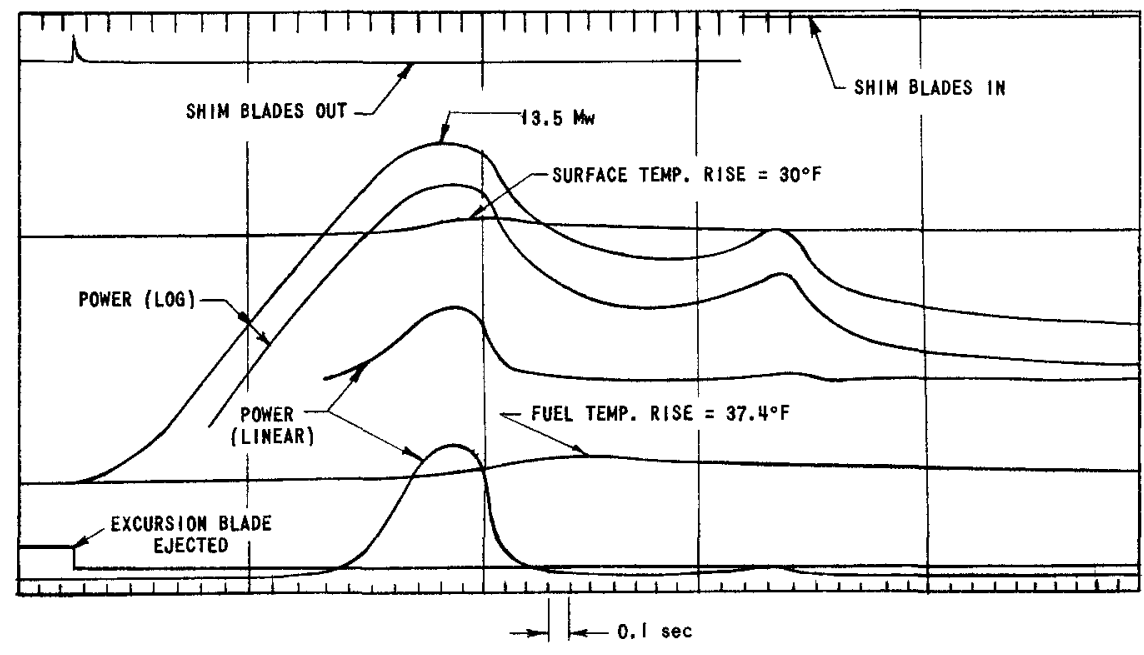

FIG. 22

TYPICAL EXCURSION WITH REACTOR WATER AT ATMOSPHERIC BOILING TEMPERATURE $\left(207^{\circ} \mathrm{F}\right) \mathrm{AND} \mathrm{pH}=4.15$. INITIAL PERIOD $=0.109 \mathrm{sec}$

Figure 23 shows the peak powers obtained as a function of the reciprocal period and the $\mathrm{pH}$ of the water. The sharp break in the curve is the result of a single excursion with an initial period less than 100 milliseconds. The $\mathrm{pH}$ of the water was varied to determine its effect on the self-limiting characteristics of the reactor. It was believed that if radiolytic formation of gas bubbles contributes to the self-limiting mechanism, then variation of the $\mathrm{pH}$ of the water might affect the transient behavior. This was expected since, under equilibrium conditions, radiolytic production of gas is a function of the $\mathrm{pH}$ of the water. It is evident from Fig. 23 that the values of $\mathrm{pH}$ investigated, had no detectable effect on the peak power. However, these results do not rule out the existence of radiolytic formation of gas bubbles since (1) the $\mathrm{pH}$ may not have exercised a strong influence on transient radiolytic production of gas or (2) the peak power may have been insensitive to radiolytic production of gas. 


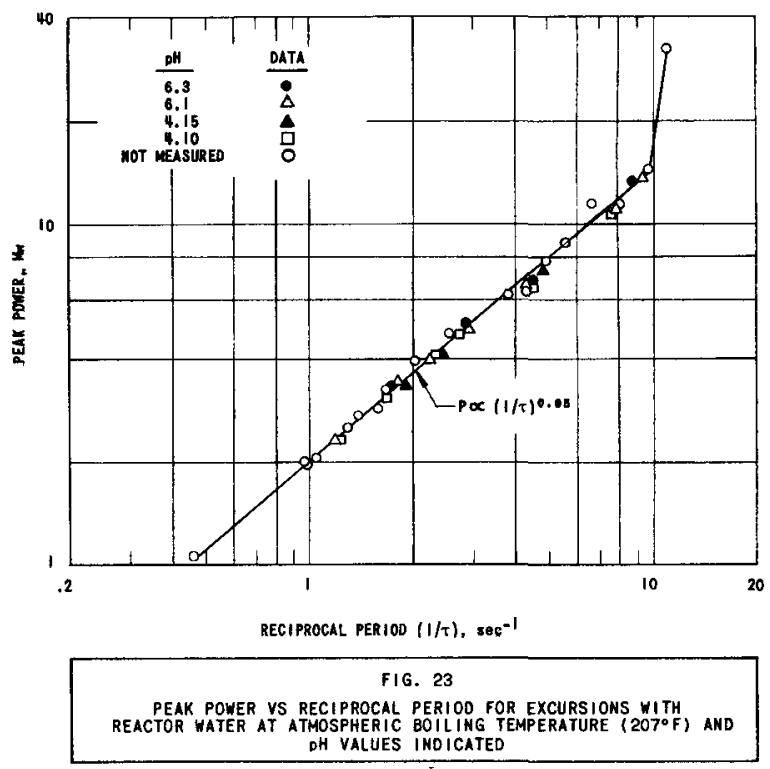

Figure 24 shows the burst shape during three excursions of different periods.

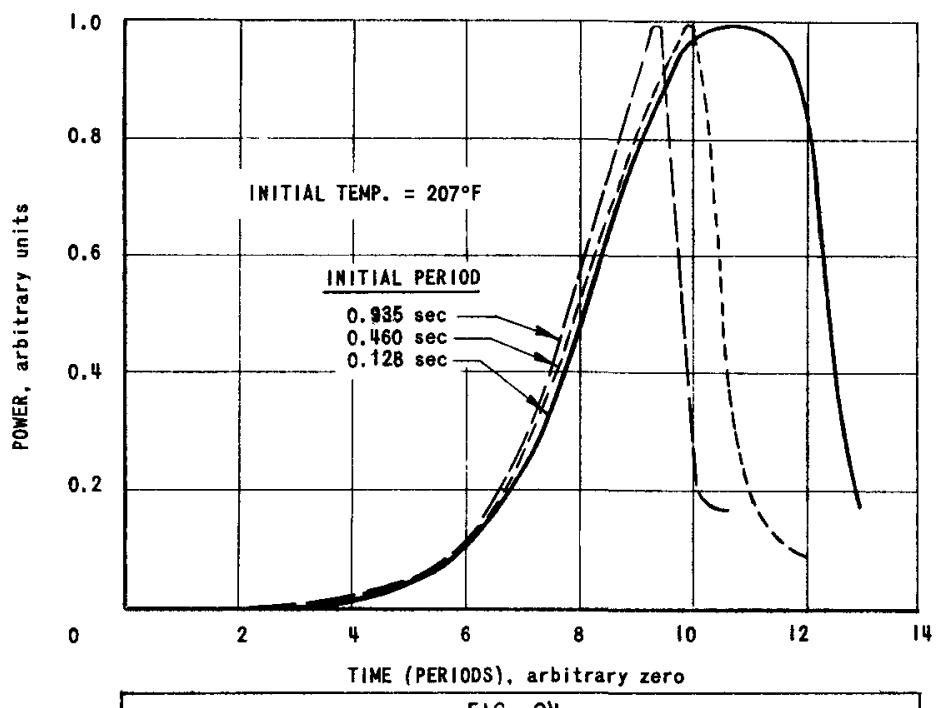

FIG. 24

BURST SHAPE DURING EXCURSIONS OF DIFFERENT INITIAL PERIODS

The energy (including delayed energy) released up to the time of peak power is given in Fig. 25 as a function of reciprocal period.

Figure 26 shows the maximum rise of surface temperature of a fuel bayonet located near the core center, as a function of reciprocal period. 


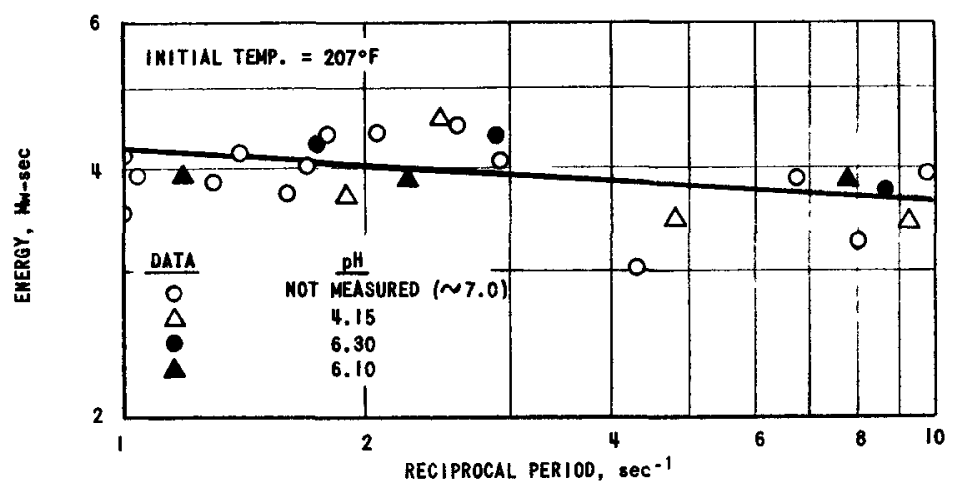

FIG. 25

ENERGY RELEASED UP TO PEAK POWER VS RECIPROCAL PERIOD

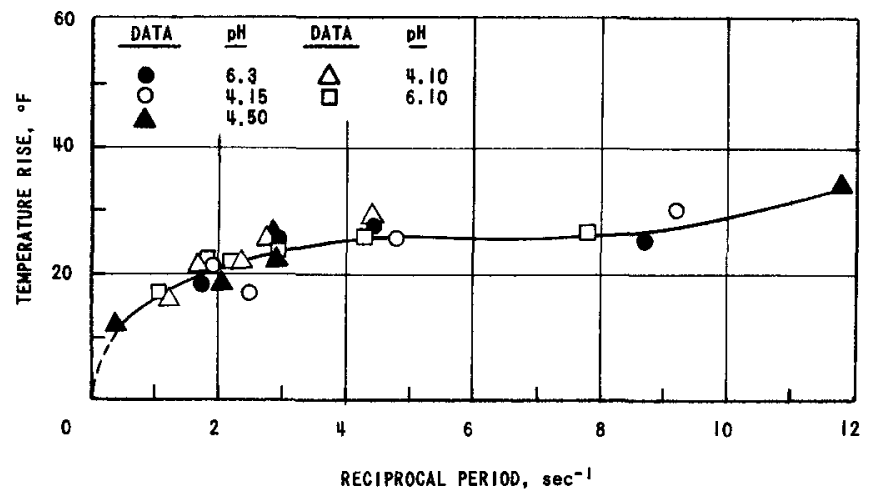

FIG. 28

MAXIMUM SURFACE TEMPERATURE RISE OF A FUEL BAYONET NEAR CORE CENTER VS RECIPROCAL PERIOD FOR EXCURSIONS WITH REACTOR WATER AT ATMOSPHERIC BOILING TEMPERATURE (207\%)

C. Transients with Water Initially Subcooled

Excursions with the water initially subcooled were performed since there was reason to suspect that a shutdown mechanism other than boiling was occurring in the subcooled excursions in SPERT-I.(8) Because of the long time constant of the fuel in BORAX-IV, it was felt that shutdown would occur before the clad surface had reached a temperature equal to the boiling point of water.

The results of a typical subcooled excursion is shown in Fig. 27. Figure 28(a) shows the maximum rise of surface temperature for a fuel bayonet at the core center at peak power for various periods in excursions from $120^{\circ} \mathrm{F}$. The peak power was attained before the temperature of clad surface reached the boiling point of the coolant. This was also observed in excursions from $120-130^{\circ} \mathrm{F}$ [Fig. 28(c) and (d)]. In excursions from $150^{\circ} \mathrm{F}$, the temperature of the clad surface exceeded the coolant boiling point for only the longer periods [Fig. 28(b)]. 


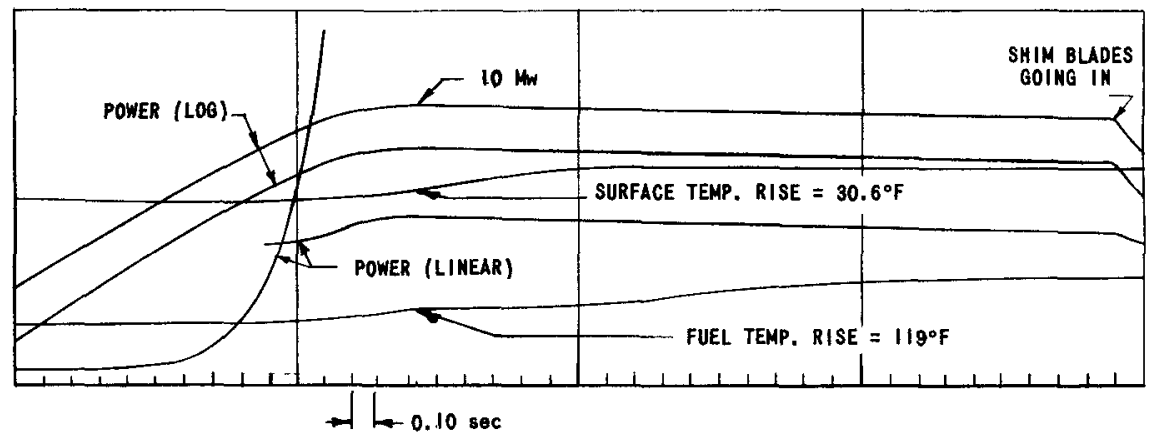

FIG. 27

TYPICAL SUBCOOLED EXCURSION WITH REACTOR WATER INITIALLY AT $120^{\circ} \mathrm{F}$ AND DH $=4.05$. PERIOD $=0.121 \mathrm{seC}$.
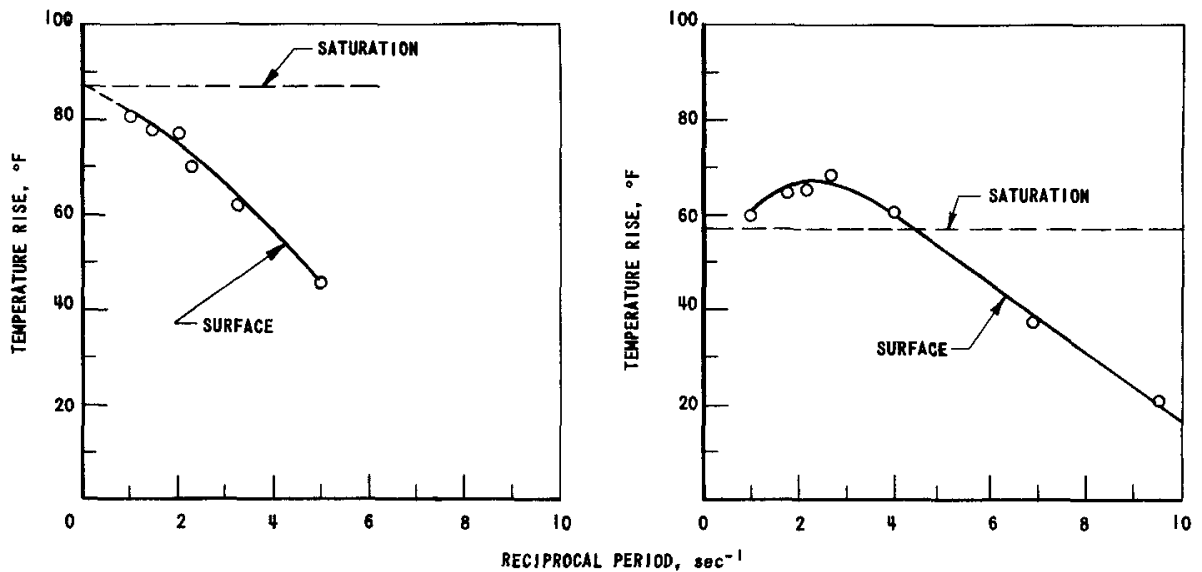

(A)

$\begin{aligned} \text { IMITIAL TEMP. } & =120^{\circ} \mathrm{F} \\ \text { pH } & =4.05\end{aligned}$

INITIAL TEMP. $=150^{\circ} \mathrm{F}$
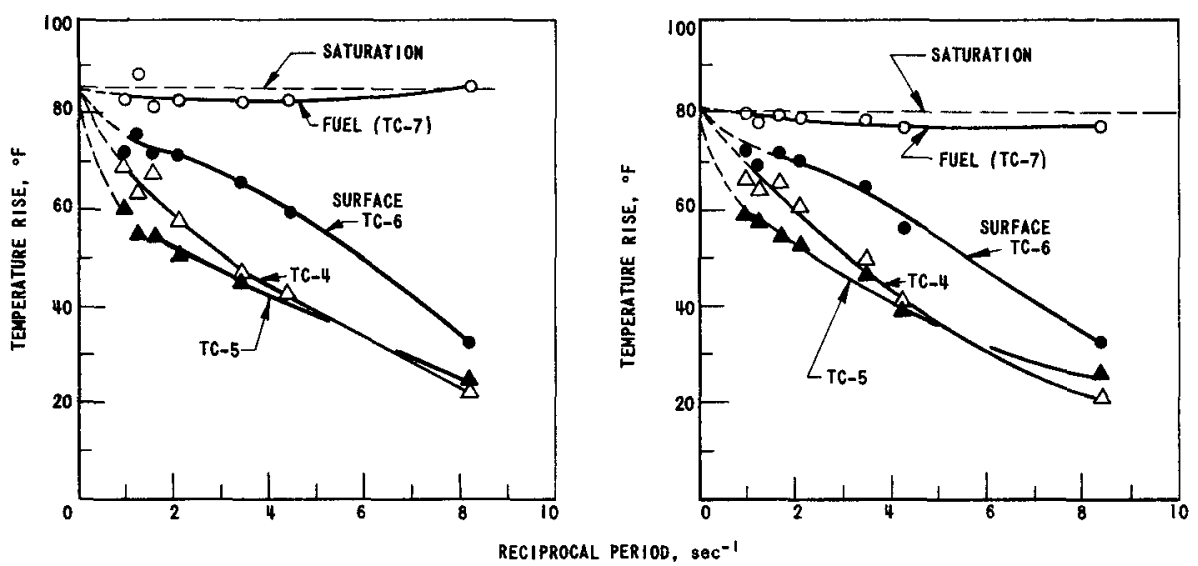

$\begin{aligned}(C) & \\ \text { IKITIAL TEMP. } & =120-125^{\circ} \mathrm{F} \\ \text { DH } & =5.5\end{aligned}$

(D)
$\begin{aligned} \text { INITIAL TEMP. } & =126-130^{\circ} \mathrm{F} \\ \text { PH } & =3.98\end{aligned}$

FIG. 28

SURFACE AND FUEL TEMPERATURE RISE OF A FUEL BAYONET NEAR CORE CENTER AT PEAK POWER VS RECIPROCAL PERIOD FOR SUBCCOLED EXCURSIONS 
Figure 29 presents the temperatures of the fuel and surface thermocouples at peak power as a function of liberated energy (including delayed energy). Since in this period range energy increases as the period increases, the temperature difference between fuel and cladding increases as the period decreases, a result which is to be expected. Figure 30, however, does not show this trend in excursions from $150^{\circ} \mathrm{F}$. It is believed that the reading of the fuel thermocouple used in this experiment may not have been proportional to the actual fuel temperature. The readings of the fuel thermocouple are, instead, proportional to the surface temperatures.
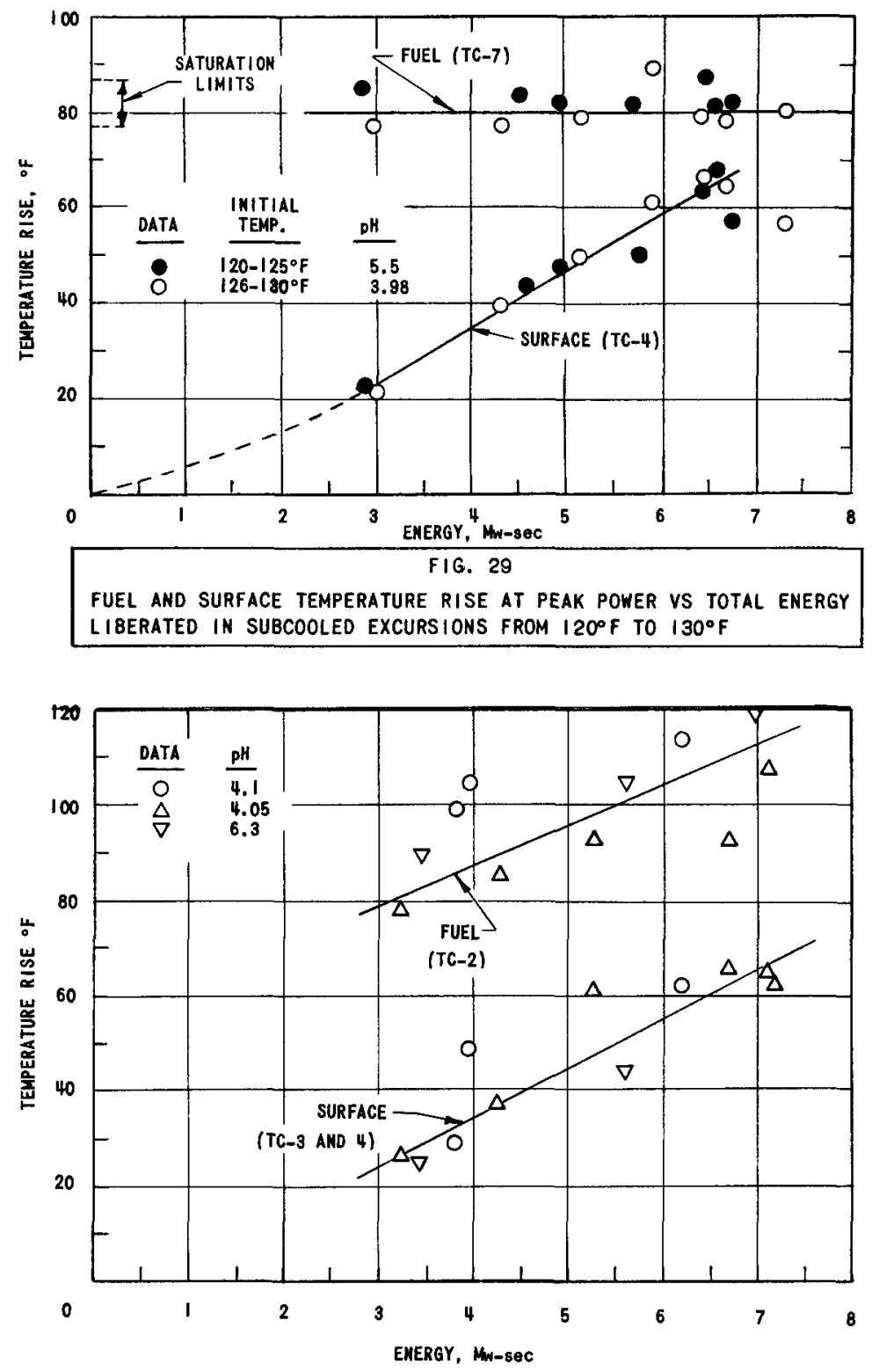

FIG. 30

FUEL AND SURFACE TEMPERATURE RISE AT PEAK POWER VS TOTAL ENERGY LIBERATED IN SUBCOOLED EXCURSIONS FROM $150^{\circ} \mathrm{F}$ 
The peak powers attained in subcooled excursions are shown in Fig. 31 as a function of reciprocal period. A slight dependence of peak power on the degree of subcooling is observed; there is no detectable effect of the $\mathrm{pH}$ of the water. Figure 32 shows the power behavior during three typical subcooled excursions. The energy liberated to peak power in the subcooled excursions is given as a function of period in Fig. 33.

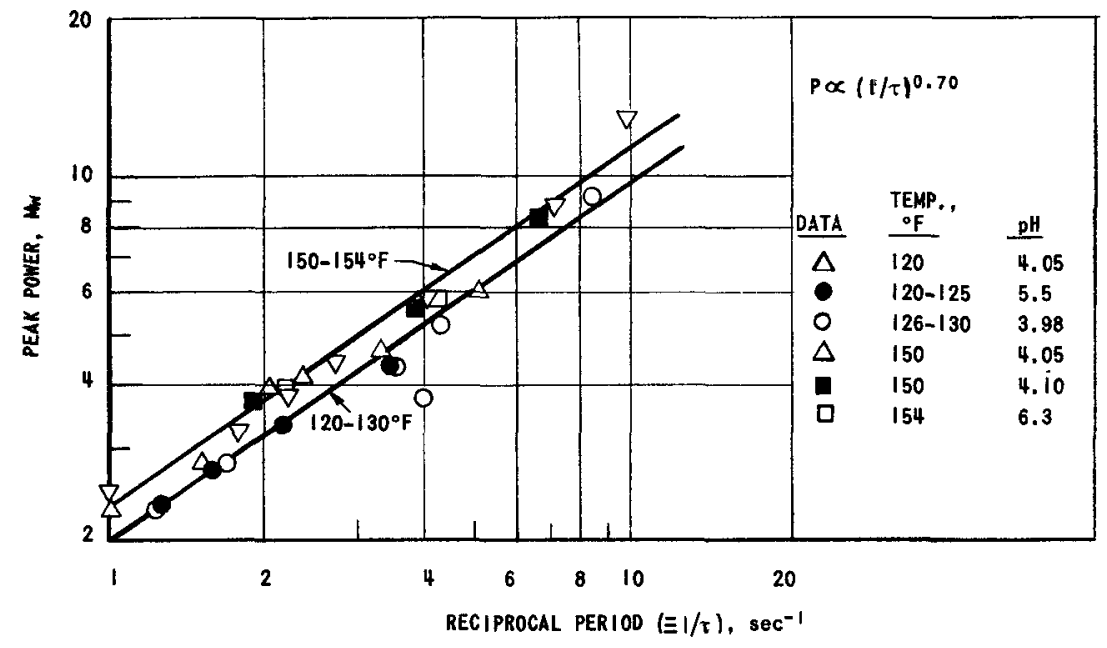

FIG. 3 I

PEAK POWER VS RECIPROCAL PERIOD FOR SUBCOOLED EXCURSIONS FROH $120^{\circ} \mathrm{F}$ TO $154^{\circ} \mathrm{F}$

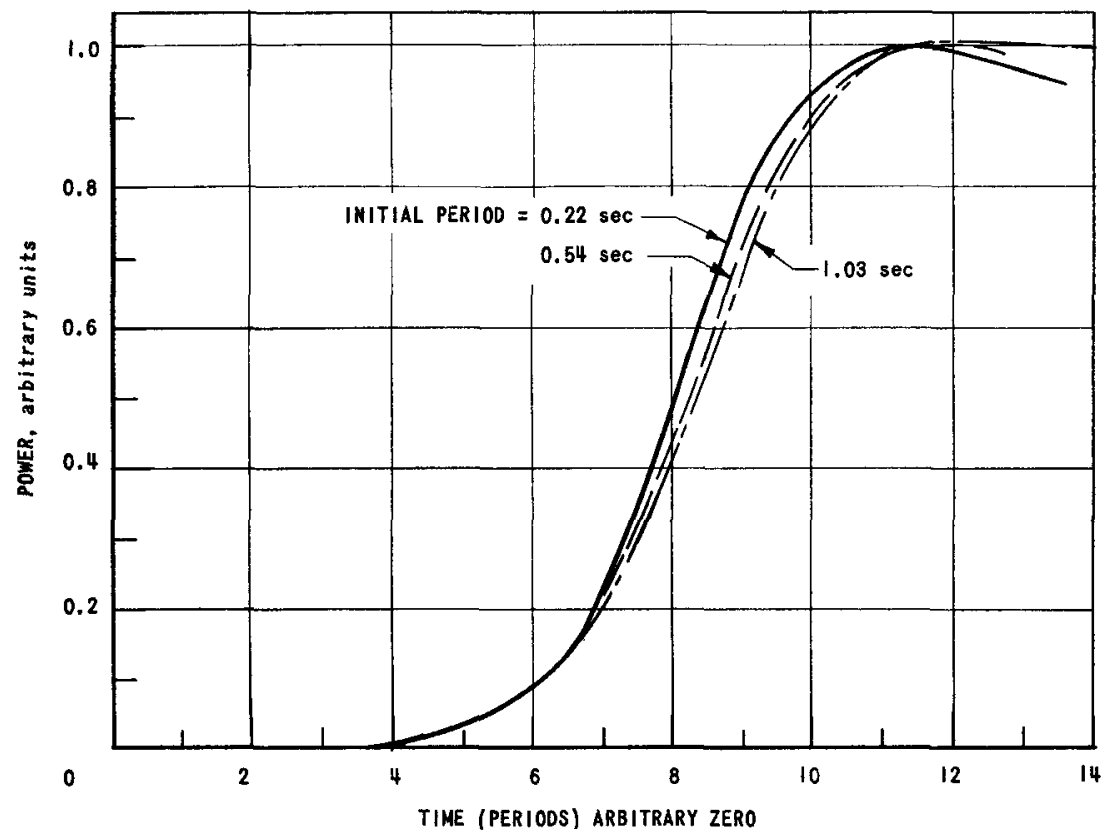

FIG. 32

POWER VS TIME FOR SUBCOOLED EXCURSIONS FROM $120^{\circ} \mathrm{F}$ 


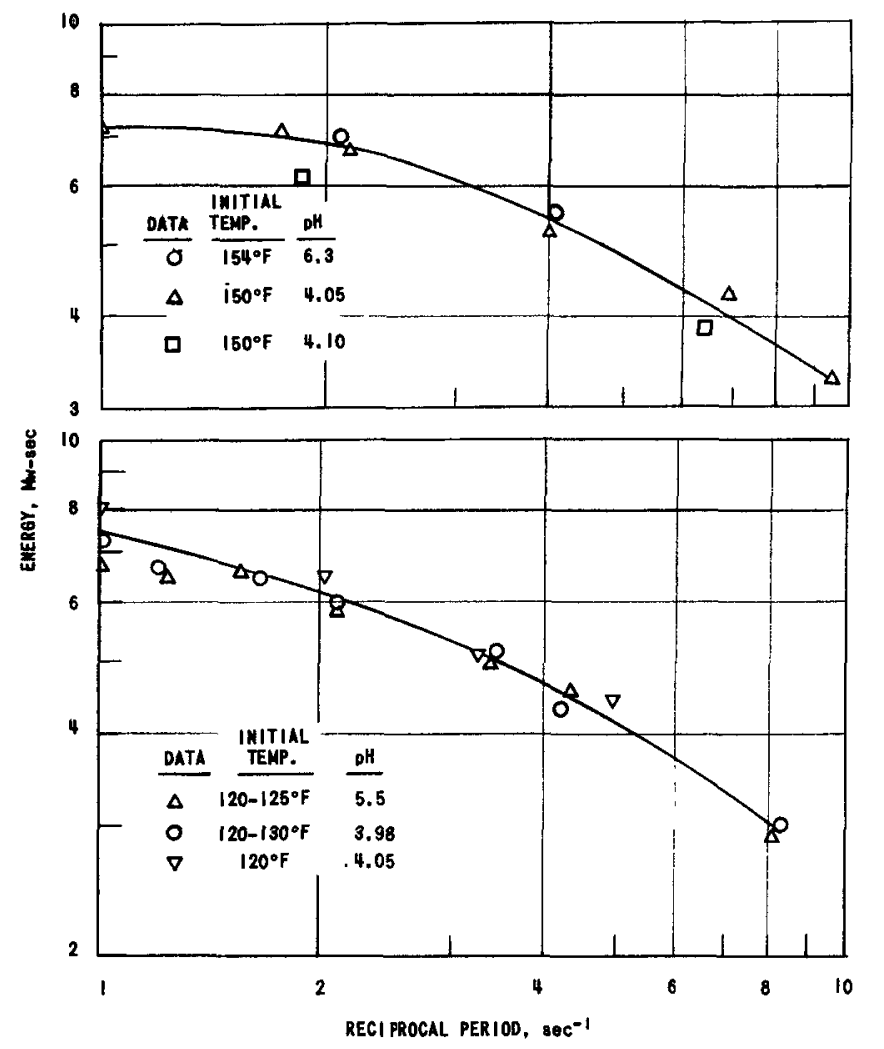

FIG. 33

ENERGY TO PEAK POWER VS RECIPROCAL PERIOD FOR SUBCOOLED EXCURSIONS

\section{Summary of Transient Behavior}

The relationships between peak power, energy release, and reactor period for saturated and subcooled excursions are summarized in Fig. 34. In both types of excursions the peak power attained was proportional to the reciprocal period raised to a power with a constant exponent down to a period of about 100 milliseconds. The "break" in the curve that occurs at about this period is based on a single 83-millisecond excursion from saturation. The sharp "break" was also observed for the subcooled excursions on SPERT-I,(8) although it occurred at a period approximately twice that in BORAX-IV. For a given initial period, the peak power increases as the initial core temperature is increased.

A major difference in transient behavior between subcooled and saturated excursion is noted by comparison of Figs. 22 and 27. The two excursions shown had about the same initial period and peak power. In the excursion from saturation, the power after reaching the peaklevel decreased rapidly, passed through a minimum, and began to rise again. This behavior 

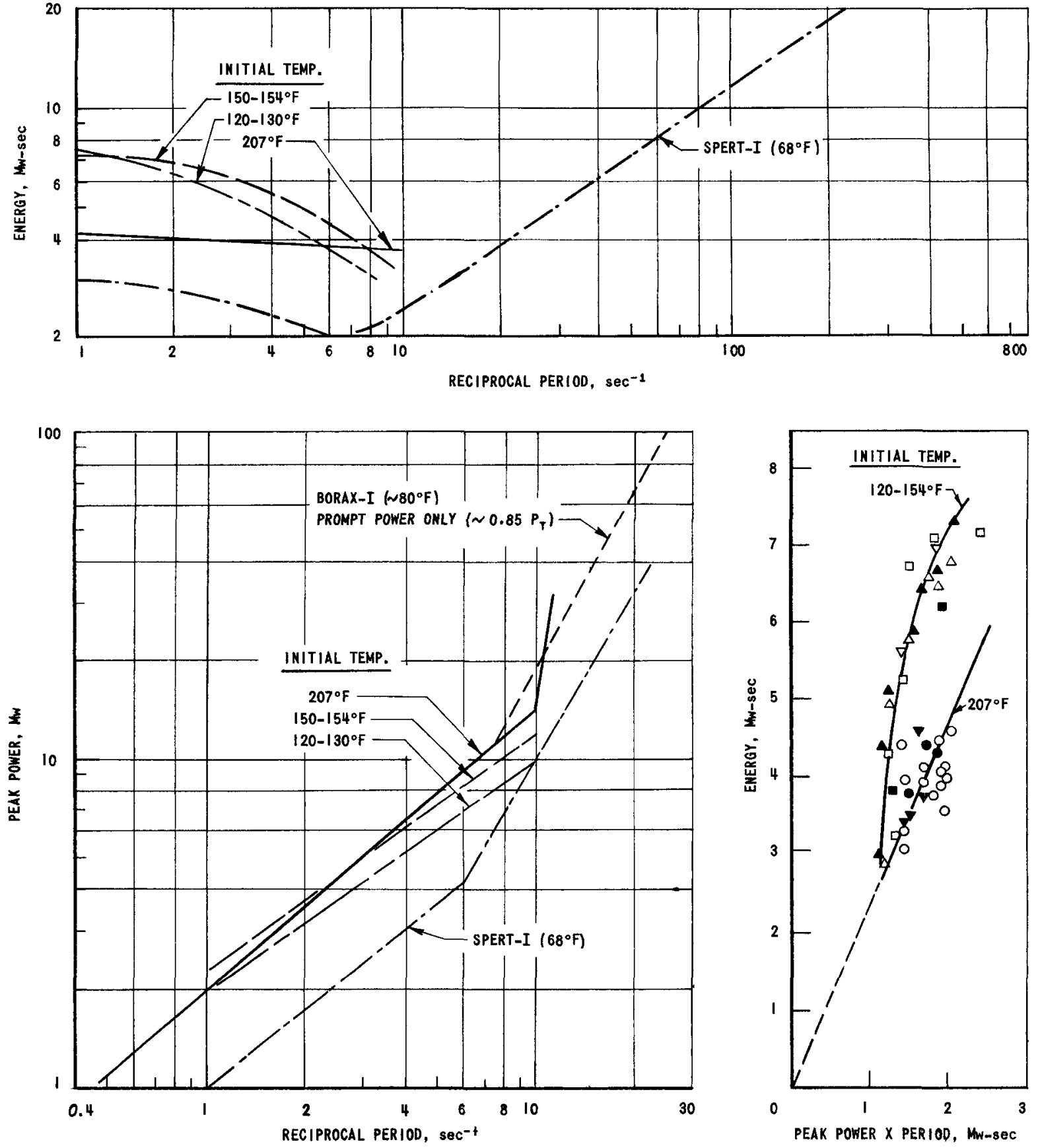

\begin{tabular}{|c|c|c|c|c|c|}
\hline DATA & INITIAL TEMP. & $\mathrm{pH}$ & DATA & INITIAL TEMP. & pH \\
\hline 0 & $207^{\circ} \mathrm{F}$ & $\sim 7$ & $\Delta$ & $125-130^{\circ} \mathrm{F}$ & 3.98 \\
\hline - & $207^{\circ} \mathrm{F}$ & 6.3 & 口 & $i 50^{\circ} \mathrm{F}$ & 4.05 \\
\hline$\nabla$ & $207^{\circ} \mathrm{F}$ & 4.15 & ш & $150^{\circ} \mathrm{F}$ & 4.10 \\
\hline$\Delta$ & $120-125^{\circ} \mathrm{F}$ & 5.5 & $\nabla$ & $154^{\circ} \mathrm{F}$ & 6.3 \\
\hline
\end{tabular}

FIG. 34

SUMMARY OF TRANSIENT BEHAVIOR OF BORAX-TI AND COMPARISON WITH BORAX-I AND SPERT-I 
was not observed in the subcooled excursion; the power essentially leveled off at peak power. This difference in transient behavior was observed for other excursions, as shown in Fig. 35.
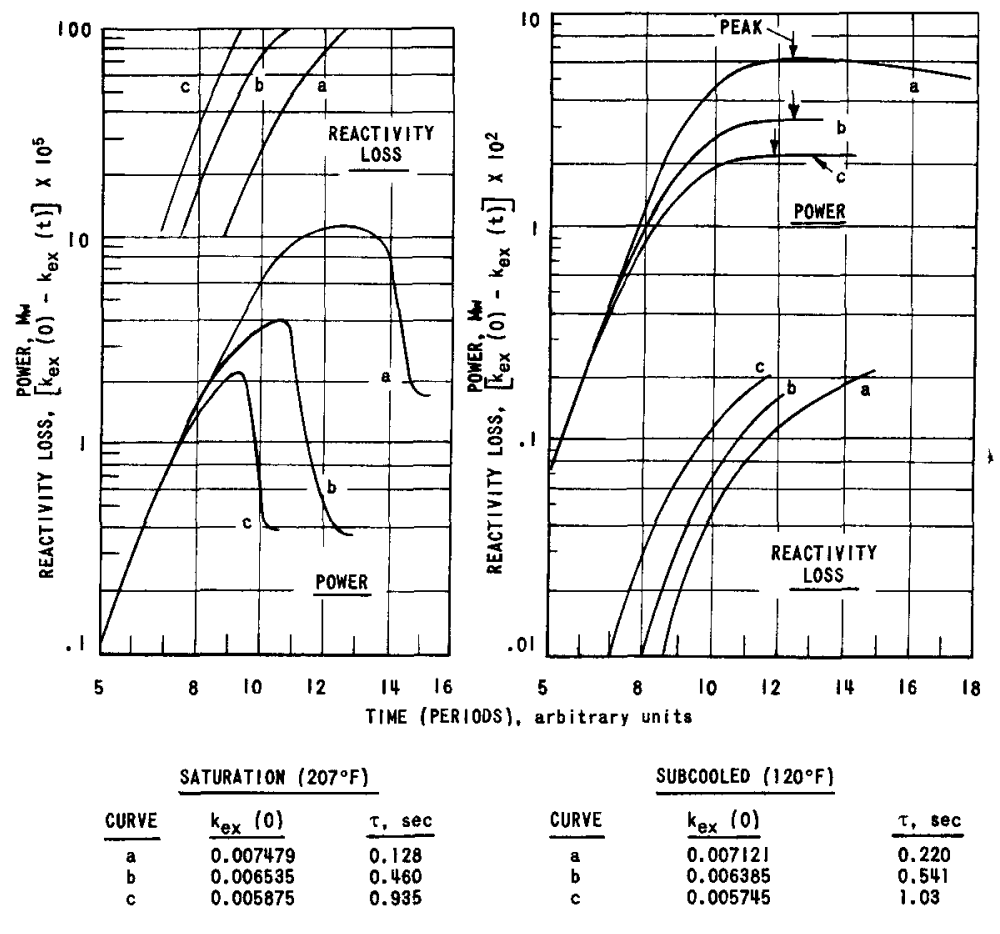

FIG. 35

POWER AND REACTIVITY LOSS VS TIME FOR SATURATED AND SUBCOOLED EXCURSIONS

Figure 36 shows the times required to reach peak power as a function of initial period for both subcooled and saturated excursions. For a given initial period, the time to reach peak power increased slightly with lower initial water temperatures. Figure 34 shows that, as the initial period decreased (i.e., increase in step-input of reactivity), the energy to peak power decreased in both types of excursions. This trend, in the period range tested, was also observed for the SPERT-I excursions.

A number of subcooled and saturated excursions were analyzed for the reactivity loss during the respective excursions (see Appendix C). Figure 37 shows the relationship of reactivity loss and energy release at peak power to reciprocal period for these tests. Two interesting characteristics are apparent: (1) the fraction of input reactivity compensated at peak power decreased as the period decreased, and (2) the reactivity loss at peak power was proportional to the energy release. Further analyses showed over the range when the power rise began to deviate from an exponential type, that the reactivity compensated was a linear function of the total energy release, independent of the initial period, and only slightly dependent of the initial temperature. Energy coefficients of reactivity of 


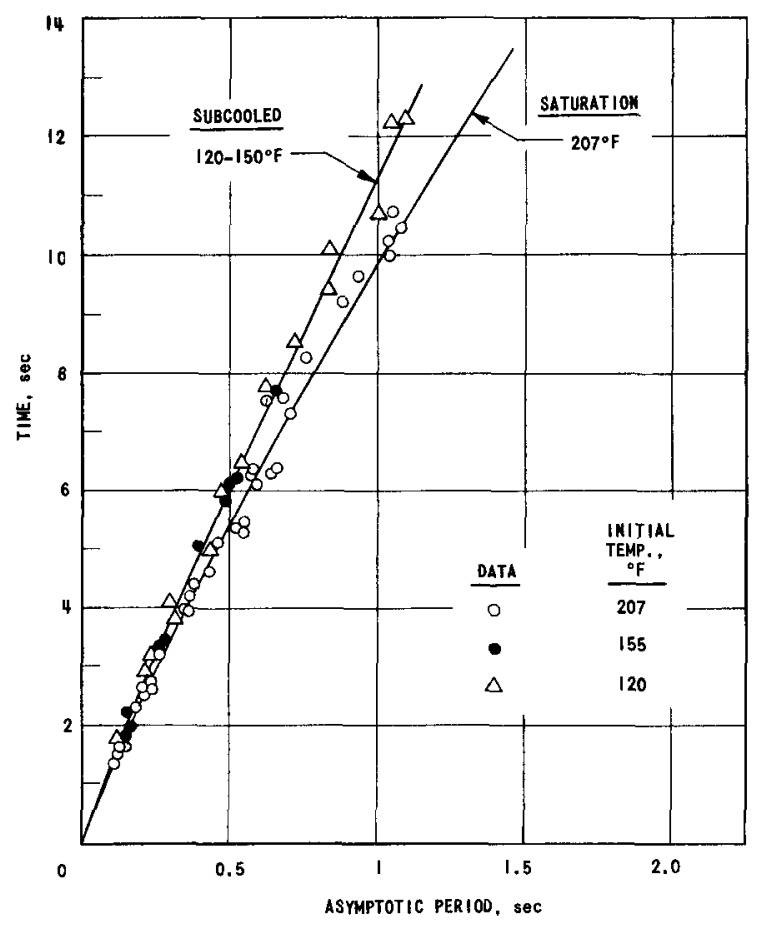

FIG. 36

TIME REQUIRED FOR POWER TO RISE FROM 100 WATTS TO PEAK VALUE

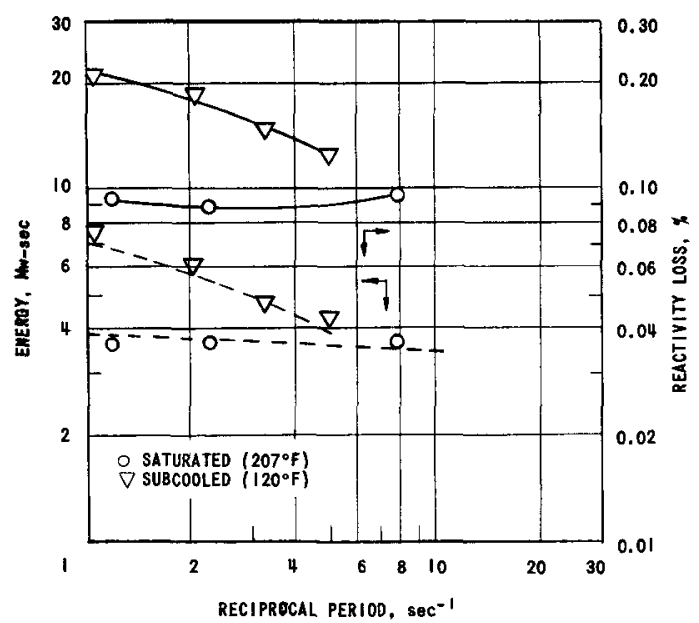

FIG. 37

ENERGY AND REACTIVITY LOSS TO PEAK POWER

VS RECIPROCAL PERIOD. DELAYED ENERGY NOT INCLUDED

about 0.03 and $0.028 \%(\Delta \mathrm{k} / \mathrm{k}) / \mathrm{Mw}-\mathrm{sec}$ for subcooled and saturated excursions, respectively, fit the experimental data in the period range between about one second and 100 milliseconds. (In this same range SPERT-I(8) gives about $0.067 \% / \mathrm{Mw}-$ sec.) Calculations (Appendix C) show that the combined effects of radiolytic formation of gas bubbles and of heating of water and fuel accounted for between 45 and $75 \%$ of the reactivity in these experiments.

Figure 38 shows the typical appearance of the special enriched fuel pellets that were contained in the fuel bayonets described on page 23. The aluminum jackets were dissolved in sodium hydroxide. The lead bond was removed with nitric acid.

Examination of the pellets failed to show any preferential deterioration due to either enrichment or irradiation history. Therefore the final appearances of the pellets must be attributed to factors such as firing or other properties inherent in the pre-irradiated material, as well as to possible damage due to handling.

\section{ATMOSPHERIC PRESSURE BOILING}

Upon completion of the transient tests, the reactor was operated at various power levels and core loadings with the pressure vessel open to the building atmosphere. 


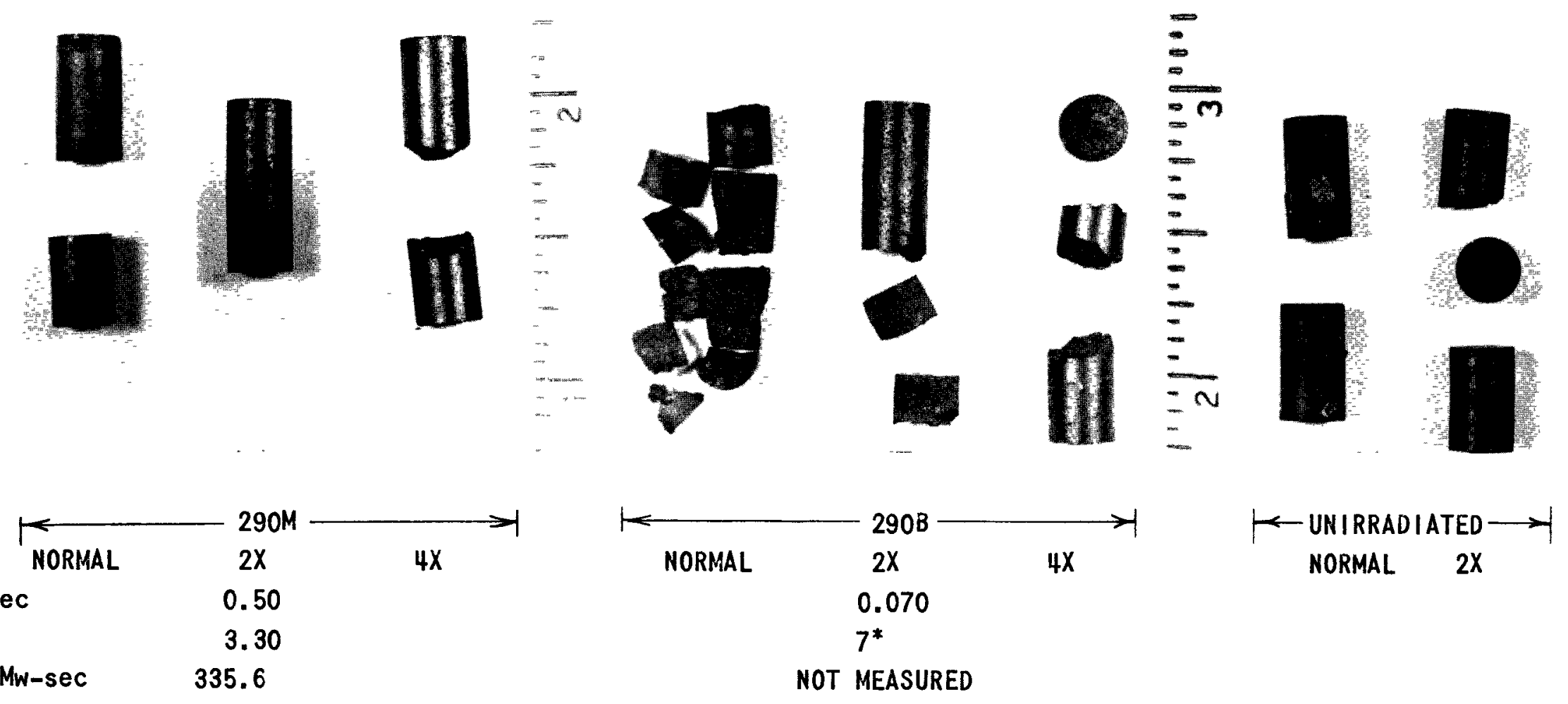

BAYONET NO。 ENRICHMENT

MIN. PERIOD, sec

MAX. POWER, MW

TOTAL ENERGY, MW-sec
335.6

*EXCURSION FROM I MW POWER

NOTE: TOTAL ENERGY INCLUDES SOME LOW-POWER STEADY-STATE TESTS.

\section{FIG. 38}

TYPICAL APPEARANCE OF SPECIAL ENRICHED FUEL FELLETS REMOVED FROM FUEL BAYONET DETECTORS. 


\section{A. Reactivity in Steam Voids}

The reactivity held by the steam voids was determined by measuring the changes in positions of the shim blades using the calibration obtained at zero power $\left(207^{\circ} \mathrm{F}\right)$. The results for the various core loadings are summarized in Fig. 39.

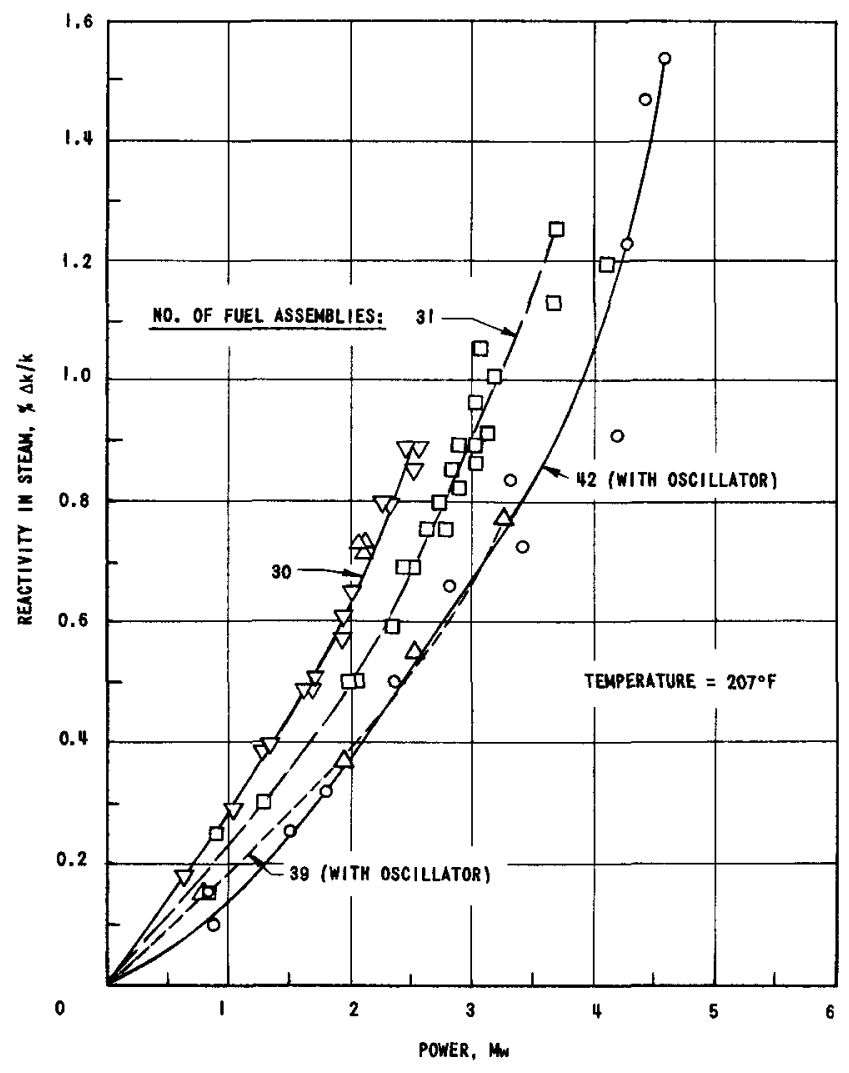

Figure 40 shows the reactivity held in steam voids as a function of average power density. On this basis, there are no detectable differences between the core loadings studied. The scatter in data is probably due to errors in the worths of the shim blades, inaccuracies in zero-power conditions, and uncertainties in the power calibrations. Figure 41 shows that the average power density coefficient of reactivity $(\Delta k / \Delta P)$ increased as the power increased. The highest average power level attained during this series of tests was about $4.6 \mathrm{Mw}$ ( 42 fuel assemblies), with slightly less than $1.6 \%$ reactivity held by the steam (Fig. 42 ).

\section{B. Fuel and Clad Temperatures}

Figure 43 shows the maximum measured and calculated temperature rises of the fuel and surface of a bayonet located in the center of the 


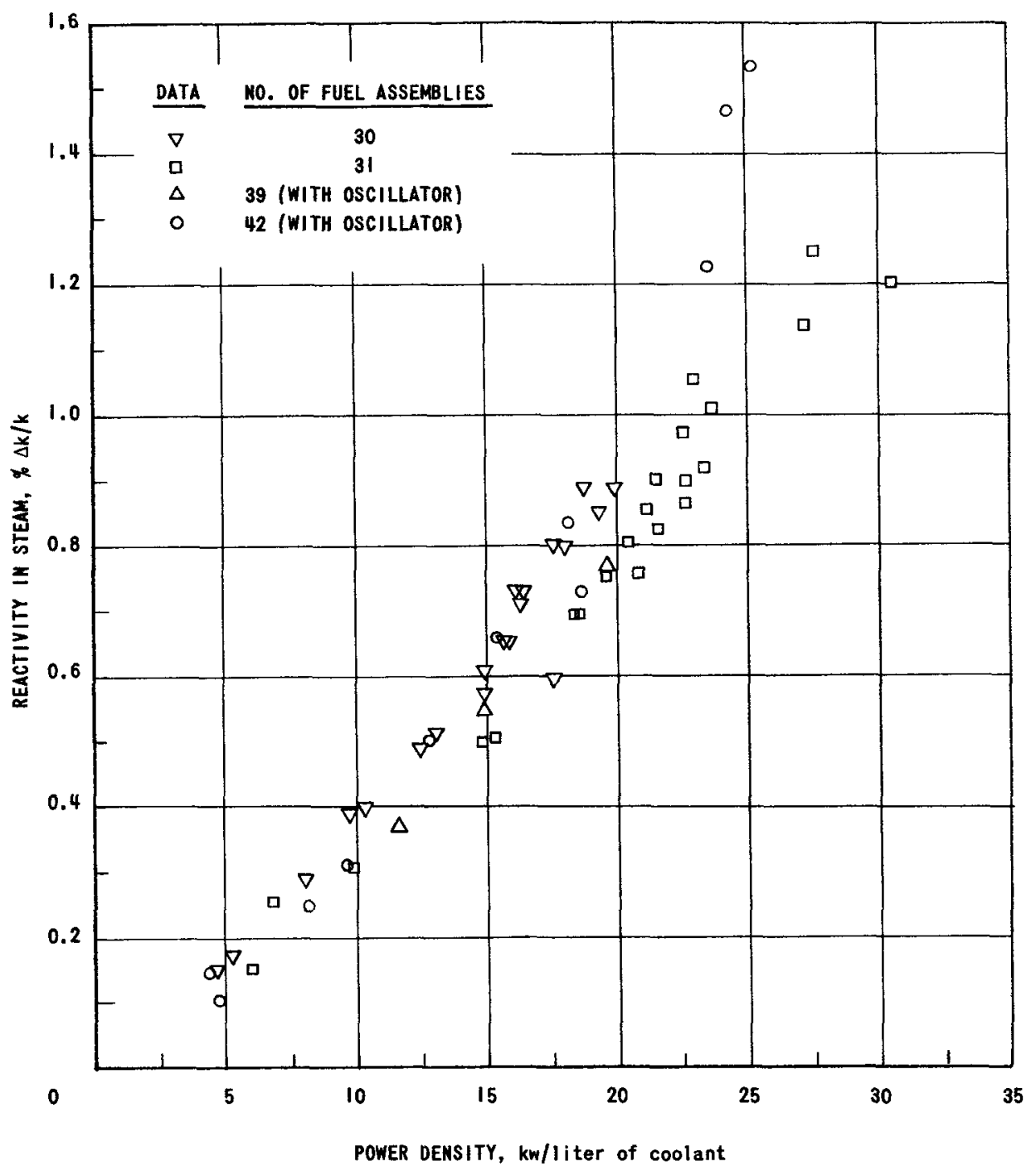

FIG. 40

REACTIVITY IN STEAM VS POWER DENSITY

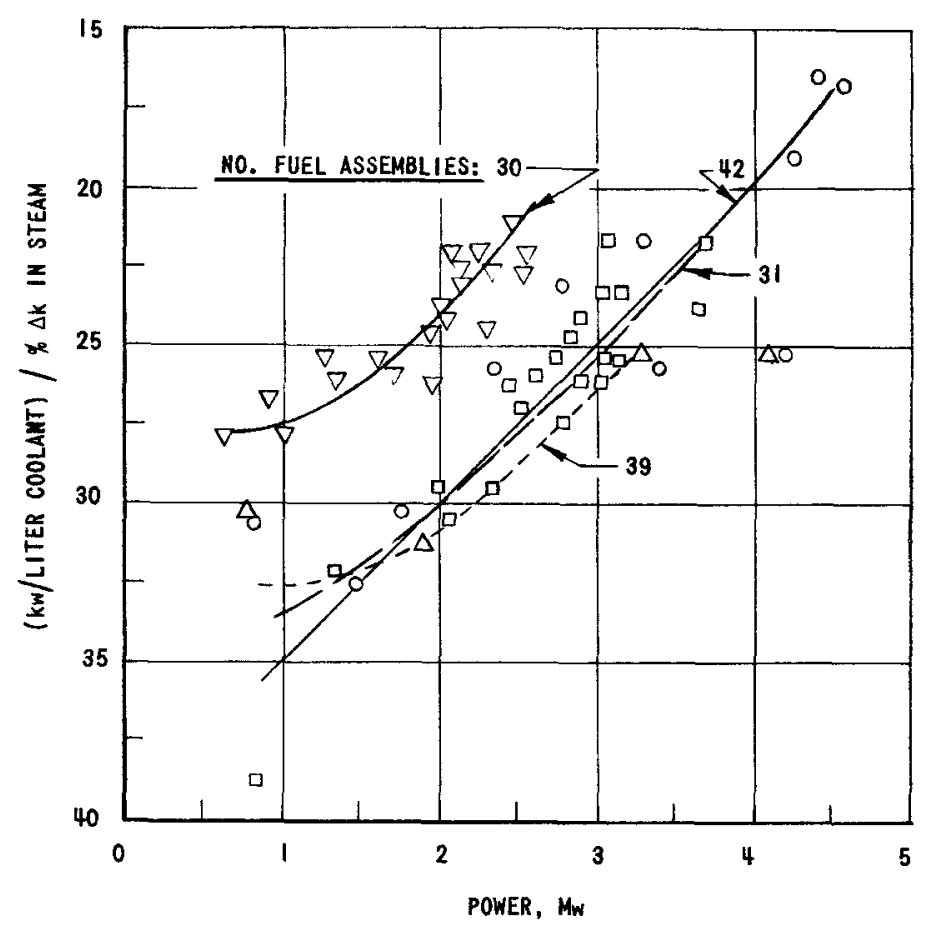

FIG. 4I

POWER DEPENDENCE OF THE RECIPROCAL OF THE POWER DENSITY COEFFICIENT OF REACTIVITY 


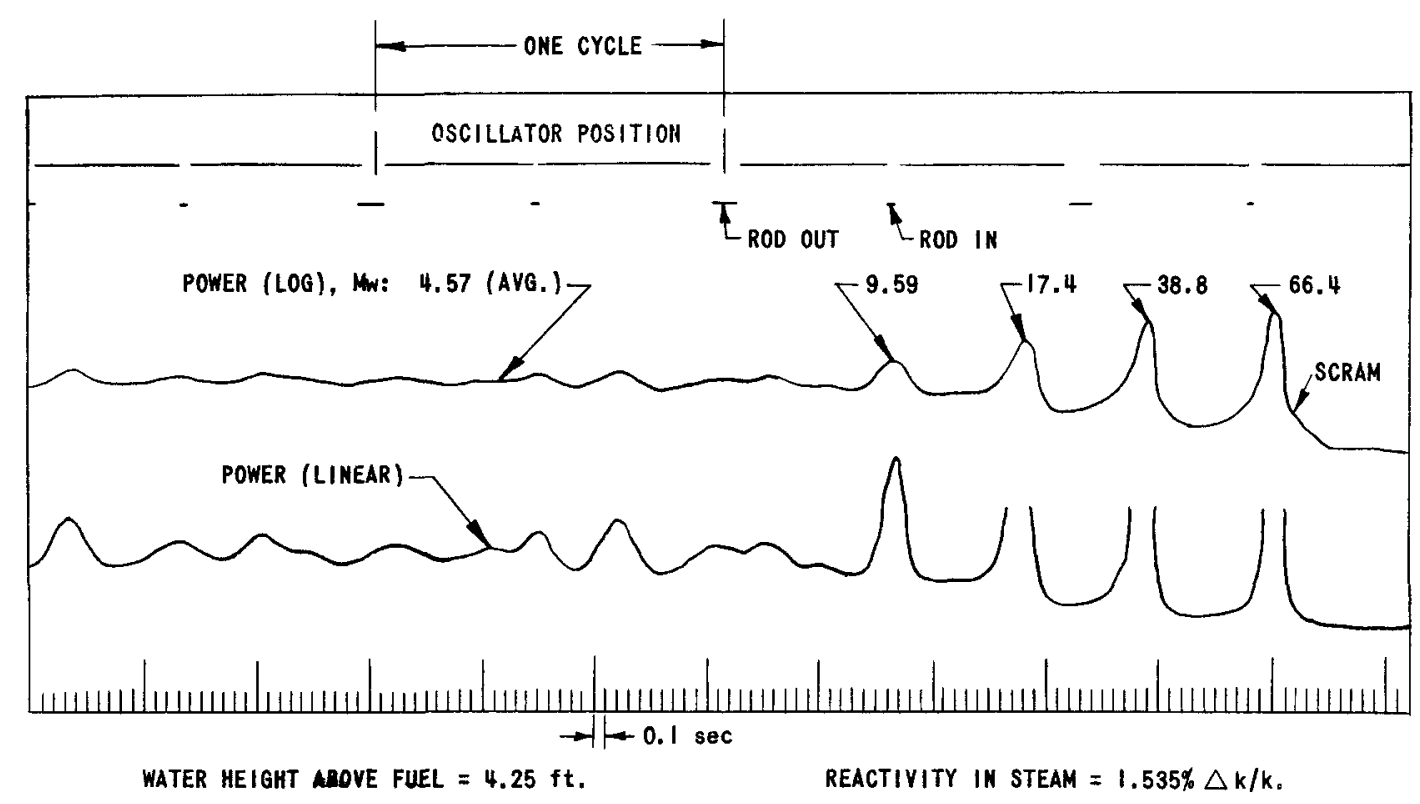

FIG. 42

4.57-MW POWER TEST WITH OSCILLATOR IN 42-ASSEMBLY CORE
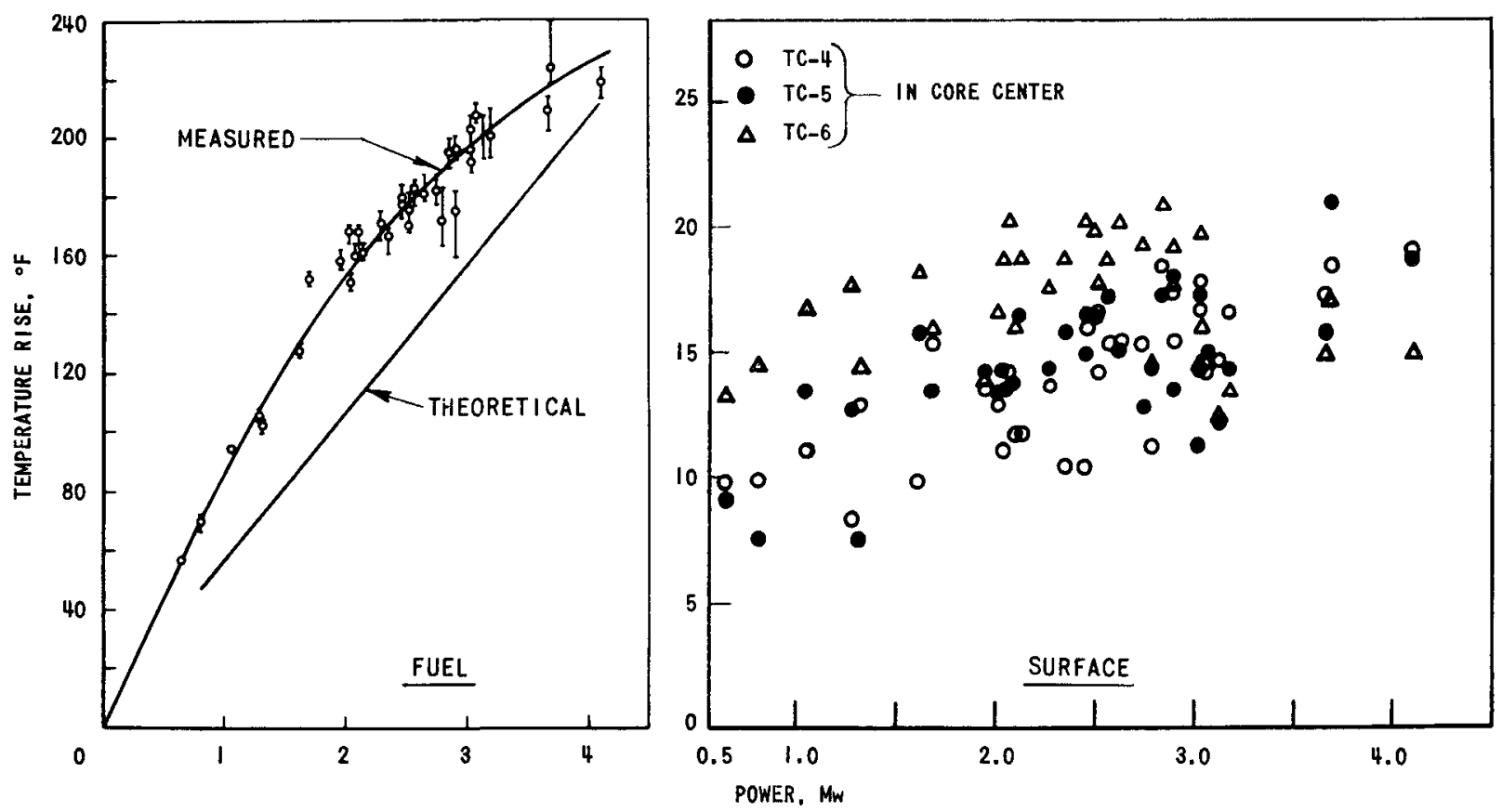

FIG. 43

MAXIMUM MEASURED TEMPERATURE RISE IN FUEL AND SURFACE OF FUEL BAYONET AT CENTER OF 30-AND 31-ASSEMBLY CORES DURING STEADY-STATE POWER TESTS 
core during steady-state power tests. The calculated curve was based on the following temperature differentials in the fuel bayonet:

Temperature Differential $(\Delta \mathrm{T})$

${ }^{\circ} \mathrm{F}$

\begin{tabular}{|c|c|c|c|c|}
\hline $\begin{array}{c}\text { Power, } \\
\text { Mw }\end{array}$ & Film & $\mathrm{Al}$ & $\mathrm{Pb}$ & Fuel \\
\hline 1 & 14.7 & 0.53 & 1.38 & 40.6 \\
\hline 2.5 & 21.5 & 1.32 & 3.53 & 105 \\
\hline 4 & 24.1 & 2.11 & 5.64 & 176 \\
\hline
\end{tabular}

Total

Temperature Differential,

${ }^{\circ} \mathrm{F}$

57.2

131.4

207.9

The discrepancies between the measured and calculated values can be attributed to uncertainty in the thermal conductivity of the fuel, possible small air gaps, and the systematic experimental errors associated with the difficult art of measuring fuel temperatures by thermocouples. It has been estimated that a gap in the fuel region occupied by the thermocouple can result in an error of $\sim 4^{\circ} \mathrm{F}$.

\section{Water-Head Effect}

Figure 44 shows the effect of water height above the fuel on the power densities for various core loadings. For a given loading, the reactivity held by the steam voids was maintained constant. It appears
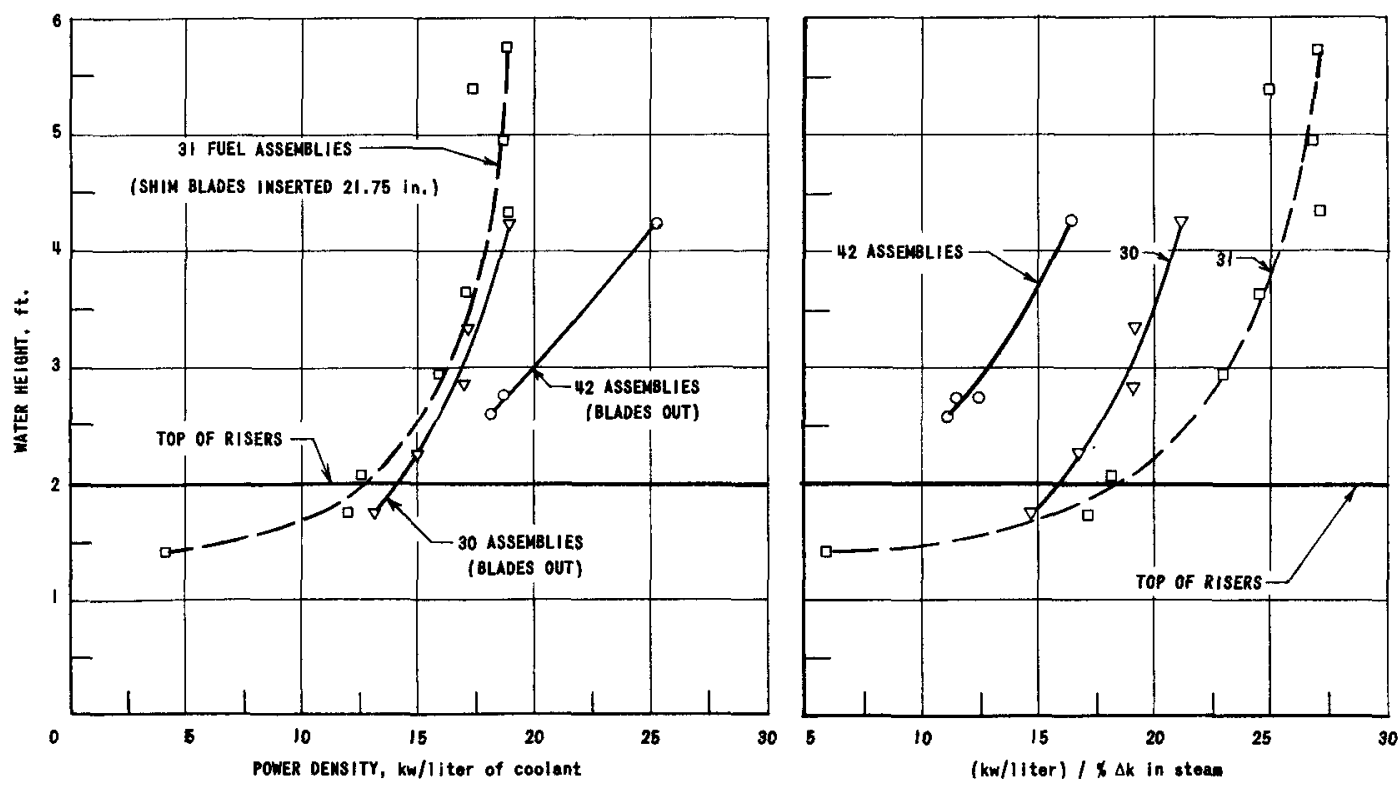

FIG. 44

EFFECT OF WATER HEIGHT ABOVE FUEL ON POWER DENSITY AND THE RECIPROCAL OF ITS REACTIVITY COEFFICIENT 
that water heights greater than about four feet above the fuel had little effect on the power output. However, the power decreased rapidly as the water level dropped to two feet (to the top of riser). This is to be expected because of the consequent decrease in recirculation rate and, perhaps, the change in core boiling boundary effected by the static head. The slight increase in power density with a water head greater than four feet may be due to the resultant increase in average core pressure.

Figure 45 is a linear instrument recording of the flux behavior as the top reflector was bolled off. The oscillations became more pronounced as the water level fell below the top of the riser, despite the small reactivity held in the steam.

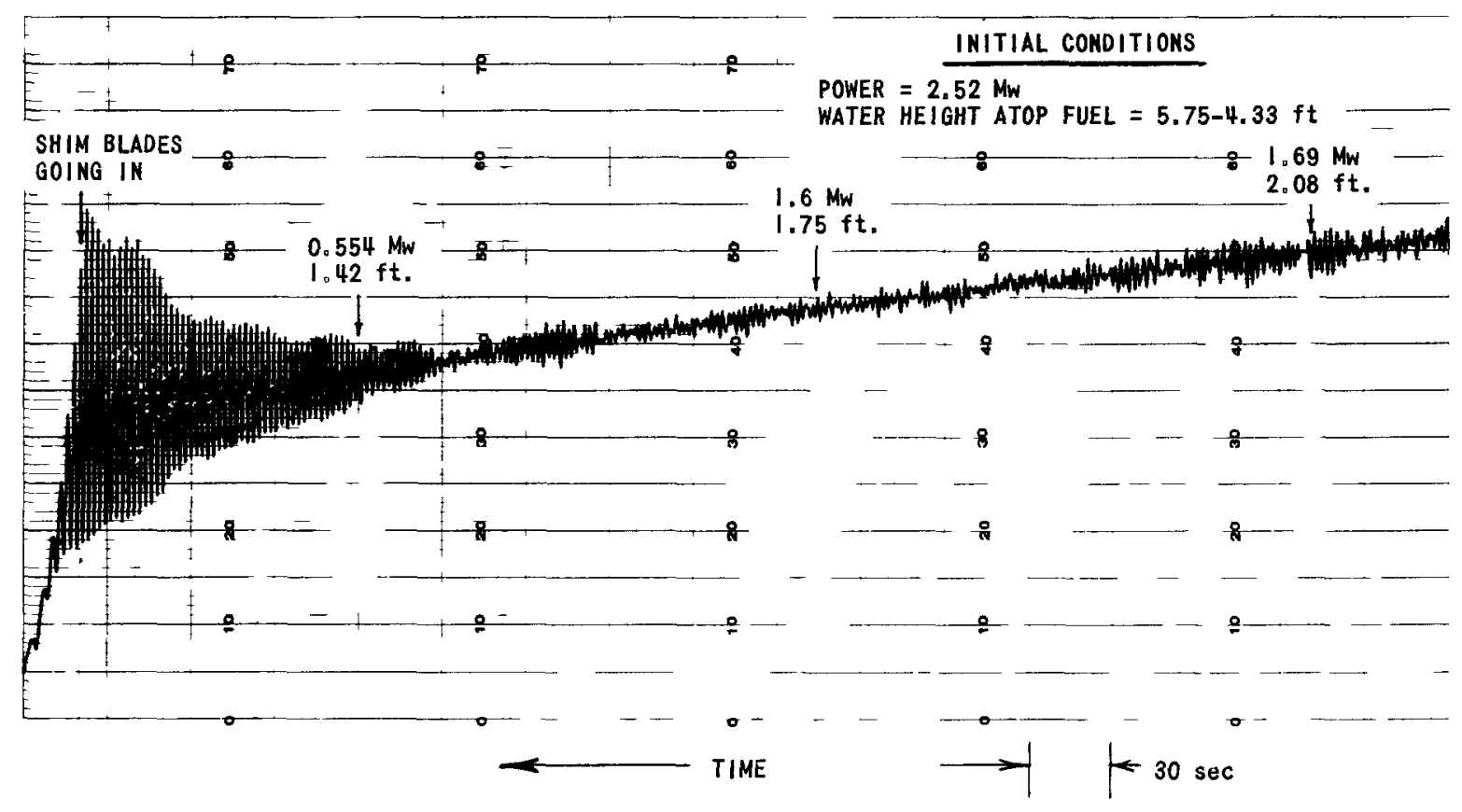

FIG. 45

UNSTABLE OPERATION RESULTING FROM BOIL-OFF OF TOP REFLECTOR (REACTIVITY IN STEAM $=0.695 \% \Delta \mathrm{k} / \mathrm{k}$ )

Heiland recordings of the central fuel and clad surface temperatures and of the reactor power during the reflector boil-off were used to determine the reactor power-to-temperature transfer function, $\Delta \mathrm{T} /(\Delta \mathrm{P} / \mathrm{P})$. The results for these oscillations where

$$
\frac{\Delta \mathrm{P}}{\mathrm{P}}=\frac{\text { amplitudes }}{\text { average power }}=0.5
$$


and the frequency was 0.495 cycle/second, are given in Table I. The phases indicate that the temperature lags behind the power.

Table I

POWER-TO-TEMPERATURE TRANSFER FUNCTIONS $[\triangle T /(\triangle \mathrm{P} / \mathrm{P})]$

\begin{tabular}{|c|c|c|}
\hline & $\begin{array}{c}\text { Magnitude, } \\
{ }^{\circ} \mathrm{F}\end{array}$ & $\begin{array}{r}\text { Phase, } \\
\text { degrees }\end{array}$ \\
\hline Clad Surface & 5.64 & -44.6 \\
\hline Fuel & 10.22 & -141.2 \\
\hline
\end{tabular}

D. Self-Induced Oscillations

As in the previous BORAX reactors, $(1-3)$ SPERT-I,
EBWR, (10) and
self-induced oscillations occurred above a certain power threshold. The threshold is defined as the power level at which a sequence of two or more oscillations of the same frequency appear above the boiling noise background. The threshold for the 31 -assemblycore was $\sim 1.8 \mathrm{Mw}$ or $0.4 \%$ reactivity in steam. Figure 46 shows a typical recording of reactor operation well above the oscillatory threshold. (This test was used for the spectral analysis discussed in Section VI-C.)

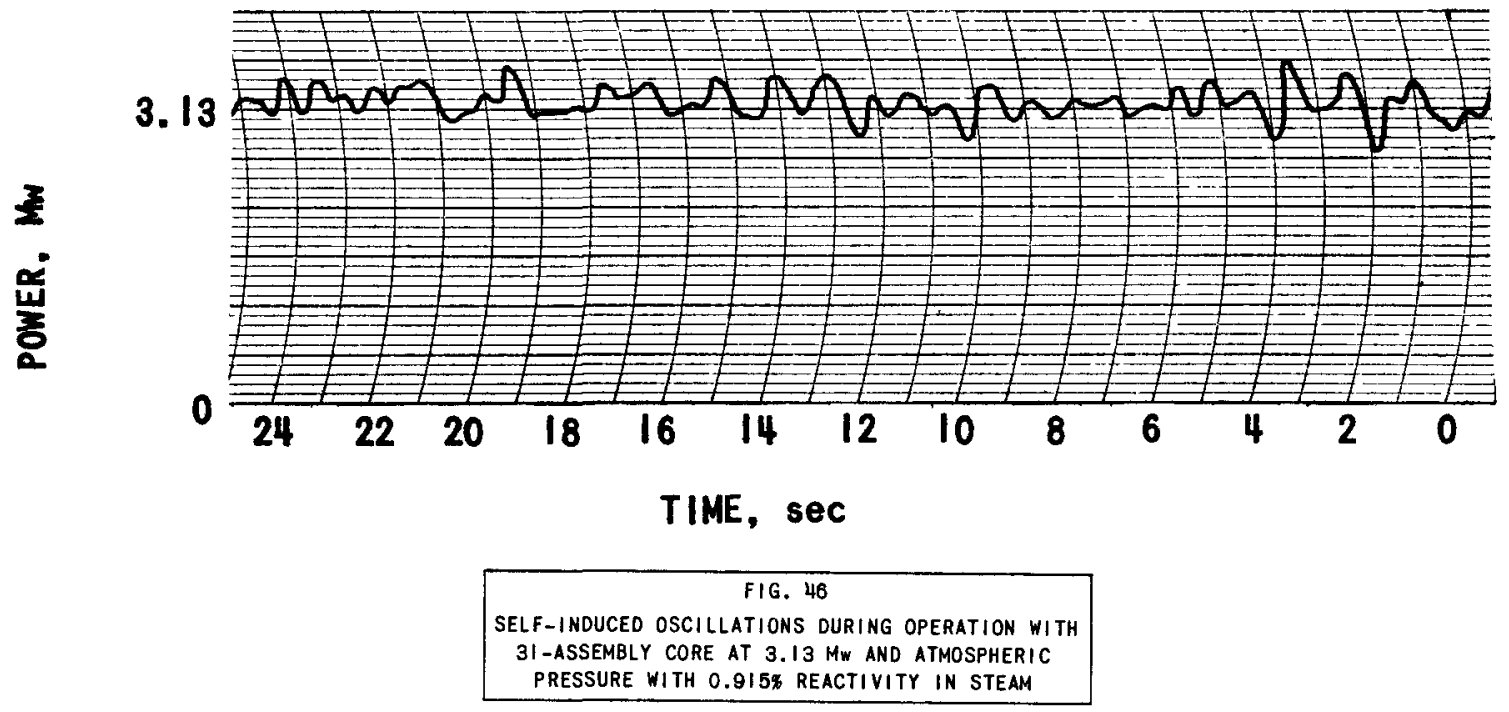

Figure 47 shows the ratio of amplitude to average power is a function increasing with average power. Using the zero-power transfer function at the average frequency of 1 cycle/sec,

$$
\frac{1}{N} \frac{\mathrm{dn}}{\mathrm{dk}}=109.2
$$


The ordinate of Fig. 47 can be converted to the $\Delta \mathrm{k}$ associated with the oscillation. Dividing this value by the reactivity in steam gives the oscillation fraction of reactivity (Fig. 48). If the oscillating fraction of reactivity is interpreted as an oscillation of void content, then the void oscillatory fraction is typically about 0.1 for small oscillatory operation.
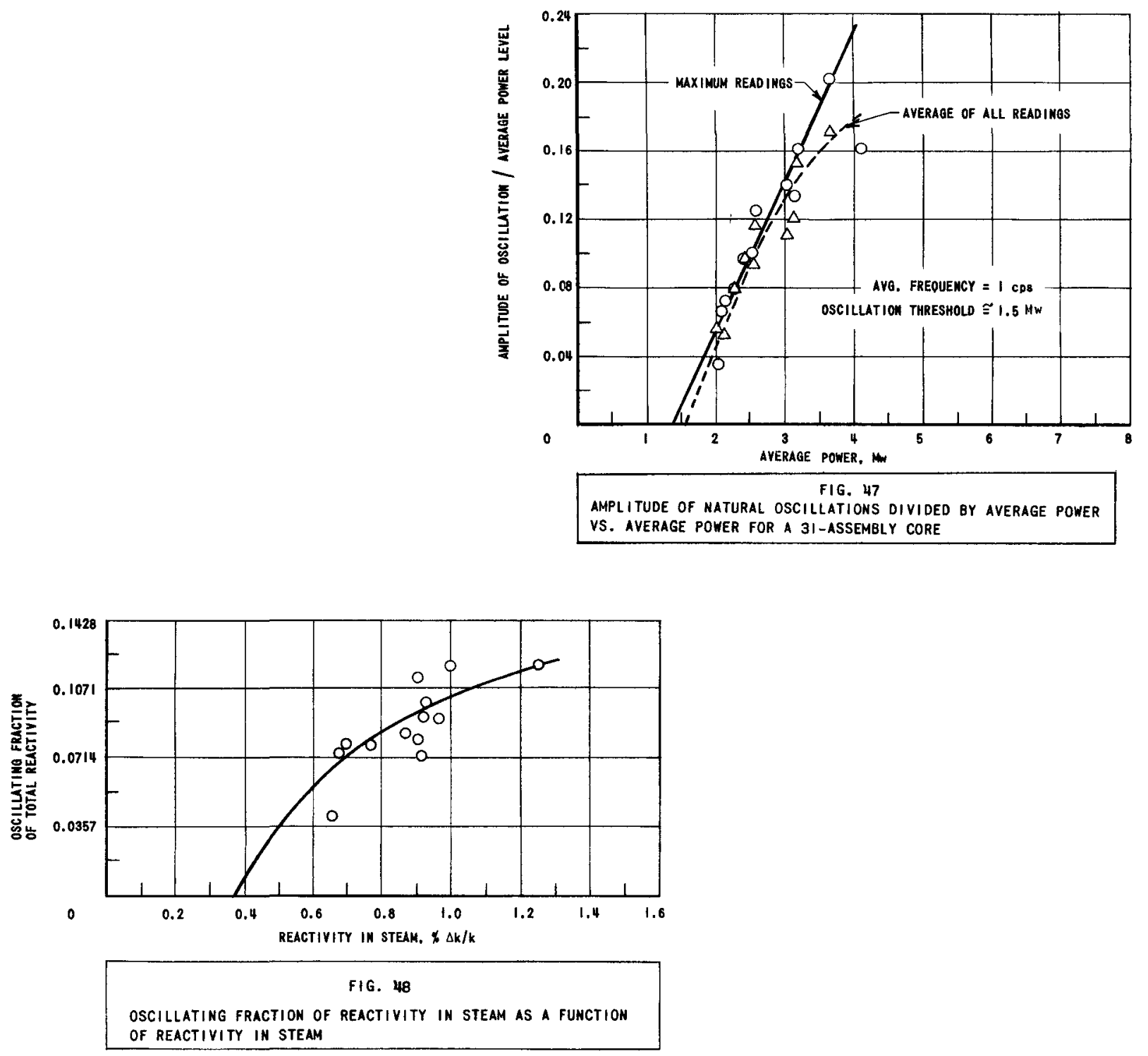

The history of oscillation studies shows that, when the reactivity amplitudes in oscillatory behavior are somewhat less than $0.75 \% \Delta \mathrm{k}$, their waveforms are either sinusoidal or very non-sinusoidal. The latter type is rare but has been observed in the EBWR.(10) The BORAX-IV data is presumed to have given evidence only of the former type.

When the power level is sufficiently above the self-oscillatory threshold, the amplitude of the oscillations can become quite large. 
Figure 42 shows the 42 -assembly core, with the rod oscillator, reaching an unstable point at $4.57 \mathrm{Mw}$, which is well above the threshold for this core loading. The oscillations produced by rod cycling are negligible by comparison with the noise and self-induced oscillations even before the final divergence. Figure 49 compares the power with the corresponding reactivity at the end of this test. It should be noted that the reactivity peaks are in the vicinity of prompt critical. Eventually about one-half the reactivity in steam ( $\mathrm{Fig} .42$ shows $1.535 \% \Delta \mathrm{k} / \mathrm{k}$ ) appears as excess reactivity at the peak. This might be interpreted that one-half of the equilibrium voids disappear from the reactor. The violent oscillations are evidence of a trend toward lower frequency, a conclusion obtained by comparison with the smaller oscillations at the beginning of the test. Presumably the shift in frequency, along with the limiting amplitudes attained, eventually might be understood in terms of the nonlinear effects which enter into the hydraulic relationships of natural circulation boiling.
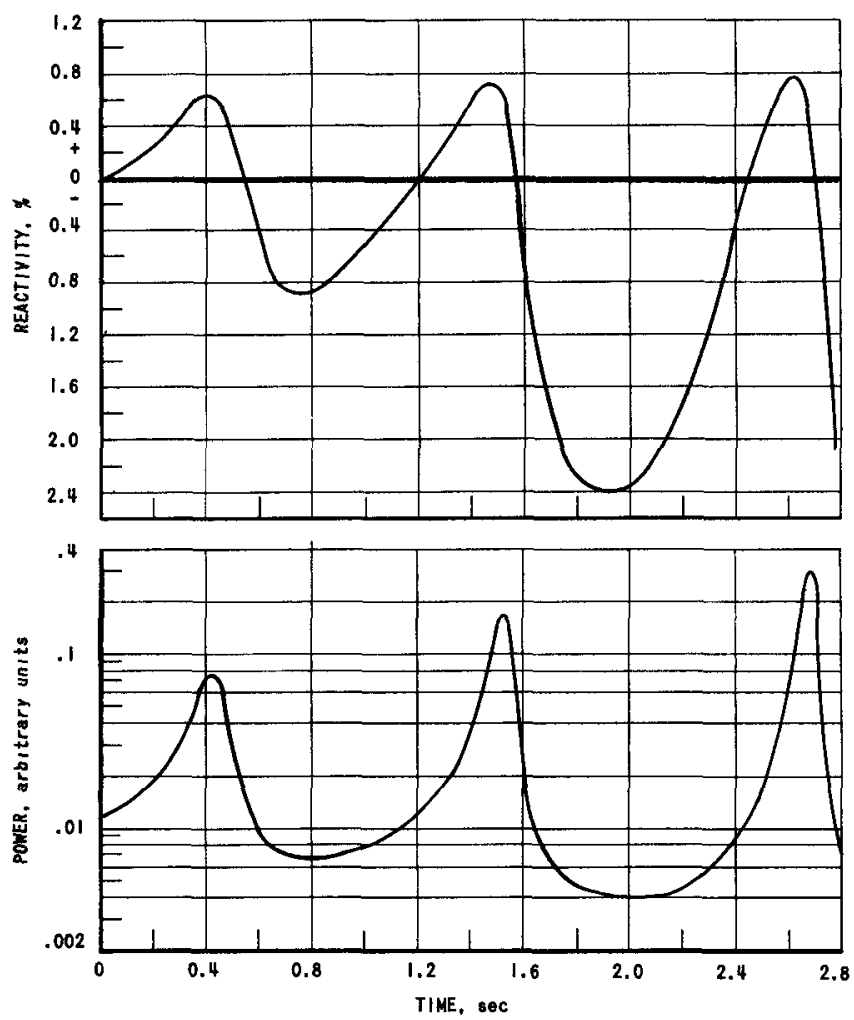

$$
\begin{aligned}
& \text { DIVERGENT REACTIVITY AND PONER OSCILLATIONS AT END OF } \\
& \text { 4.57-MW TEST (F/g. } 42 \text { ). }
\end{aligned}
$$

Another example of large self-induced oscillations is shown in Fig. 31. The apparent contradiction of the reactor becoming less stable as the power decreases is easily explained: the oscillatory threshold decreased more rapidly than the average power upon loss of water height above the fuel. 


\section{PRESSURIZED BOILING}

With one exception, pressurized operations (in the range from 70 to $300 \mathrm{psig}$ ) were performed with a core loading of 59 fuel assemblies (Fig. 15) or with the maximum amount of reactivity controlled by the control blades at room temperature. One test was conducted with a core loading of 69 assemblies at a pressure of $322 \mathrm{psig.} \mathrm{In} \mathrm{this} \mathrm{loading,} \mathrm{the} \mathrm{boron}$ rods were removed from the central assemblies, and boric acid at room temperature was added to assist in compensating for the excess reactivity. The methods of operation were essentially the same as for BORAX-III.

In most cases, the powers were computed from a heat balance between reactor heat, steam flow, and feed-water flow, the main steam and feed water-flow rates being equal during steady-state operation.

\section{A. Reactivity in Steam Voids}

The reactivity in steam voids is defined as that reactivity corresponding to the period that would be generated if all the steam voids disappeared. [This is equivalent to using the results of the calibration (4 shims as a bank), obtained at operating pressure but zero voids, of the control blades. The two control blade positions, i.e., at zero power and at power, are then used with this calibration.]

Figure 50 shows the dependence of reactivity in the voids on the power level and pressure. It is obvious that appreciably higher stable powers and power densities can be attained at elevated pressures. Thus for a given power density the stabilizing influence of pressure in BORAXIV is stronger than the loss of stability expected from larger negative void coefficients at high pressures (see Appendix B).

\section{B. Self-Induced Oscillations}

The self-induced oscillations were of the same type observed during the tests at atmospheric pressure. The operating characteristics of BORAX-IV and the previous BORAX systems affirm that lower pressures and higher powers are more conducive to self-induced oscillations. Figure 51 shows the onset of oscillations as the power is increased with constant pressure at 100 psig. By the definition used here, the oscillatory threshold is about $6 \mathrm{Mw}$ at $100 \mathrm{psig}$. The resonant frequencies increased with power (Fig. 52), which is also in agreement with previous BORAX operations. The frequencies were somewhat higher than observed during the tests at atmospheric pressure.

Perhaps the first successful application of a period scram to the operation of boiling reactors was demonstrated by the termination of 


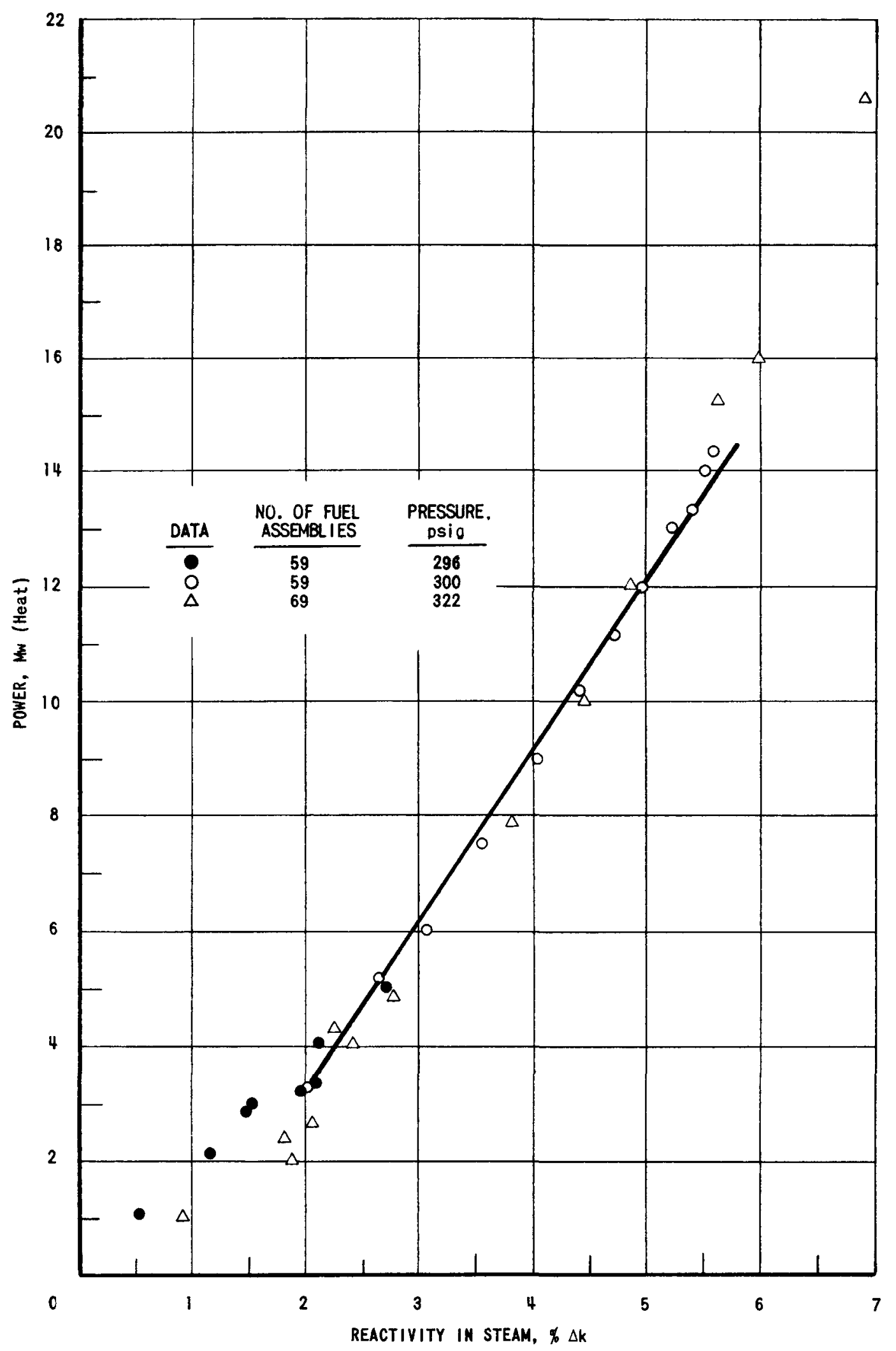

FIG. 50

REACTIVITY IN STEAM AS A FUNCTION OF POWER AND PRESSURE 


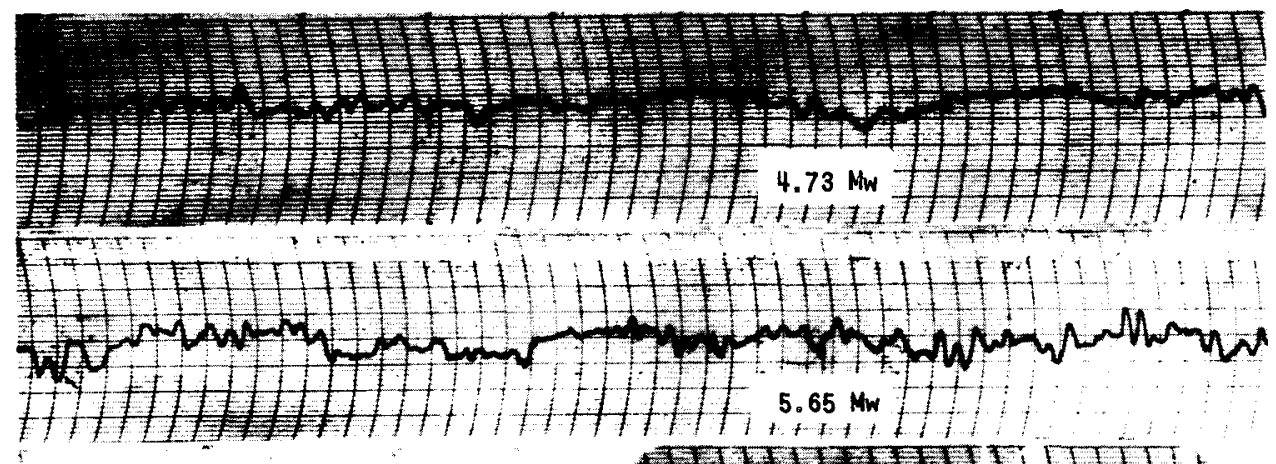

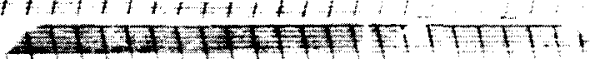

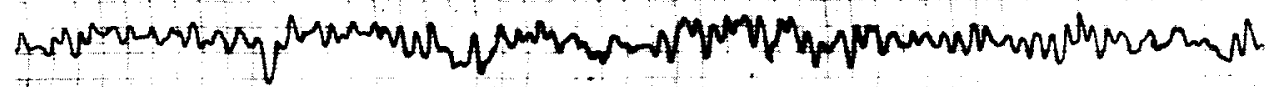
H+ $+11+6.48 \mathrm{Mw}$

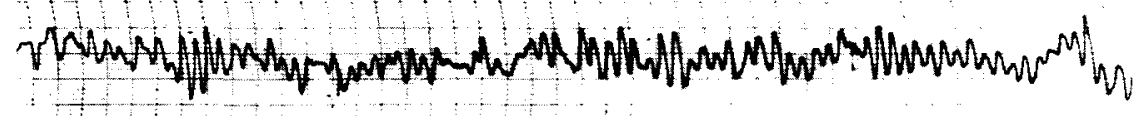

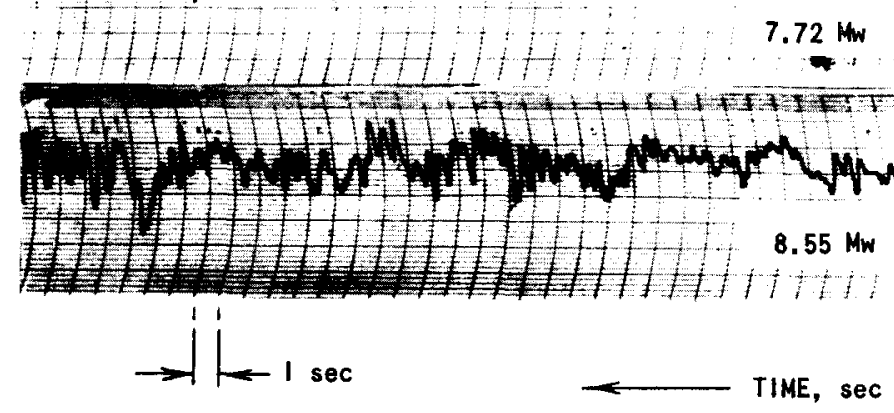

FIG. 5I

ONSET OF SELF-INDUCED OSCILLATIONS WITH INCREASED

POWER AND CONSTANT PRESSURE AT 100 DSIG

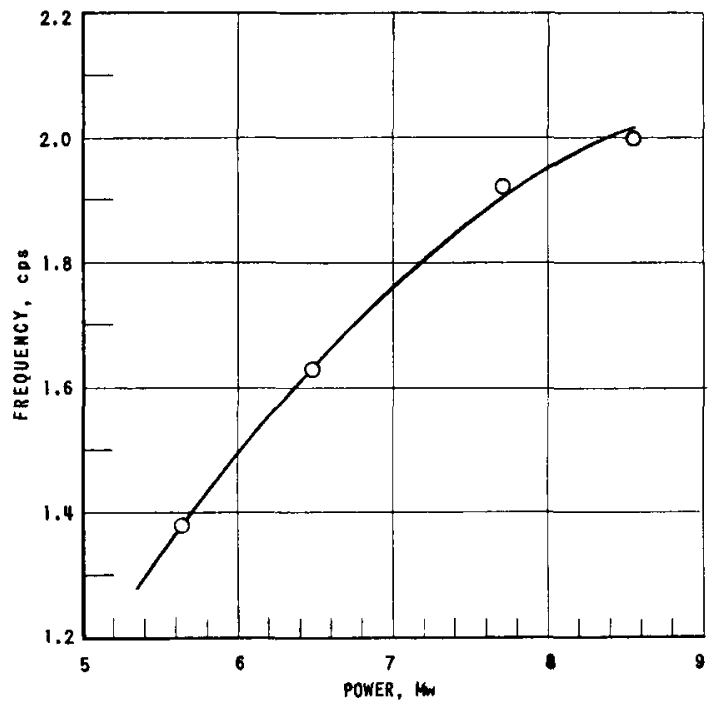


a test at $8.55 \mathrm{Mw}$ and 70 psig. As shown in Fig. 53 the ratio of power os cillations to random noise was relatively high during the course of the test. At the time of period scram the reactor was on a half-second period for about a quarter second, the condition required for scramming.

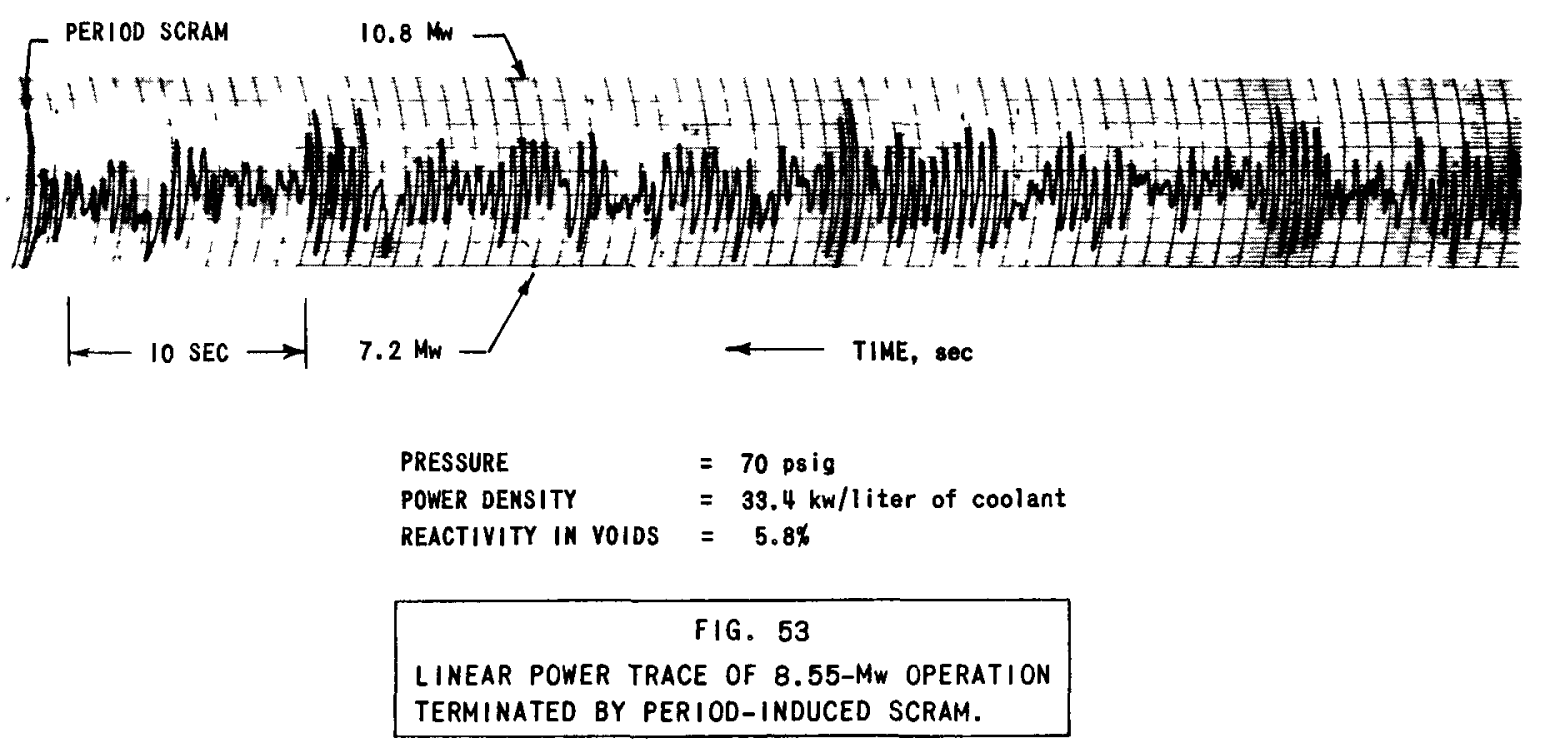

A significant observation made during this series of tests was that the rate of rise of the envelope of the amplitudes was not excessive. In a region of increasing amplitudes the variation in reactivity associated with the power oscillation can be related by the expression

$$
k_{0} e^{-\alpha t} \sin \omega t \text {, }
$$

where the damping constant, $\alpha$, is slightly negative and also time dependent. Theoretical considerations indicate that $\alpha$ should become strongly negative as the reactivity in void becomes more negative. Previous $B O R A X$ reactors with less reactivity in voids have shown substantially stronger negative values of $\alpha$. The inference is that the hydraulics and heat-transfer characteristics of BORAX-IV are less conducive to divergent oscillations for a given reactivity in voids.

\section{Production of $\mathrm{U}^{233}$}

Figure 54 shows the total loss in reactivity as a result of intermittent experimental operation for one year, equivalent to $300 \mathrm{MWD}$. The loss includes effects due to burnup of $\mathrm{U}^{235}$ and boron rods, as well as the production of $\mathrm{U}^{233}$, samarium, and miscellaneous fission products. Computations based on the theoretical initial conversion ratio for $\mathrm{U}^{233}$ : 


\section{$\frac{0.227 \text { atom } U^{233} \text { generated }}{\text { atoms } U^{235} \text { destroyed }}$}

show that $71 \mathrm{gm} \mathrm{U}^{233}$ were produced.

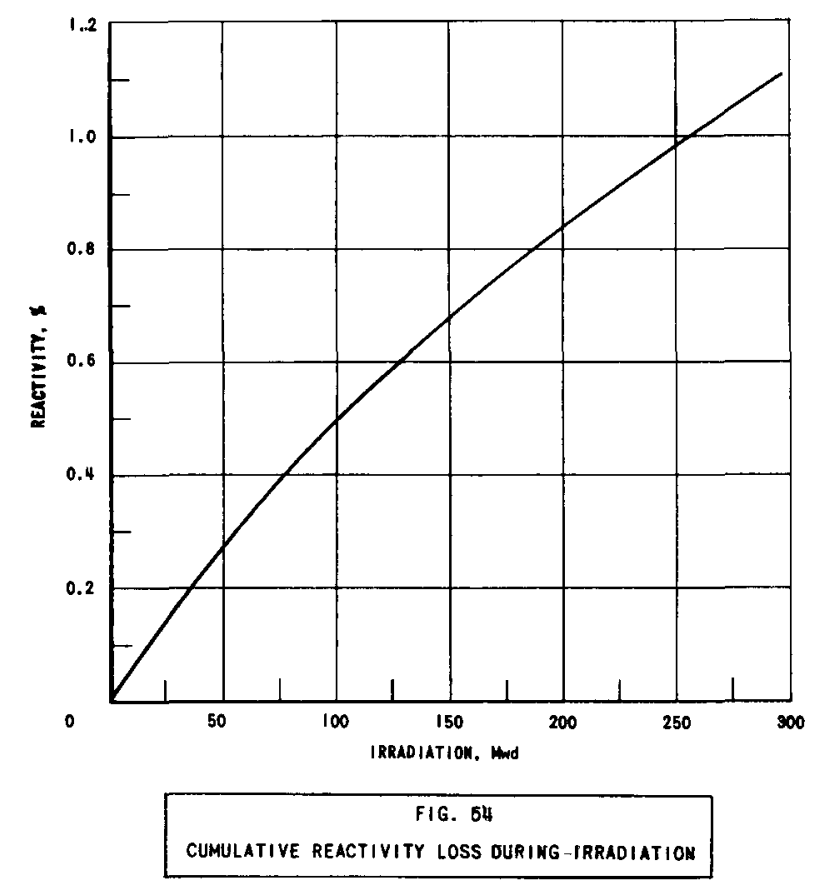

VII. TRANSFER FUNCTION MEASUREMENTS

\section{A. Rod Oscillator Experiments}

The reactor transfer function, $G(\omega)=(n / N) / k_{i n}$, is defined experimentally as the ratio of oscillatory power amplitude to average power, $n / N$, caused by a driving oscillatory reactivity amplitude, $k_{i n}$, having a frequency $\omega / 2 \pi$. All quantities are complex, i.e., having both a magnitude and a phase. An equivalent, although more elegant and fundamental, definition is that $G(\omega)$ is the Fourier Transform of the kernel, $B(\sigma)$, in the convolution

$$
\frac{\mathrm{n}}{\mathrm{N}}(t)=\int B(\sigma) \mathrm{k}_{\mathrm{in}}(\mathrm{t}-\sigma) \mathrm{d} \sigma
$$

Figure 12 shows a typical loading used for the rod oscillator experiments at atmospheric pressure. The oscillator rod assembly consisted of a water-filled cadmium tube ( 12 in. long) with an aluminum tube extension. The extension tube was connected to a drive mechanism designed to generate a sinusoidal rod stroke (up to 9 in.) and thus to produce a sinusoidal variation in reactivity. Since the oscillator rod replaced a fuel assembly and consequently introduced a water hole in the core, it is 
probable that the nuclear and hydraulic characteristics of these loadings differed from those of the smaller cores. However, for a given power density, Fig. 40 shows the reactivity in voids is about the same for all cores during operations at atmospheric pressure. The magnitude and phase of $n / N$ were determined by the tedious method of reading the chart recording for many amplitudes and phases, and averaging the results. Figure 55 shows a typical recording. The disadvantage of this method is the loss of precision because of the poor signal-to-noise ratio at high powers. An improved analytical technique is to compute the cross correlation function between the control rod and the reactor power. This can be done either by analog or digital methods. Unfortunately, the necessary equipment was not readily available to process the BORAX-IV data.

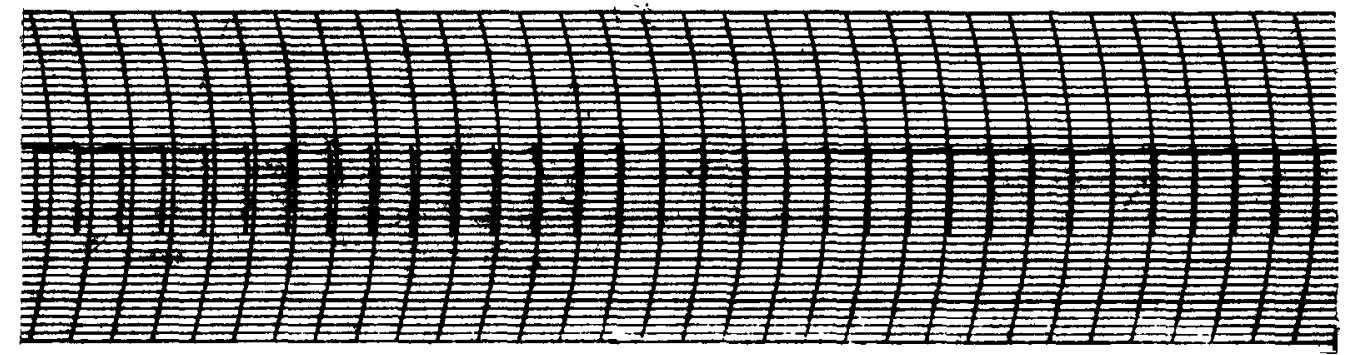

NOTE: PIPS OCCUR WHENEVER OSCILLATOR ROD OF $0.505 \% \triangle K$ AMPLITUDE IS AT THE TOP OR BOTTOM OF ITS STROKE.

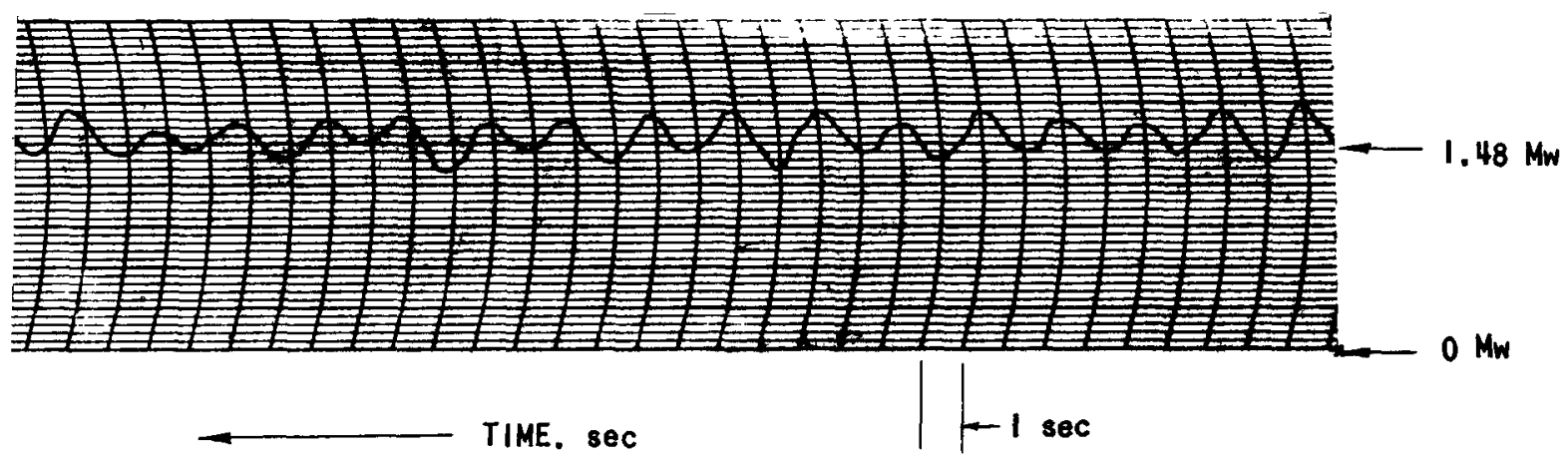

FIG. 55

TYPICAL OSCILLATOR ROD TEST WITH .25\% REACTIVITY IN STEAM AT ATMOSPHERIC PRESSURE.

The value of $\mathrm{k}_{\mathrm{in}}$ was determined from a period generated by moving the oscillator rod a fraction of a cycle from criticality at zero power.

The measured values of the amplitude and phase of the transfer function are plotted in Figs. 56 and 57. The discrepancies between 

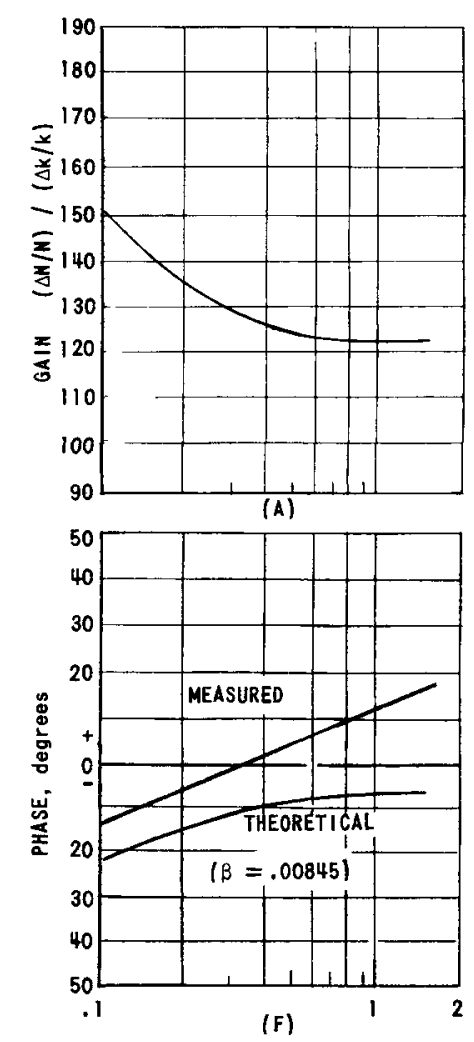

ASSEMBLIES:

POWER, Mw:

\% $\Delta k$ (voids):

x. $\triangle k$ AMPLITUDE OF ROD:

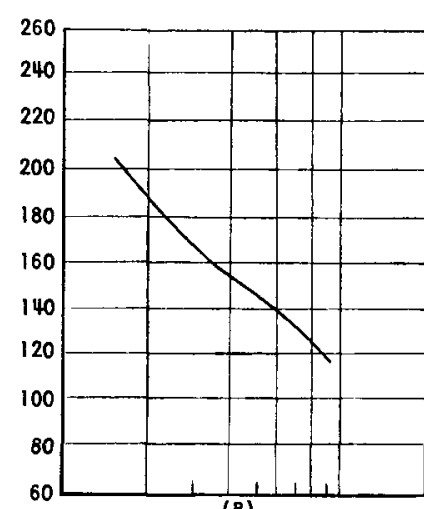

(B)

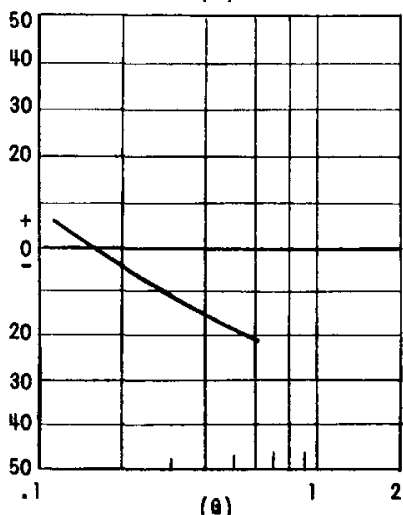

(0)

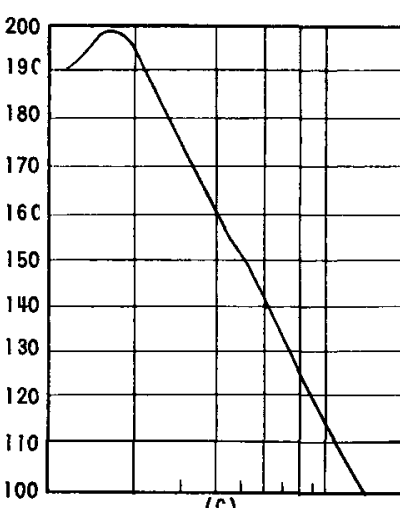

(c)

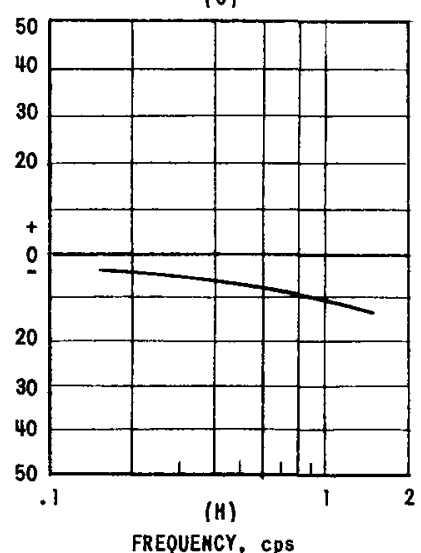

42
.81
.145
.0505

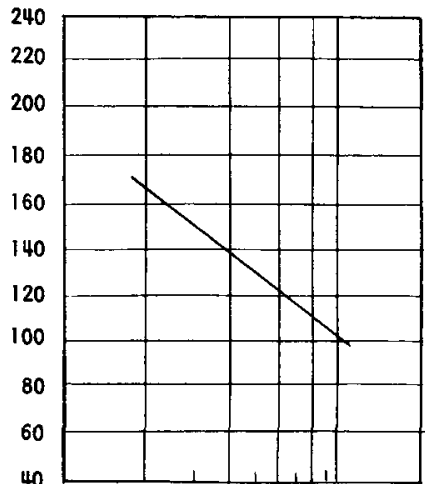

(D)

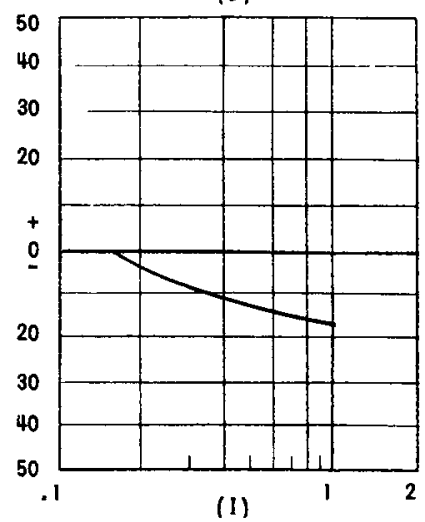

(1)

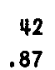

.87

.10
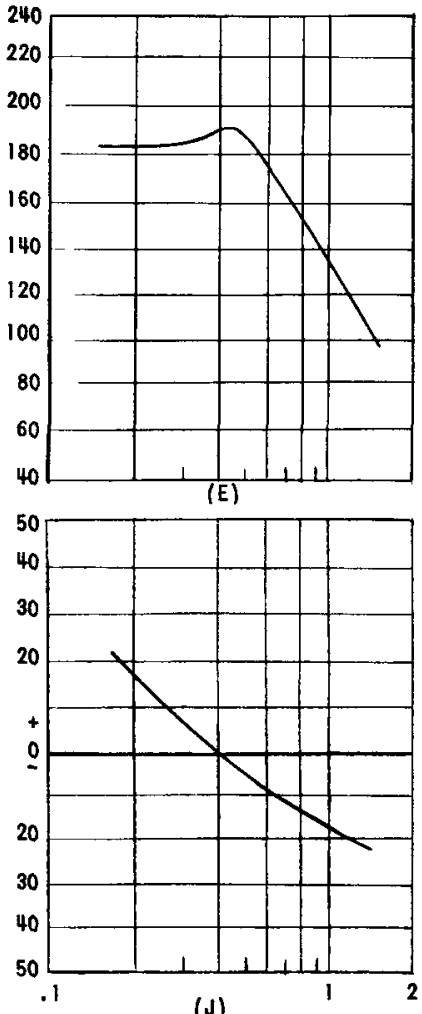

(J)

42
1.48

.0505 

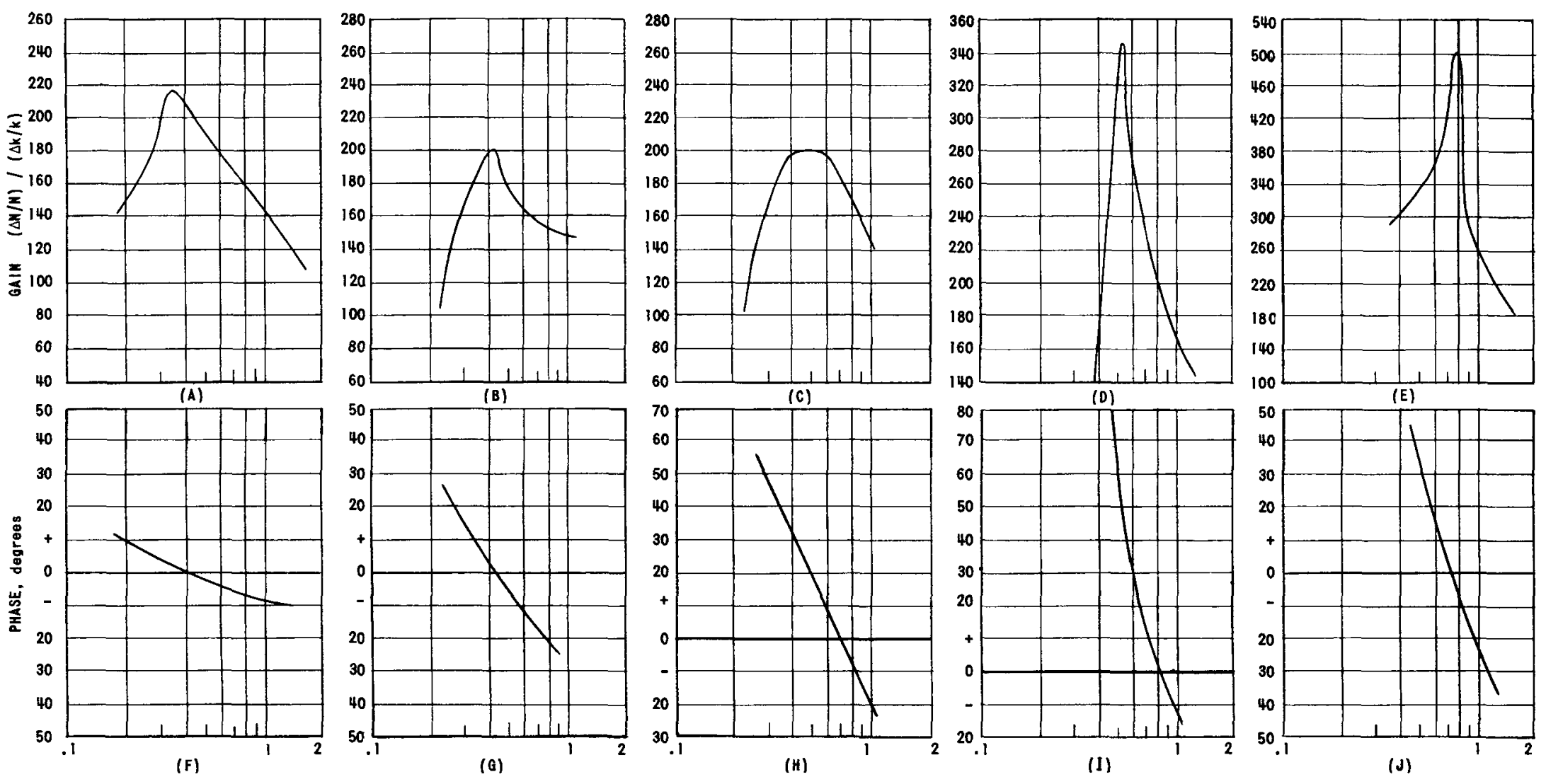

$\begin{array}{lc}\text { ASSEMBLIES: } & 42 \\ \text { POWER, } & 1.77 \\ \text { X } \triangle \mathrm{K} \text { (VOIOS): } & .32\end{array}$

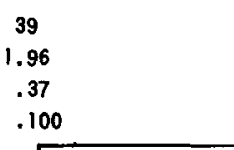

FREQUENCY, CDS

( )

12
.77
.32

\% $\triangle \mathrm{K}$ AMPLITUDE OF ROD: .0505

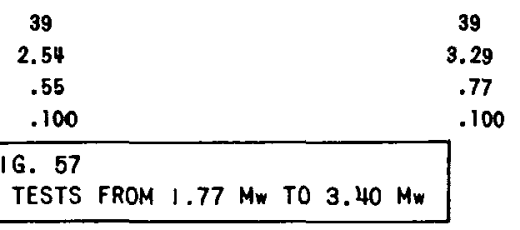

42
3.40

.725
.0505

SUMMARY OF ROD OSCILLATOR TESTS FROM $1.77 \mathrm{Mm}$ TO $3.40 \mathrm{Mm}$ 
the measured and calculated zero power transfer function (Fig. 56) may be due to chamber location or to phase shifts in the electronic system (see Appendix B).

The rod oscillator measurements, the first of their kind performed on boiling reactors, are considered to be a major step forward in the understanding of the self-oscillatory tendencies of boiling reactors. A sharp resonance in the transfer function was observed in the region of the self-oscillatory frequency. Figure 58(a) shows that the resonant gain increased with power. The half-width of the resonance decreased as the power increased. Finally, as shown in Fig. 58(b), the resonant frequency increased with power, the same effect observed for the self-induced oscillatory frequency.
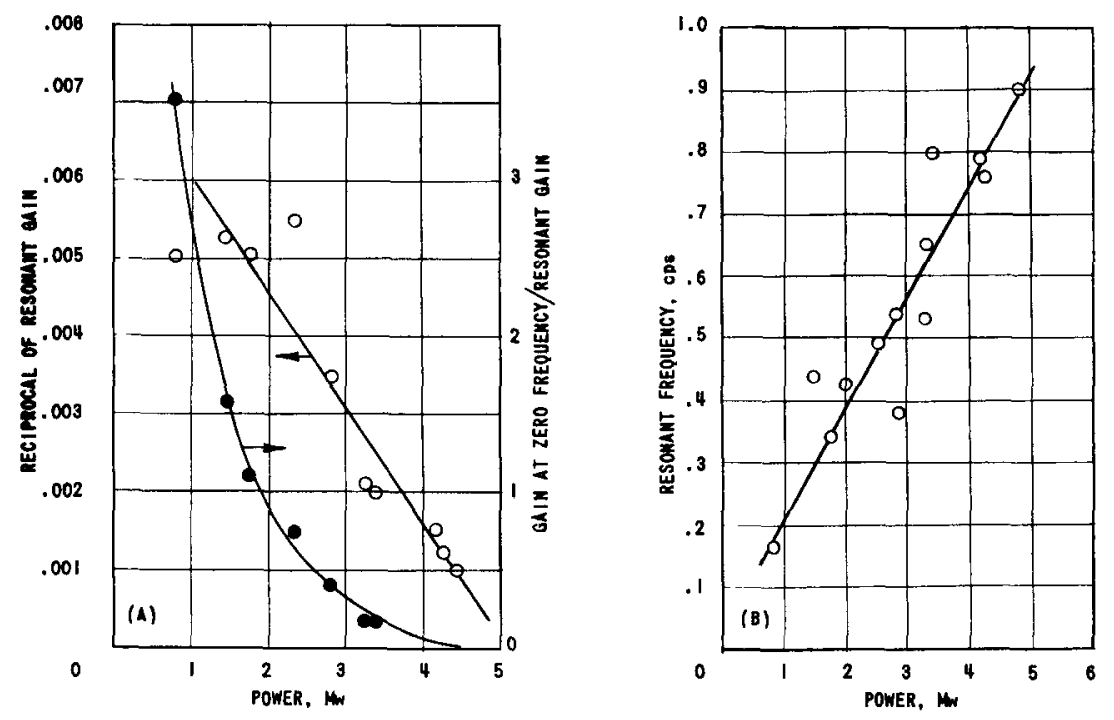

FIG. 58

BEHAVIOR OF GAIN AND FREQUENCY OF THE TRANSFER FUNCTION WITH POWER

Experience with the rod oscillator technique in BORAX-IV (and subsequently in EBWR) affirmed that the method may be used to obtain information on boiling reactor stability at low power levels without incurring the risk associated with large, self-induced chugs at the unstable point at high power levels. When a completely satisfactory theory of instability exists, the constants can be evaluated by low-power transfer function measurements, and the theory then applied to higher powers. If all that exists is a phenomenological theory, then it can at least be used to predict transfer functions at powers slightly above those measured.

Finally, Fig. 59 shows than an empirical relationship exists between the reciprocal of the resonant gain and the reciprocal of the os cillatory amplitude divided by the average power. Such a correlation can 

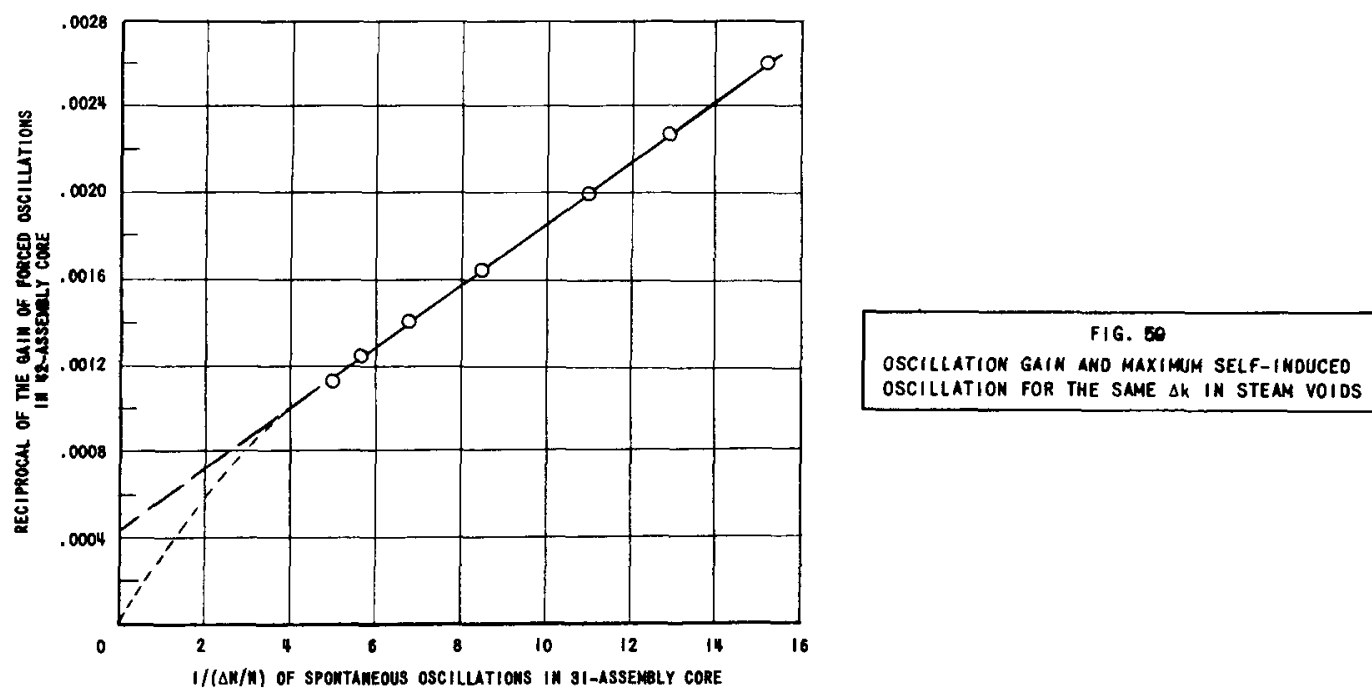

be used to estimate self-induced oscillatory amplitudes at higher powers, provided that the transfer function data at lower powers can be extrapolated satisfactorily by the theoretical method discussed in Appendix B.

\section{B. Ringing Tests}

In its general form, the ringing test consists of introducing a sudden step disturbance into a system and measuring the resultant response of the system. The term "ringing" is derived from the popularity of such tests on resonant acoustical systems in which an audible ring results from a step input. The ringing test has been proposed by Bethe(li) for fast reactors.

As applied to BORAX-IV, the ringing tests consisted of a series of ejections of the central blade at various initial powers, the procedure otherwise being similar to the conduct of excursions from essentially zero power. The results of this series of tests are typified in Fig. 60. It was found from many such tests under various conditions that the damping of the disturbance decreased as the power increased. This is to be expected since the peak in the transfer function "sharpened" as the power increased.

The transfer function from a ringing test is given by

$$
G(\omega)=\frac{1}{N(0) k_{0}}\left\{N(\infty)-N(0)+i \omega \int_{0}^{\infty}[N(t)-N(\infty)] e^{-i \omega t} d t\right\}
$$

where $\mathrm{N}(\mathrm{t})$ is the reactor power that is disturbed by the step input of reactivity, $k_{0}$, at $t=0$. Figures 61 and 62 show the amplitude and phase of 


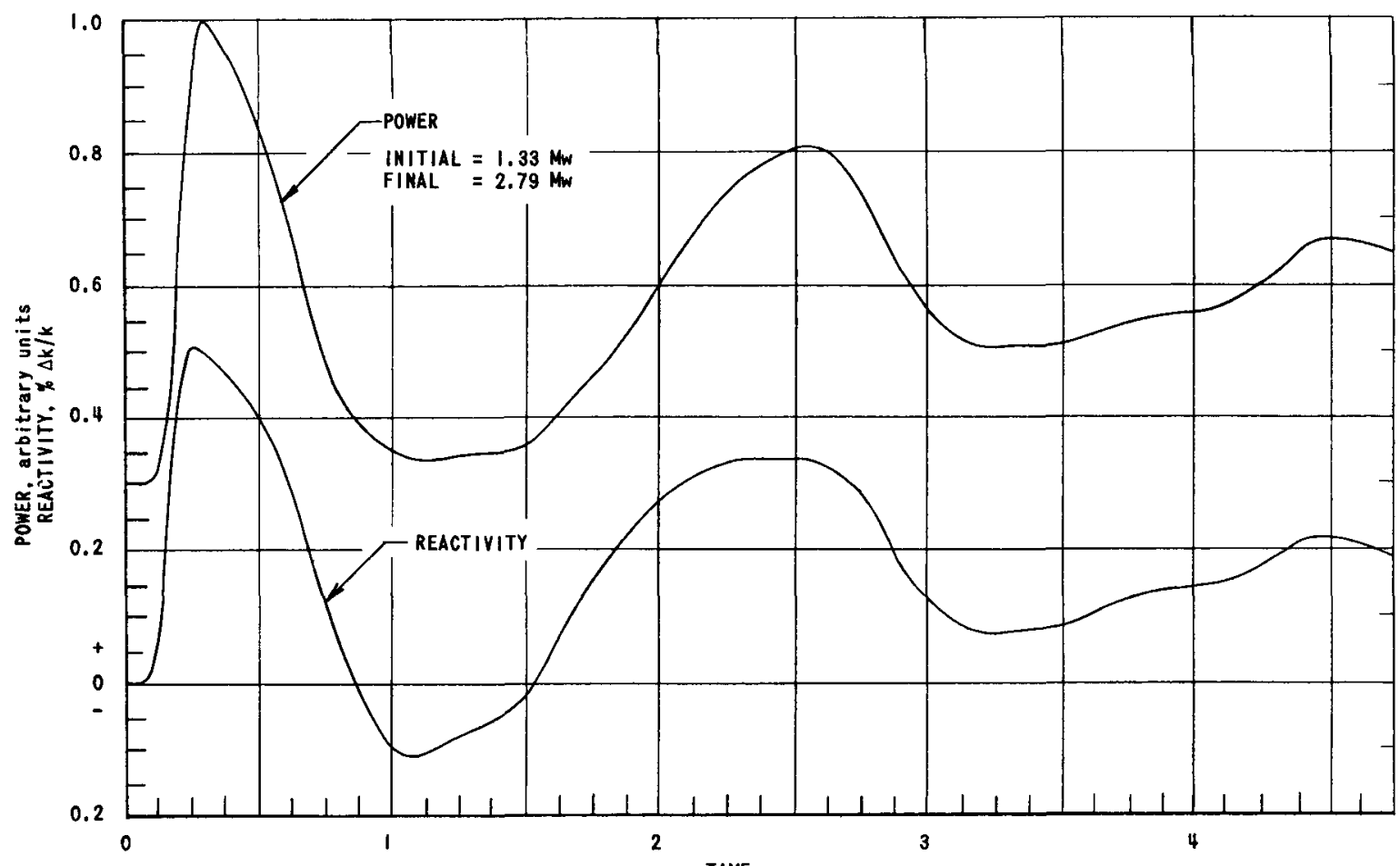

TIME, sec

FIG. 60

RINGING TEST ON 3I-ASSEMBLY CORE AT ATMOSPHERIC PRESSURE. STEP INPUT OF REACTIVITY = 0.45\%

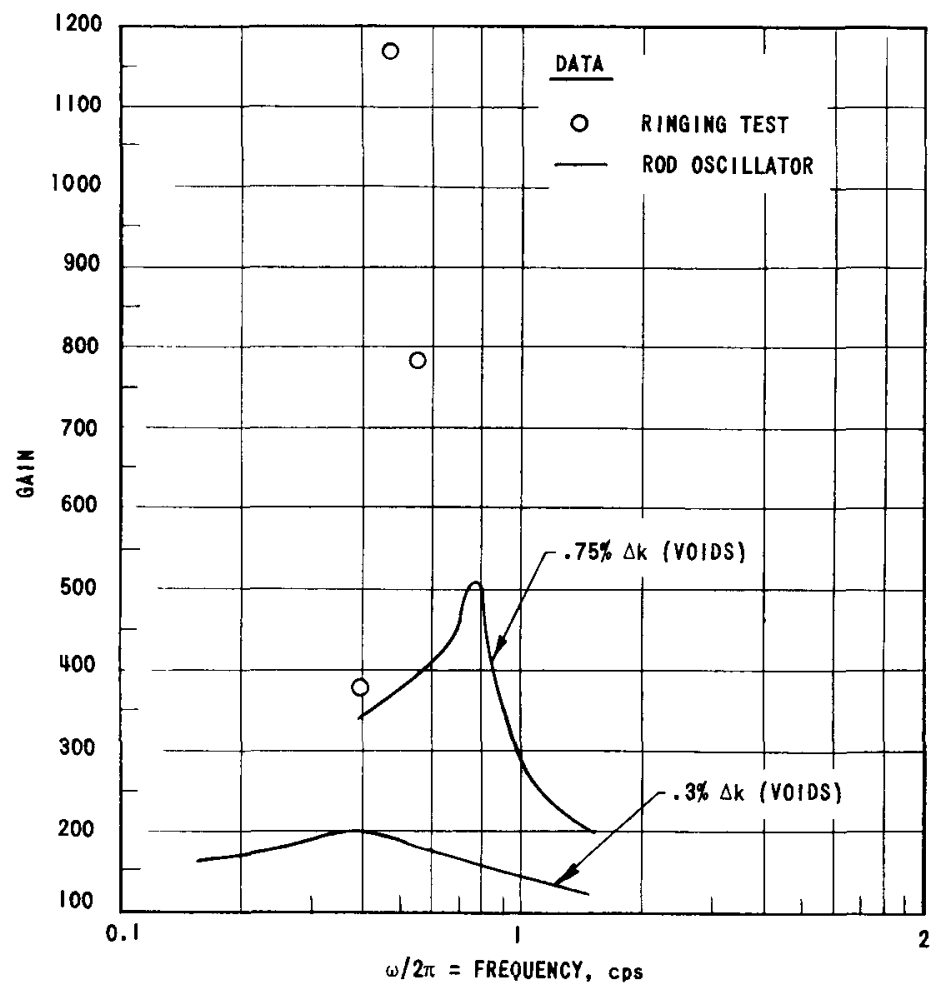

FIG. BI

AMPLI TUDE OF TRANSFER FUNCTION DETERMINED BY ROD OSCILLATOR AND BY RINGING TEST (FiO. BO). 


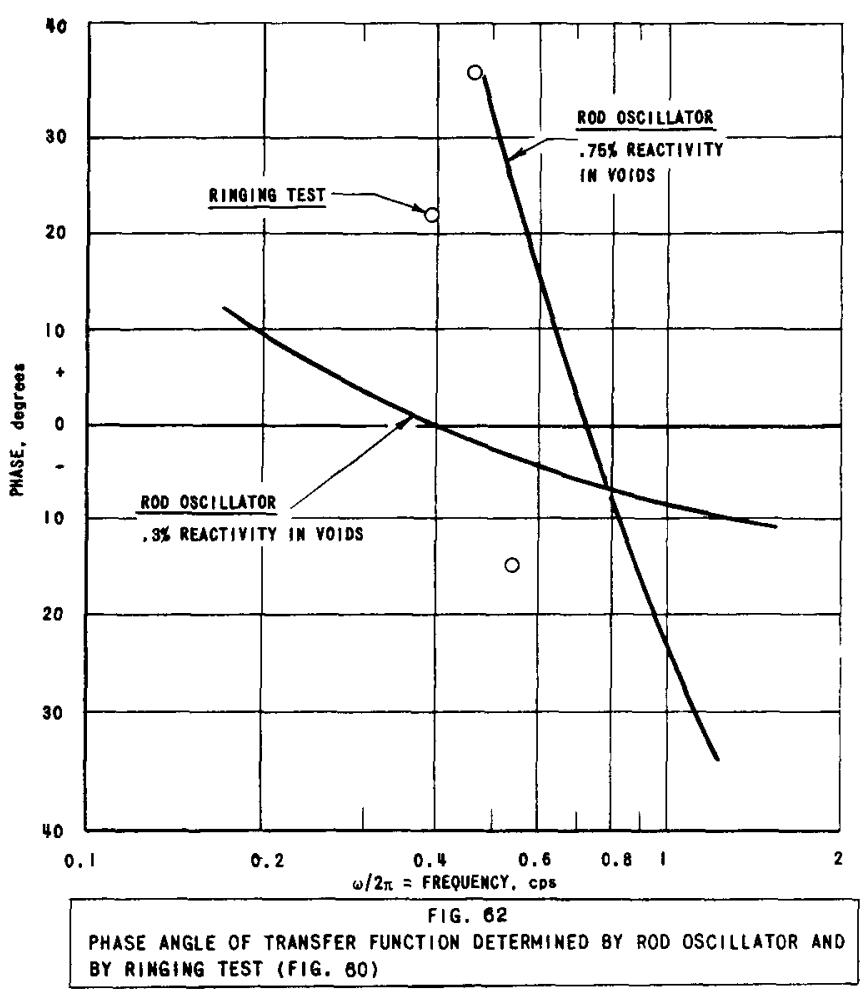

the transfer function determined by Eq. (1), using the results of Fig. 60 . Transfer functions determined by the rod oscillator technique are included for comparison.

The results obtained by the two methods did not agree for several reasons. The respective core volumes differed by about $30 \%$. The core for the rod oscillator test contained a large water hole. The step input of reactivity in the ringing test was somewhat large for strict application of Eq. (1). Further, because of the reactor noise, the results of a ringing experiment are somewhat statistically uncertain, unless many such experiments are averaged. Finally, the transfer function may be amplitude dependent.

Because of its simplicity and rapidity of execution, the ringing test affords approximate stability information via the reactor transfer function. The analysis need not be involved provided an approximate maximum value of the transfer functions is sufficient for immediate purposes. For example, if the power for $t>0$ is represented approximately by a fit of the form

$$
N(t) \cong N(0)+A \sin \left(\omega^{\prime} t+\phi\right) e^{-\alpha t},
$$

then at

$$
\omega=\omega^{\prime} \gg \lambda(\text { i.e., at a sharp resonance }),
$$


the maximum value for Eq. (1) is:

$$
G\left(\omega^{\prime}\right) \cong \frac{A \omega^{\prime}}{2 N(0) \alpha k_{0}}
$$

\section{Power-Frequency Spectrum}

Moore (12) has suggested that the use of autocorrelation methods to obtain the power-frequency spectrum may also yield information about the reactor transfer function. In this respect boiling reactors are ideal systems since the resonant characteristic of the transfer function can be expected to "shape" the boiling noise so that the power-frequency spectrum will also have a resonance.

The first step in obtaining the spectrum is to compute the autocorrelation function, $\phi(\tau)$, for various correlation times, $\tau$, from the power trace of an undisturbed steady-state boiling test:

$$
\phi(\tau)=\frac{\sum_{i} n\left(t_{i}\right) n\left(t_{i}+\tau\right)}{\sum_{i} n\left(t_{i}\right) n\left(t_{i}\right)},
$$

where $n\left(t_{i}\right)$ represent deviations of the power at times, $t_{i}$, from the average value of the power. Thus $\sum_{i} n\left(t_{i}\right)=0$.

The autocorrelation function of a typical power trace (Fig. 46) is shown in Fig. 63. Since standard automated techniques for obtaining this function were not available, only 200 points in a 20 -second interval were used. The statistical uncertainty of the curve determined from 200 points is less than would be occasioned by the use of only 49 points. Sufficient precision existed, however, to observe that the autocorrelation function was a strongly damped cosine function during the first second of correlation time.

By Wiener's theorem, the Fourier transform of $\phi(\tau)$ is the frequency spectrum of the power deviations, $n$ :

$$
W(f)=\int_{0}^{\infty} \phi(\tau) \cos 2 \pi f \tau d \tau
$$

As expected, Figs. 64 and 65 show that $W$ and $\sqrt{W}$ peak sharply in the region of the resonance frequency of the reactor. The quantity $\sqrt{W}$ may have special significance, as pointed out by Moore.(12) If the boiling noise before being "shaped" by the reactor transfer function is "white" (i.e., its frequency spectrum is a constant), then $\sqrt{W}$ is proportional to 

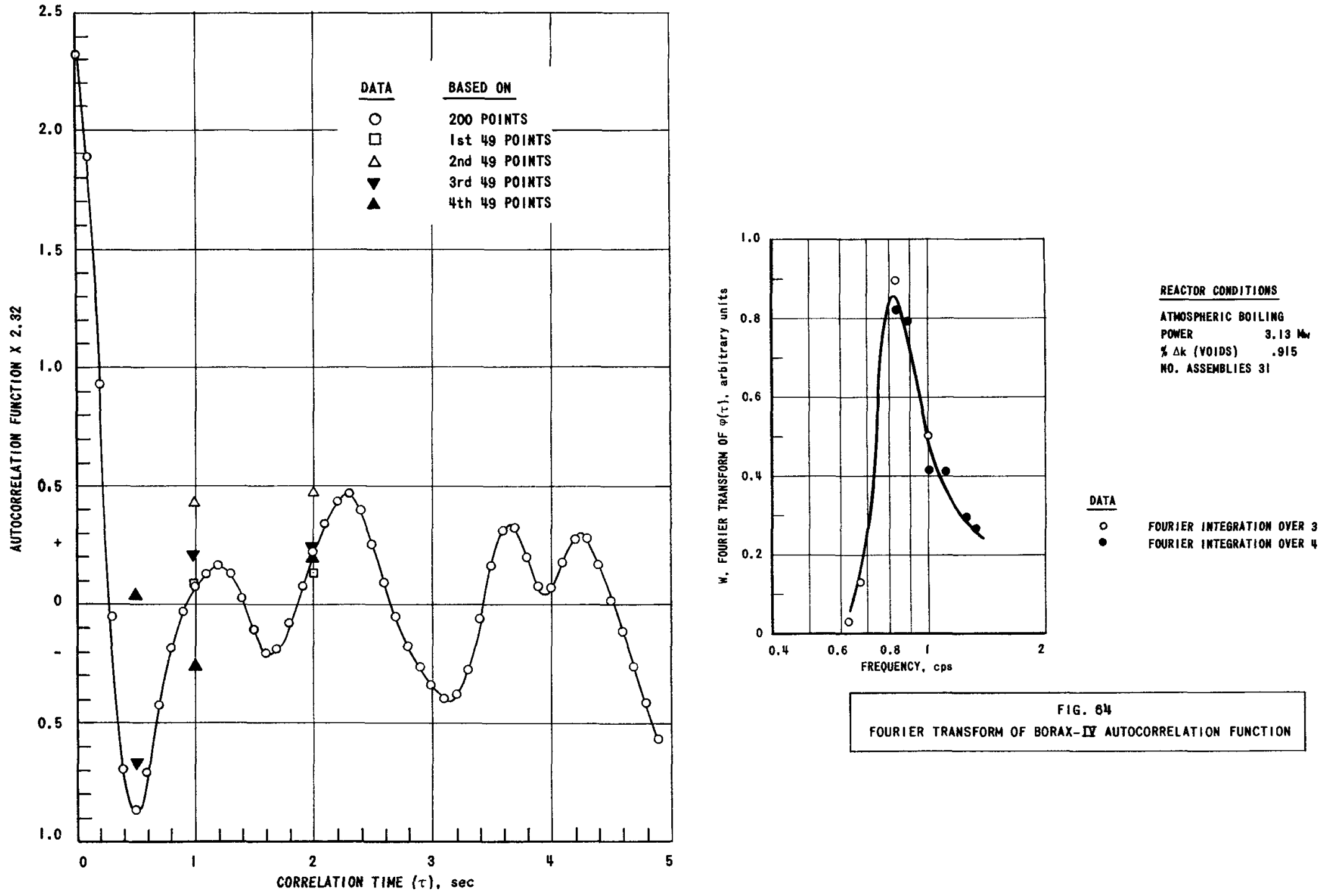

FIG. 63

AUTOCORRELATION FUNCTION FOR TYPICAL POWER TRACE AT $3.13 \mathrm{Mm}$ (FIG. 46) 


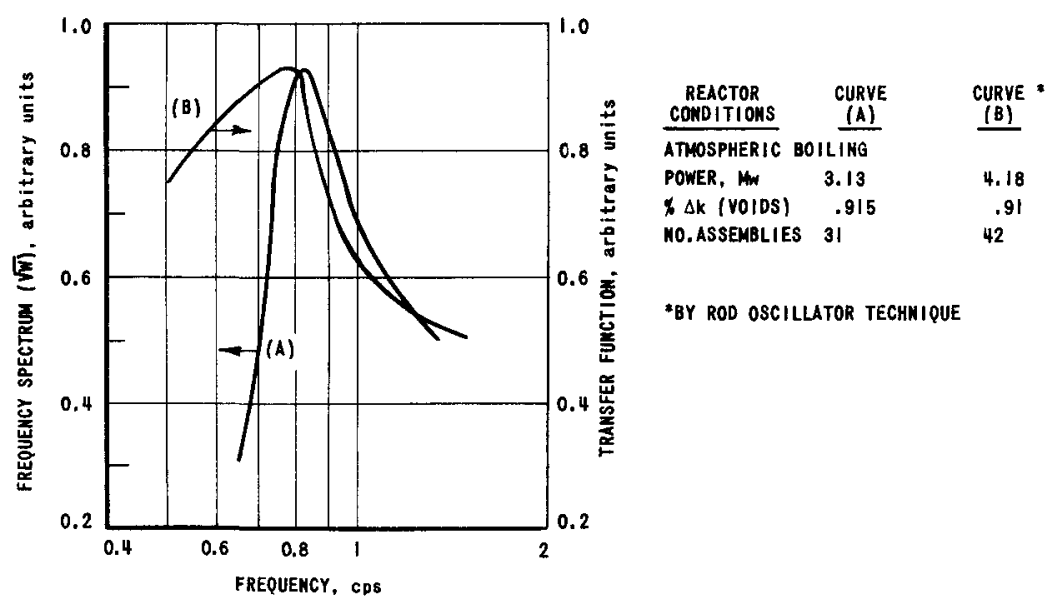

FIG. B5

BORAX-IY TRANSFER FUNCTION BY AUTOCORRELATION

the amplitude of the transfer function. For purposes of comparison, a renormalized rod oscillator transfer function is included in Fig. 65.

If not constant, the input boiling noise spectrum should vary slowly in the resonance region; thus the square root of the output frequency spectrum should be a good approximation of the reactor transfer function.

In summation, Fourier analysis of the reactor autocorrelation function can provide data on reactor transfer functions with a minimum of experimental work. Further, with appropriate automating procedures, the data analysis can be quite rapid and effortless. 
○ 


\section{APPENDIX A}

\section{REACTOR CORE PHYSICS}

Criticality Calculations

Physics calculations made prior to initial criticality had overestimated the reactivity of the core. Two-group theory predicted a cold, clean critical core of 15.5 fuel assemblies, whereas BORAX-IV first achieved criticality with a core loading of 28 assemblies. The disparity between theory and experiment may be attributed to (1) the calculations which ignored the effects on reactivity of control rods in the top reflector and the stainless steel tie-down rods in the core center, and (2) the critical reactor size which is quite sensitive to small reactivity errors.

The reactor characteristics reported here are based on postcriticality calculations revised to include the above effects. In addition, the slowing-down kernel of two-group theory has been replaced by the Fermi slowing-down kernel, and the two-group critical equation replaced by the age-diffusion critical equation.

\section{Core Description}

The active core section consists of four quadrants separated by rectangular channels in which four control blades operate. The core support plate can accommodate up to 88 assemblies in a symmetrical array. The dimensions and compositions of the fuel assemblies are given in Table II.

Core Volume Fractions

Due to the presence of the channels, followers and guides for the control blades, the volume fractions of the various core constituents are a function of the core size. Table III lists the volume fractions calculated for cores consisting of 28 and 59 fuel as semblies.

Nuclear Parameters

The nuclear parameters for the various conditions studied are summarized in Table IV.

The thermal macroscopic cross sections $\left(\Sigma_{\mathrm{ac}}\right)$ are based on Maxwellian-averaged thermal microscopic cross sections reported in BNL-325 at effective neutron energies of $0.03232 \mathrm{ev}, 0.04092 \mathrm{ev}$, and $0.0539 \mathrm{ev}$, corresponding to moderator temperatures of $68^{\circ} \mathrm{F}, 207^{\circ} \mathrm{F}$, and $421^{\circ} \mathrm{F}$. 
Table II

COMPOSITION AND DIMENSIONS OF

BORAX IV FUEL ASSEMBLIES

Fuel Tube Plate

\section{Material}

Fuel Channels per plate

Width (before forming)

End plate

Other Plates

Thickness of webs between channels

Plate edges

Thickness

Width

End plates

Other plates

O.D. of fuel channels

I.D. of fuel channels

Internal ribs in channel

Number per channel

Radius
Al - 1 wt-\% Ni
8
4.688 in.
4.781 in.
0.0875 in.
0.043 in.
0.660 in.
0.508 in.
0.2975 in.
0.256 in.
6
0.005 in.

Side Plates

Material

Width

Thickness

Over-all length

Fuel Pellets

Composition

O.D. of pellets

Length

Pellet density

Grams $\mathrm{U}^{235}$ per gram $\mathrm{ThO}_{2}$

Fuel Assembly

No. tube plates

Width

Thickness

Active fuel length

No. fuel tubes filled (in 6 plates)

Grams $\mathrm{UO}_{2}$ and $\mathrm{ThO}_{2}$ (average)

Grams $\mathrm{U}^{235}$ (average)

Lead bond thickness
$\mathrm{A} 1-1 \mathrm{wt}-\% \mathrm{Ni}$

3.828 in.

$0.051 \mathrm{in.}$

$31.80 \mathrm{in.}$

$\mathrm{UO}_{2}+\mathrm{ThO}_{2}$

0.230 in.

0.375 to 0.75 in.

$9.1 \mathrm{gm} / \mathrm{cc}$

0.0556

Unit Cell

Width

6

$3.828 \mathrm{in.}$

3.875 in.

$24{ }_{-0}^{+0.75} \mathrm{in}$.

47

5425

283

0.013 in.

Thickness

4.000 in.

$3.888 \mathrm{in}$. 
Table III

\begin{tabular}{|c|c|c|c|}
\hline \multirow[b]{2}{*}{ Region } & \multirow[b]{2}{*}{ Material } & \multicolumn{2}{|c|}{ No. of Assemblies } \\
\hline & & 28 & 59 \\
\hline Control Blade Channels & $\begin{array}{l}\mathrm{Al}-1 \text { wt }-\% \mathrm{~N} 1 \\
\mathrm{H}_{2} \mathrm{O}\end{array}$ & $\begin{array}{l}0.0665 \\
0.0227\end{array}$ & $\begin{array}{l}0.0433 \\
0.0150\end{array}$ \\
\hline Fuel Assembly & $\begin{array}{l}\mathrm{Al}-1 \mathrm{wt}-7 \% \mathrm{~N} 1 \\
\mathrm{UO}_{2}+\mathrm{ThO}_{2} \\
\mathrm{~Pb} \\
\mathrm{H}_{2} \mathrm{O}\end{array}$ & $\begin{array}{l}0.1273 \\
0.0872 \\
0.0536 \\
0.6414\end{array}$ & $\begin{array}{l}0.1317 \\
0.0902 \\
0.0554 \\
0.6636\end{array}$ \\
\hline Tie-Down Rods & SST & 0.0013 & 0.0006 \\
\hline Boron & SST -2 wt $-\%$ B & - & 0.0004 \\
\hline
\end{tabular}

Table IV

NUCLEAR CONSTANTS

$\begin{array}{lllccccc}\text { Temperature }\left({ }^{\circ} \mathrm{F}\right) & 68 & 207 & 207 & 421 & 421 & 421 & 421 \\ \text { Void in Coolant }(\%) & 0 & 0 & 10 & 0 & 0 & 10 & 10 \\ \text { Borated-SST Rods } & 0 & 0 & 0 & 0 & 16 & 0 & 16 \\ \eta^{\mathrm{U}^{235}} & 2.053 & 2.053 & 2.053 & 2.053 & 2.053 & 2.053 & 2.053 \\ \mathrm{f}^{\mathrm{U}^{235}}-\frac{\mathrm{U}^{235} \text { absorption }}{\text { Total absorption }} & 0.6792 & 0.6798 & 0.6905 & 0.7029 & 0.6830 & 0.7138 & 0.6934 \\ \mathrm{p} & 0.9738 & 0.9728 & 0.9699 & 0.9687 & 0.9687 & 0.9653 & 0.9653 \\ \epsilon & 1.0121 & 1.0120 & 1.0116 & 1.0115 & 1.0115 & 1.0112 & 1.0112 \\ \mathrm{k}_{\infty} & 1.3742 & 1.3739 & 1.3908 & 1.4140 & 1.3740 & 1.4303 & 1.3895 \\ \tau_{\mathrm{c}}\left(\mathrm{cm}^{2}\right) & 47.96 & 51.00 & 59.96 & 61.47 & 61.47 & 72.65 & 72.65 \\ \mathrm{~L}_{\mathrm{c}}^{2}\left(\mathrm{~cm}^{2}\right) & 3.500 & 5.181 & 5.793 & 6.282 & 6.104 & 7.005 & 6.805 \\ \Sigma_{\text {ac }}\left(\mathrm{cm}^{2}\right) & 0.07148 & 0.06249 & 0.06153 & 0.05594 & 0.05757 & 0.05545 & 0.05708 \\ R_{\text {eflector savings }}(\mathrm{cm}) & 7.11 & 7.79 & 8.38 & 8.79 & 8.79 & 9.53 & 9.53\end{array}$

The thermal disadvantage factors for the fuel and moderator were obtained from diffusion theory corrected by the ratio of $\mathrm{P}_{3}$ to diffusion theory results for similar cases studied previously. The effect of the borated steel rods was estimated by diffusion theory, assuming the rods to be black to the rmal neutrons. Perturbation theory was then employed to take into account the fact that the rods were limited to 16 center fuel assemblies in a 59-assembly core.

The effective resonance integral for the thoria-urania fuel was determined from the effective resonance integral reported(13) for thorium metal, corrected for the additional resonance scattering in thoria. For a thoria density of $9.1 \mathrm{gm} / \mathrm{cc}$, the effective resonance integral obtained is

$$
\int \sigma_{\text {eff }} \frac{\mathrm{dE}}{\mathrm{E}}=10.14\left\{1+\frac{0.1214}{R_{0}+0.0207}\right\}
$$


where $R_{0}$ is the rod radius in centimeters. The slowing down cross section $\left(\xi \Sigma_{s}\right)$ used for light water was $1.353 \mathrm{~cm}^{-1}$.

The core age was determined from the experimental results for various aluminum-to-water ratios corrected for the slowing down effect of the thoria-urania fuel and lead bonding.

Fast fission factors were estimated from the results for uranium$\mathrm{H}_{2} \mathrm{O}$ lattices and the thorium and uranium fast cross sections,

The reflector savings were determined from an empirical relation based on previous BORAX core calculations:

$$
\delta=0.0661 \tau+4.73-5.3 \times 10^{-6}(450-\mathrm{T})^{2},
$$

where $\mathrm{T}$ is the temperature $\left({ }^{\circ} \mathrm{F}\right)$ and $T$ is the core age $\left(\mathrm{cm}^{2}\right)$. The reflector savings of the top reflector poisoned by the control blades was taken as 0.55 in. (i.e., the distance between the top of the fuel and the blade tips in the full "out" position).

Table $\mathrm{V}$ lists the effective multiplication constant calculated for cores consisting of 28,30, and 59 fuel assemblies under a variety of conditions.

Table V

REACTIVITY CALCULATIONS

(Control Blades Out)

\begin{tabular}{|c|c|c|c|c|c|c|}
\hline $\begin{array}{c}\text { Temp., } \\
{ }^{\circ} \mathrm{F} \\
\end{array}$ & $\begin{array}{c}\text { Uniform } \\
\text { Voids } \\
\% \\
\end{array}$ & $\begin{array}{l}\text { Boron } \\
\text { Rods } \\
\end{array}$ & $\begin{array}{c}\text { Fuel } \\
\text { Assemblies } \\
\end{array}$ & $\begin{array}{c}\text { Geometric } \\
\text { Buckling } \\
\left(\mathrm{B}_{\mathrm{g}} \times 10^{4} \mathrm{~cm}^{-2}\right) \\
\end{array}$ & $\mathrm{k}_{\infty}$ & $k_{\text {eff }}$ \\
\hline \multirow[t]{2}{*}{68} & 0 & 0 & 28 & 61.87 & 1.3742 & 1.000 \\
\hline & 0 & 0 & 30 & 59.30 & 1.3742 & 1.013 \\
\hline \multirow[t]{2}{*}{207} & 0 & 0 & 28 & 59.82 & 1.3739 & 0.9828 \\
\hline & 0 & 0 & 30 & 57.43 & 1.3739 & 0.9954 \\
\hline \multirow[t]{2}{*}{207} & 10 & 0 & 28 & 58.10 & 1.3908 & 0.9502 \\
\hline & 0 & 0 & 30 & 55.81 & 1.3908 & 0.9642 \\
\hline \multirow[t]{2}{*}{421} & 0 & 0 & 59 & 40.16 & 1.4140 & 1.0775 \\
\hline & 0 & 16 & 59 & 40.16 & 1.3740 & 1.0477 \\
\hline \multirow[t]{2}{*}{421} & 10 & 0 & 59 & 39.02 & 1.4303 & 1.0486 \\
\hline & 0 & 16 & 59 & 39.02 & 1.3895 & 1.0194 \\
\hline
\end{tabular}

The effective neutron lifetime for the BORAX-IV core was $5.6 \times 10^{-5}$ sec. 
The theoretical temperature and void coefficients of reactivity for uniform effects in the core are given in Table VI.

Table VI

THEORETICAL TEMPERATURE AND VOID COEFFICIENTS OF REACTIVITY

No. Fuel

\begin{tabular}{|c|c|c|c|}
\hline Coefficient & Assemblies & Range & Value \\
\hline Temperature & 30 & $68-207^{\circ} \mathrm{F}$ & $-1.26 \times 10^{-4}(\Delta \mathrm{k} / \mathrm{k}) /{ }^{\circ} \mathrm{F}$ \\
\hline Void & 30 & $0-10 \%\left(207^{\circ} \mathrm{F}\right)$ & $-0.32 \%(\Delta \mathrm{k} / \mathrm{k}) / \%$ Void \\
\hline Void & 59 & $0-10 \%\left(421^{\circ} \mathrm{F}\right)$ & $-0.28 \%(\Delta \mathrm{k} / \mathrm{k}) / \%$ Void \\
\hline
\end{tabular}

The Doppler coefficient of reactivity for a uniform fuel temperature range from 68 to $207^{\circ} \mathrm{F}$ was calculated to be $-3 \times 10^{-6}(\Delta \mathrm{k} / \mathrm{k}) /{ }^{\circ} \mathrm{F}$. This result was based on the temperature coefficient of the volume term in the resonance integral equation reported for thorium metal:

$$
\frac{\mathrm{l}}{\mathrm{A}} \frac{\delta \mathrm{A}}{\delta \mathrm{T}}=-2.8 \times 10^{-4} /{ }^{\circ} \mathrm{C} \text {. }
$$

Theory vs Experiment

The theoretical $k_{\text {eff }}$ of unity for the 28 -assembly core at room temperature (Table V) is in good agreement with the experimental value obtained with this core on an asymptotic period of $18 \mathrm{~min}$. The agreement, however, may be fortuitous. The average worth of an assembly added to the periphery of the core (average of 3 assemblies) was about $+0.64 \% \Delta \mathrm{k} / \mathrm{k}$ by experiment, as compared to $+0.65 \% \Delta \mathrm{k} / \mathrm{k}$ by theory. This tends to confirm the theoretical value of $\mathrm{M}^{2}$. The averaged measured temperature coefficient of reactivity for the temperature range from 68 to $207^{\circ} \mathrm{F}$ (see Fig. 21 ) was $-2.47 \times 10^{-5}\left(\Delta \mathrm{k} / \mathrm{k}\right.$ ) $/{ }^{\circ} \mathrm{F}$; theory (Table VI) gave a value of $-1.26 \times 10^{-4}(\Delta \mathrm{k} / \mathrm{k}) /{ }^{\circ} \mathrm{F}$.

The theoretical excess reactivity for a 59-assembly core (containing 16 boron-steel rods) at $300 \mathrm{psig}\left(420^{\circ} \mathrm{F}\right)$ was $+4.55 \% \Delta \mathrm{k} / \mathrm{k}$. The experimental value, determined from shim blades calibration and critical position, was $+5.6 \% \Delta \mathrm{k} / \mathrm{k}$. The temperature coefficient of reactivity at $420^{\circ} \mathrm{F}$ was about $-1.35 \times 10^{-4}(\Delta \mathrm{k} / \mathrm{k}) /{ }^{\circ} \mathrm{F}$ by experiment (see Fig. 21), compared to about $-2.5 \times 10^{-4}(\Delta \mathrm{k} / \mathrm{k}) /{ }^{\circ} \mathrm{F}$ predicted by theory. 
-

t

* 


\section{APPENDIX B}

\section{TRANSFER FUNCTION ANALYSIS}

In order to obtain a better understanding of the response of a reactor to an oscillator, as well as of the tendency to oscillate, it is desirable to attempt the separation of the measured transfer function into simpler components. The model assumed here (Fig. 66) is that of a single (powerdependent) feedback loop, whose characteristics are then determined from the data. It is fairly general since the power-to-void transfer function can be the composite of many loops. Factoring the feedback loop does represent a slight loss of generality; however, the analysis below can also be pursued without this factorization. The differential equations representing the system are as follows:

$$
\begin{aligned}
& \frac{\mathrm{n}}{\mathrm{N}_{0}}=\mathrm{k}\left(\frac{1}{\mathrm{~N}} \frac{\mathrm{dN}}{\mathrm{dk}}\right)_{\mathrm{ZP}} ; \\
& \mathrm{k}=\mathrm{k}_{\mathrm{in}}+\mathrm{k}_{\mathrm{V}} ; \\
& \mathrm{k}_{\mathrm{v}}=\frac{\mathrm{n}}{\mathrm{N}_{0}}\left(\frac{\mathrm{dv} / \mathrm{V}_{0}}{\mathrm{dn} / \mathrm{N}_{0}}\right) \mathrm{V}_{0} \frac{\mathrm{dk}}{\mathrm{dv}}
\end{aligned}
$$

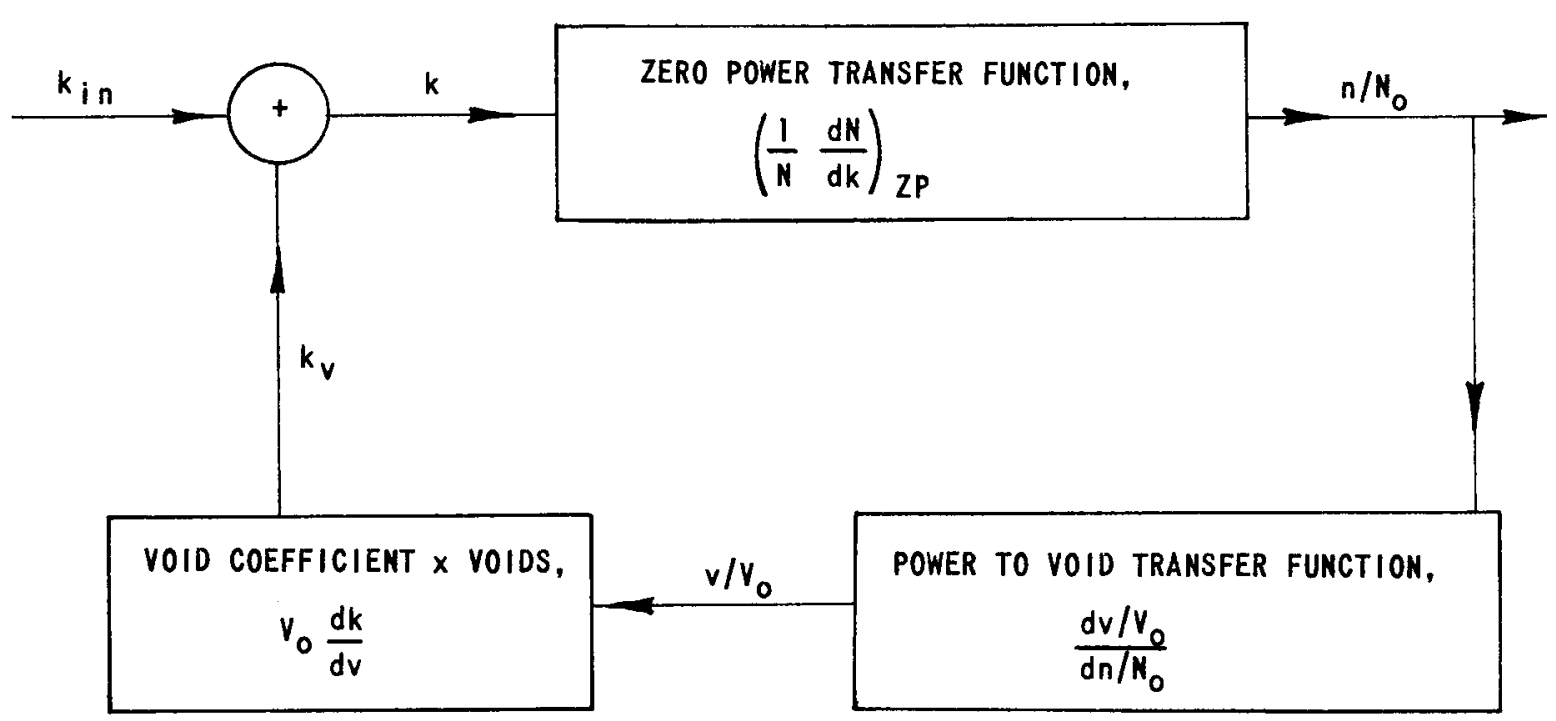

FIG. 66

SINGLE FEEDBACK REPRESENTATION OF A REACTOR 
Equation (1) is merely a simplified representation of the linearized reactor kinetics equation,

$$
\begin{aligned}
& \frac{\mathrm{dn}}{\mathrm{dt}}=\frac{\mathrm{N}_{0}}{\ell}(1-\beta) \mathrm{k}+\sum_{\mathrm{i}} \lambda_{\mathrm{i}} \mathrm{C}_{\mathrm{i}}-\frac{\beta \mathrm{n}}{\ell} \\
& \frac{\mathrm{dC}_{\mathrm{i}}}{\mathrm{dt}}=-\lambda_{\mathrm{i}} \mathrm{C}_{\mathrm{i}}+\frac{\beta_{\mathrm{i}} \mathrm{k}}{\ell} \mathrm{N}_{0}+\frac{\beta_{\mathrm{i} n}}{l} \\
& \mathrm{~N}=\mathrm{N}_{0}+\mathrm{n},
\end{aligned}
$$

where $\mathrm{n}$ and $\mathrm{C}_{\mathrm{i}}$ are small deviations of total neutrons and delayed neutrons, respectively, from their mean values. Similarly in Eq. (3), v is the deviation of the steam voids from its mean value, $V_{0}$.

The solution of Eqs. (1) to (3) for the transfer function of the entire system is, by elimination of $\mathrm{k}$ and $\mathrm{k}_{\mathrm{v}}$,

$$
\frac{n / N_{0}}{k_{\text {in }}}=\frac{\left(\frac{1}{N} \frac{d N}{d k}\right)_{Z P}}{I-\left(\frac{1}{N} \frac{d N}{d k}\right)_{Z P}\left(\frac{d v / V_{0}}{d n / N_{0}}\right) V_{0} \frac{d k}{d v}} .
$$

Also, the solution for the feedback transfer function is

$$
\frac{\mathrm{dv} / \mathrm{V}_{0}}{\mathrm{dn} / \mathrm{N}_{0}}\left(\mathrm{~V}_{0} \frac{\mathrm{dk}}{\mathrm{dv}}\right)=\left[\left(\frac{1}{\mathrm{~N}} \frac{\mathrm{dN}}{\mathrm{dk}}\right)_{\mathrm{ZP}}^{-1}-\left(\frac{\mathrm{n} / \mathrm{N}_{0}}{\mathrm{k}_{\mathrm{in}}}\right)^{-1}\right] .
$$

Equation (5) is useful for the evaluation of the unknown transfer function, $\left(\mathrm{dv} / \mathrm{v}_{0}\right) /\left(\mathrm{dn} / \mathrm{N}_{0}\right)$, from the measured $\left(\mathrm{n} / \mathrm{N}_{0}\right) / \mathrm{k}_{\mathrm{in}}$ and the theoretical or measured $\left(\frac{1}{N} \frac{d N}{d k}\right)_{Z P}$. It should be borne in mind that all quantities in these equations are complex and dependent upon frequency. This treat ment is seen to be analogous to that given to electronic amplifiers with frequency-dependent feedback.

Figure $56(\mathrm{~F})$ shows the zero-power transfer function computed for $\beta=0.00845$. All experimental points fall within $\pm 20 \%$ of this curve. Any discrepancy between theory and experiment must be ascribed to inherent experimental inaccuracies. The zero-power, non-feedback theory has been proven out by many experiments on other reactors. (14) The phase error between theory and experiment in Fig. 56 (F) was used to correct the measured phases of other transfer functions shown in Fig. $56(\mathrm{G}-\mathrm{J})$ and Fig. $57(\mathrm{~F}-\mathrm{J})$. 
To obtain the feedback transfer function from Eq. (5) the amplitude and phase of $\left(\mathrm{n} / \mathrm{N}_{0}\right) / \mathrm{k}_{\text {in }}$ were obtained from Figs. 56 and 57 . In addition to correcting the phases as described, the uncorrected measured amplitudes shown were renormalized upon substitution into Eq. (5). The renormalization factor, applied at all frequencies of a given run, was whatever factor was needed at high frequencies to make the measured transfer function using $\beta=0.00704$ from leakage-corrected Keepin data. (The experimental points indicated a $\beta$ of $0.00845 \pm 20 \%$.) Without this correction the feedback would not approach zero at high frequencies. The need for this correction probably arises from: a) the increased reactivity worth of the oscillating rod at high powers over its zero-power worth used in plotting the data; and $b$ ) whatever experimental inadequacy caused the phase error.

Figure 67 shows the amplitudes and the phases of the feedback transfer functions as a function of frequency. Relatively little precision may be attached to values of the amplitude because of sensitivity to experimental errors and of the corrections applied; values for phase are somewhat more reliable. The simplest function that one might assume to correlate the data is

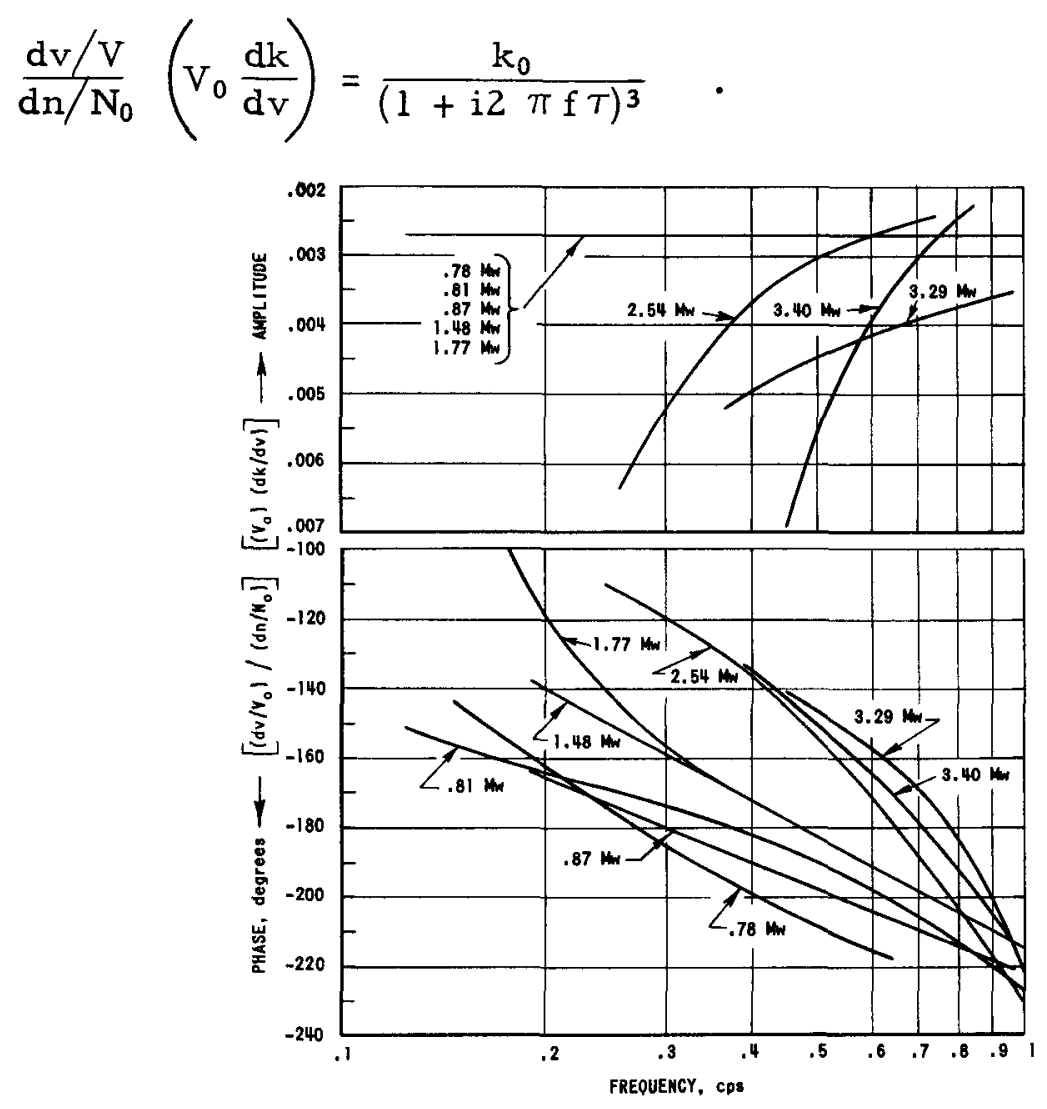

FIG. 67 
The value of $k_{0}$, which is rather imprecisely determined, is nevertheless about -0.02 at the lower powers, and about -0.03 at the highest power. On the other hand, $\tau$, the effective average of all the time constants of the system is somewhat better known (see Table VII).

Table VII

POWER DEPENDENCE OF THE FEEDBACK

\section{TIME CONSTANT}

$\begin{array}{ll}\text { Power, Mw } & \tau, \text { sec } \\ 0.78 \text { to } 0.87 & 0.93 \\ 1.48 \text { to } 1.77 & 0.60 \\ 2.54 & 0.44 \\ 3.29 \text { to } 3.40 & 0.40\end{array}$

The magnitude and trends found in both $\mathrm{k}_{0}$ and $\tau$ are in agreement with the theoretical expectations: $(15,16) \mathrm{k}_{0}$ is of the order of the reactivity in voids and is more negative at higher powers; $\tau$ is some average of fuel and steam transport time constants and is smaller at higher powers having higher flows. The commonly observed increasing resonant frequency (of transfer functions or spontaneous oscillations) with increasing power is thus attributed to the smaller time constants shifting the $180^{\circ}$ phase value of feedback to higher frequencies. 
APPENDIX C

\section{ANALYSIS OF INHERENT MECHANISMS OF REACTIVITY COMPENSATION DURING EXCURSIONS}

A number of saturation and subcooled excursions from low power levels (100 watts) at atmospheric pressure were analyzed in an attempt to ascertain the mechanisms that contribute to reactivity compensation in BORAX-IV. To facilitate theoretical interpretation, it was found advantageous to first compute two coefficients of reactivity afforded by the test data: the dynamic temperature coefficient, and the dynamic energy coefficient.

Dynamic Temperature Coefficient

The average rise of water temperature during a subcooled excursion was calculated from a heat balance based on the measured temperature rise in the fuel and aluminum clad, and the theoretical heat capacities of the fuel element. It was assumed that no water was expelled from the core during the excursion.

Figure 68 shows the excess reactivity compensated as a function of water temperature rise during subcooled excursions. From the initial slope of this curve, the dynamic temperature coefficient of reactivity was $-2.6 \times 10^{-4}(\Delta \mathrm{k} / \mathrm{k}) /{ }^{\circ} \mathrm{F}$, approximately ten times the average static temperature coefficient measured over the range from $68^{\circ} \mathrm{F}$ to $207^{\circ} \mathrm{F}$, and two times the theoretical static temperature coefficient. However, calculations of the sources of errors in the use of thermocouples for measurements of fuel temperatures showed that the indicated temperature rise may have been lower by a factor of 5 than the true temperature rise for the shorter periods. Use of the true temperature rise would lead to a stronger negative value for the dynamic temperature coefficient.

\section{Dynamic Energy Coefficient}

Oscillograph records that gave the neutron flux as a function of time were analyzed for the instantaneous excess reactivity and the corresponding total energy release at various times during the excursions. The results (Fig. 69) showed that, for a given initial uniform core temperature, the dynamic energy coefficient of reactivity was essentially independent of the initial period, and of the time after the power begins to deviate from an exponential.

\section{Theoretical Interpretation of Dynamic Energy Coefficient}

Estimates were made of the reactivity compensated by the effects of radiolytic production of gas, fuel heating, and water heating for 


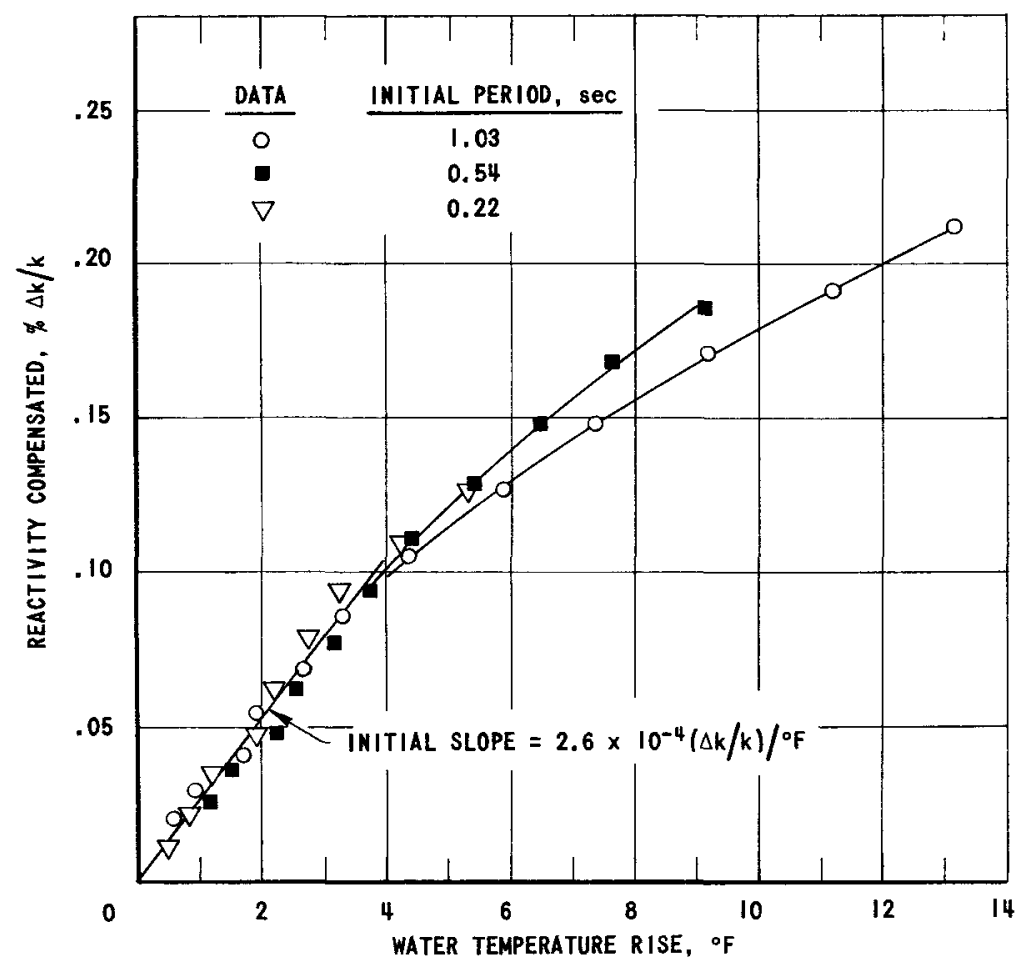

FIG. 68

REACTIVITY COMPENSATED AS A FUNCTION OF CALCULATED WATER TEMPERATURE RISE DURING SUBCOOLED EXCURSIONS $\left(120^{\circ} \mathrm{F}\right)$ AT ATMOSPHERIC PRESSURE.

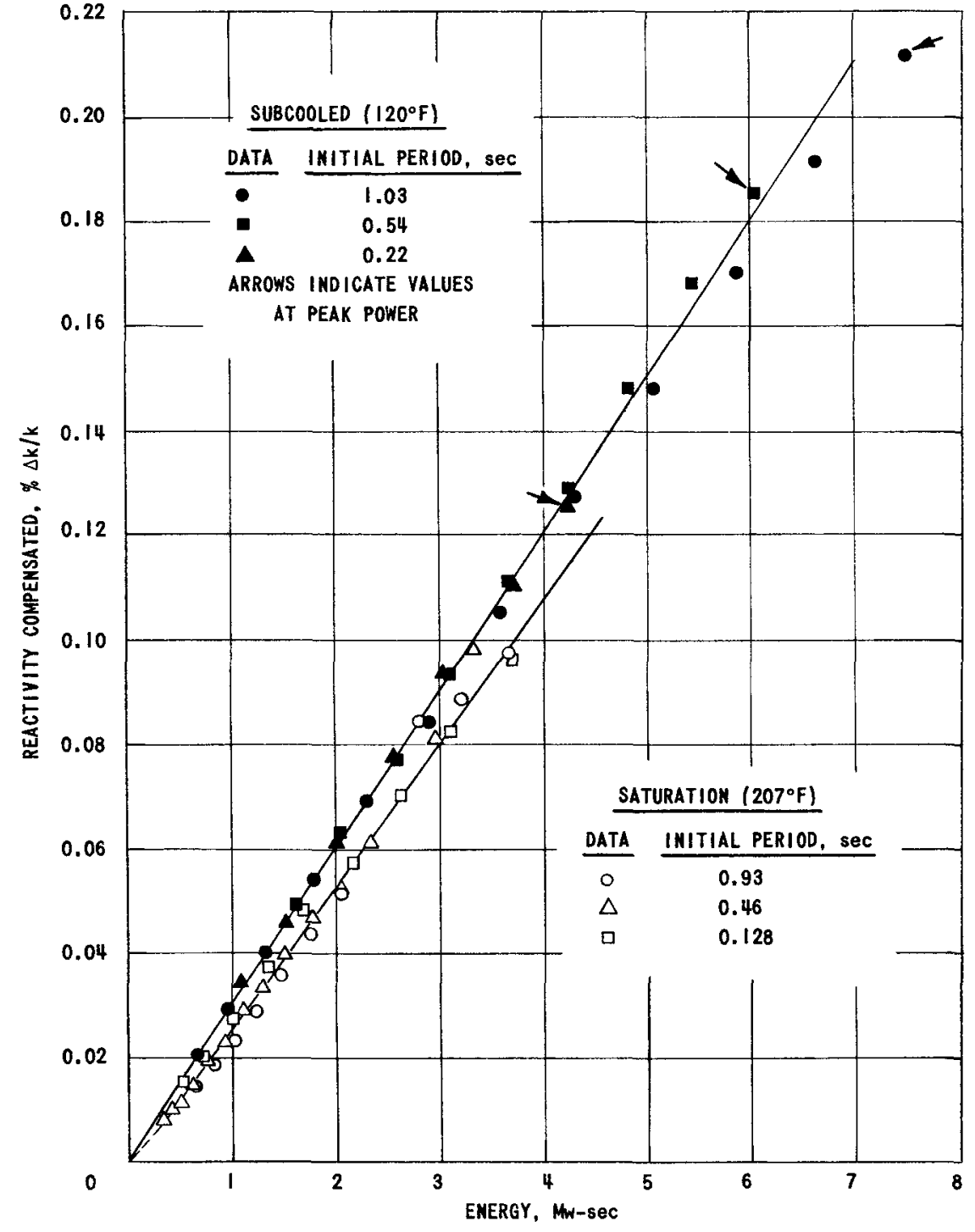

FIG. 69

REACTIVITY COMPENSATED AS A FUNCTION OF TOTAL ENERGY RELEASE DURING SATURATION AND SUBCOOLED EXCURSIONS AT ATMOSPHERIC PRESSURE 
comparison with the experimental dynamic coefficient of reactivity. In the absence of experimental data on radiolytic production of gases under transient conditions, it was assumed that:

(1) the formation of one hydrogen molecule required $100 \mathrm{ev}$ of energy;

(2) no recombination occurred under transient conditions;

(3) the formation of gas bubbles was instantaneous; and

(4) three per cent of the total energy release was available for the radiolytic production of gas.

In view of the inaccuracies associated with the method of temperature measurements, the reactivity effects due to fuel and water heating were calculated for possible maximum and minimum limits. Three methods of calculation were employed. In Method A for the maximum fuel temperature rise (i.e., the minimum water temperature rise), it was assumed that there was no transfer of energy from the fuel during the excursion. In Method B for the minimum fuel temperature rise (i.e., maximum water temperature rise), it was assumed that the temperature rises in the fuel, structural materials, and core moderator were equal. Finally, in Method $C$ the rise in water temperature was calculated by assuming that the indicated fuel center temperature was equal to the true average fuel pellet temperature.

The Doppler, temperature, and void coefficients used in these calculations (Table VIII) were, respectively $1.3,1.8$, and 1.08 times the values for uniform effects in the core to account for the nonuniform temperature rise and void formation under transient conditions.

Table VIII

COEFFICIENTS OF REACTIVITY USED IN CALCULATION FOR NON-UNIFORM EFFECTS

\begin{tabular}{|c|c|c|}
\hline Coefficient & $\begin{array}{l}\text { Source of } \\
\text { Data }\end{array}$ & Value \\
\hline Doppler & Theoretical & $-0.388 \times 10^{-5}(\Delta \mathrm{k} / \mathrm{k}) /{ }^{\circ} \mathrm{F}$ \\
\hline Temperature & $\begin{array}{l}\text { Measured } \\
\left(68-207^{\circ} \mathrm{F}\right)\end{array}$ & $-2.68 \times 10^{-5}(\Delta \mathrm{k} / \mathrm{k}) /{ }^{\circ} \mathrm{F}$ \\
\hline Void & $\begin{array}{l}\text { Inferred from } \\
\text { measured temp. } \\
\text { coefficient }\end{array}$ & $-0.0965 \%(\Delta \mathrm{k} / \mathrm{k}) / \%$ voids \\
\hline
\end{tabular}


The results of these calculations (Table IX) showed that the various mechanisms investigated accounted for 45 to $75 \%$ of the experimental reactivity compensation. The major uncertainties which may reflect errors in the values listed are:

(1) the void coefficient as deduced from the measured temperature coefficient may be too low; theory gives a void coefficient of $-0.32 \%(\Delta \mathrm{k} / \mathrm{k}) / \%$ voids at saturation temperature $\left(207^{\circ} \mathrm{F}\right)$;

(2) the theoretical Doppler coefficient of reactivity may lack precision;

(3) absence of experimental data on production of radiolytic gas under transient conditions; and

(4) lack of sufficient and accurate temperature indications for the various lattice components.

Table IX

EXPERIMENTAL AND CALCULATED DYNAMIC ENERGY COEFFICIENT OF REACTIVITY

$$
\text { (in } \% \Delta \mathrm{k} / \mathrm{Mw}-\mathrm{sec})
$$

\begin{tabular}{|c|c|c|c|c|}
\hline \multirow[b]{2}{*}{ Mechanism } & \multirow[b]{2}{*}{ Experimental } & \multicolumn{3}{|c|}{ Calculated } \\
\hline & & Method A & Method B & Method C \\
\hline & \multicolumn{4}{|c|}{ Subcooled Excursions $\left(120^{\circ} \mathrm{F}\right)$} \\
\hline Radiolytic Gas & - & 0.0059 & 0.0059 & 0.0059 \\
\hline Fuel Temperature & - & 0.0154 & 0.00087 & $0.0067 \pm 0.0007$ \\
\hline Water Temperature & - & - & 0.00668 & 0.0032 \\
\hline \multirow[t]{2}{*}{ Total } & $0.030 \pm 0.001$ & 0.0213 & 0.01345 & $0.0158 \pm 0.0007$ \\
\hline & \multicolumn{4}{|c|}{ Saturated Excursions $\left(207^{\circ} \mathrm{F}\right)$} \\
\hline $\begin{array}{l}\text { Radiolytic Gas } \\
\text { Fuel Temperature }\end{array}$ & - & $\begin{array}{l}0.0069 \\
0.0154\end{array}$ & \multicolumn{2}{|c|}{$\begin{array}{c}\text { (No fuel temperature } \\
\text { measurement) }\end{array}$} \\
\hline Total & $0.028 \pm 0.001$ & 0.0223 & & \\
\hline
\end{tabular}

Although the experimental reactivity compensation has not been entirely accounted for, it is evident that the mechanisms cited may all play an important role in the self-limiting characteristics of BORAX-IV transients. 


\section{APPENDIX D \\ CORE HYDRAULICS \\ J. Marchaterre}

The hydrodynamic performance of boiling reactors at steady-state conditions is readily calculated by the IBM-650 computer program identified as CHOP. The results for BORAX-IV are listed in Table X. The values at the higher pressures are more reliable than those at atmospheric pressure, where the slip ratio is uncertain.

Table X

BORAX-IV HYDRAULICS

Inlet

Avg. Power

Coolant

Avg. Avg.

per Assembly,

Velocity,

Core

Exit

$\mathrm{kw}$

Total Length

fps

Slip

Voids Voids

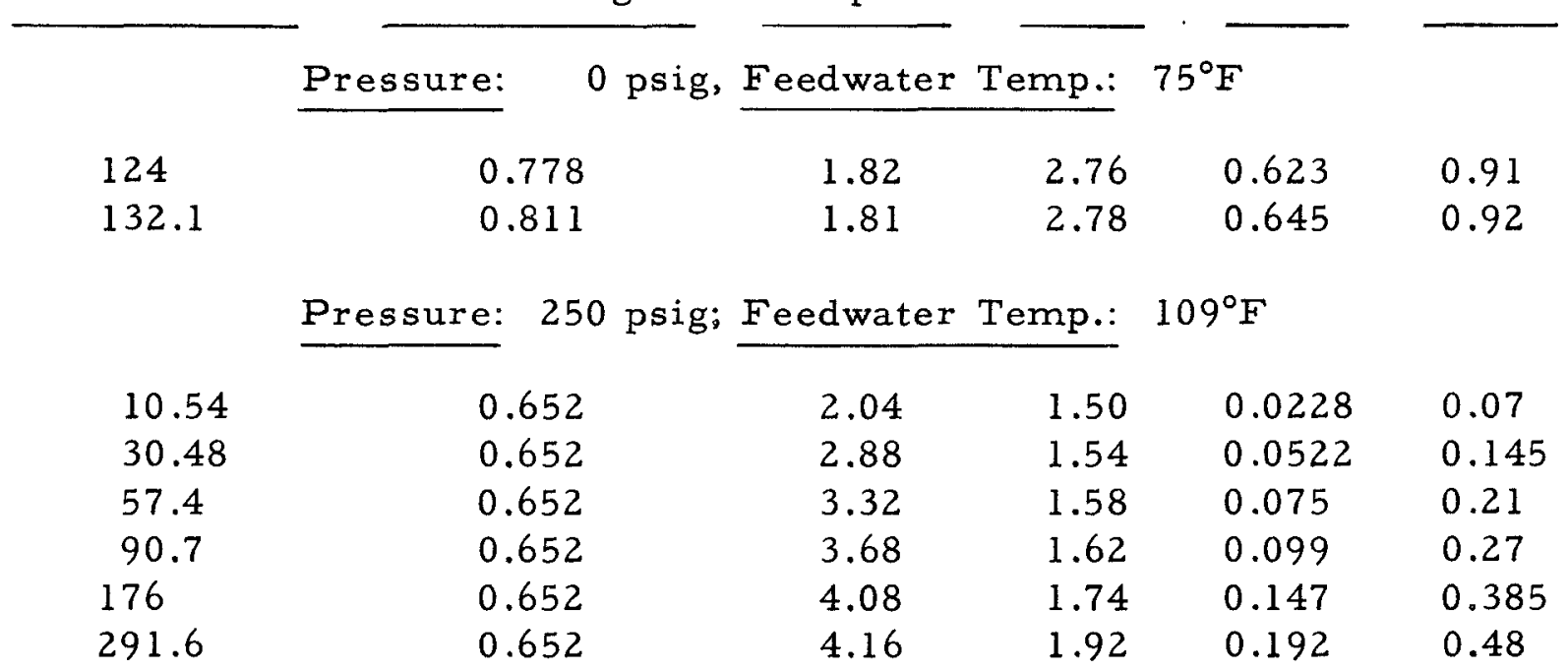

Pressure: 300 psig; Feedwater Temp.: $109^{\circ} \mathrm{F}$

$\begin{array}{rlllll}12.59 & 0.642 & 1.95 & 1.54 & 0.0225 & 0.07 \\ 36.04 & 0.642 & 2.82 & 1.58 & 0.0514 & 0.145 \\ 67.7 & 0.642 & 3.32 & 1.60 & 0.077 & 0.215 \\ 106.9 & 0.642 & 3.68 & 1.64 & 0.0995 & 0.280 \\ 207.8 & 0.642 & 4.02 & 1.74 & 0.145 & 0.385 \\ 342.8 & 0.642 & 4.12 & 1.90 & 0.194 & 0.49\end{array}$

Pressure: 300 psig; Feedwater Temp.: $75^{\circ} \mathrm{F}$

124

0.627

3.78

1.66

0.107

0.30 
•

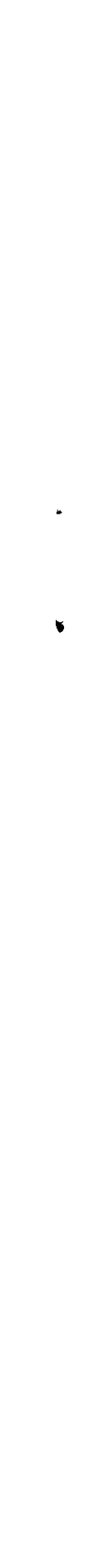

. 


\section{APPENDIX E}

\section{STEADY -STATE REACTIVITY IN VOIDS}

The steady-state reactivity in voids was approximated by simple multiplication of the void coefficients and the average voids computed in Appendices $A$ and $D$, respectively. For the utmost in rigor, a threedimensional integration of the spatially varying void coefficient and void distribution should be done.

As evidenced by Table XI the method of calculation provided information that was in excellent agreement with experimental data obtained at 300 psig, but differed considerably from values obtained at atmospheric pressure. Although the discrepancy may be attributed, in part, to the theoretical void coefficient $(\mathrm{dk} / \mathrm{d} \alpha)$, the major uncertainty lies in the hydraulic calculation, in particular, in the slip ratio.

Table XI

STEADY-STATE REACTIVITY IN VOIDS

\begin{tabular}{cccccccc} 
& & \multicolumn{4}{c}{ Calculated } & \\
$\begin{array}{c}\text { Pressure, } \\
\text { psig }\end{array}$ & $\begin{array}{c}\text { No. of } \\
\text { Assemblies }\end{array}$ & $\begin{array}{c}\text { Power, } \\
\text { Mw }\end{array}$ & $\begin{array}{c}\text { Void } \\
\text { Coeff. }\end{array}$ & $\begin{array}{c}\text { Avg. } \\
\text { Voids } / \mathrm{d} \alpha\end{array}$ & $\alpha$ & $\alpha \frac{\mathrm{dk}}{\mathrm{d} \alpha}$ & $\begin{array}{c}\text { Experimental } \\
\text { Reactivity in } \\
\text { Voids }\end{array}$ \\
& 31 & 3.85 & -0.32 & 0.623 & 0.199 & 0.0135 \\
300 & 59 & 6.3 & -0.28 & 0.0995 & 0.0279 & 0.030 \\
300 & 59 & 12.5 & -0.28 & 0.145 & 0.0406 & 0.0505
\end{tabular}


• 


\section{ACKNOWLEDGEMENTS}

The authors are indebted to J. R. Dietrich, C. N. Kelber, R. C. Howard, C. K. Soppet, S. A. Bernsen of the Reactor Engineering Division, and R. A. Noland, J. H. Handwerk of the Metallurgy Division for their active participation in the design of BORAX-IV; to N. Krisberg and $R$. Roberge of the Idaho Division who assisted in the operation of the reactor; and to J. E. Gustafson, L. Serer, J. M. Ramuta, and $\mathrm{J}$. A. Koerner who performed the computations in connection with the transfer function analysis.

\section{REFERENCES}

1. W. H. Zinn, et al, "Transient and Steady-State Characteristics of a Boiling Reactors," ANL-5211 (February, 1954).

2. A. J. Ulrich, "Results of Recent Analysis of BORAX-II Transient Experiments," ANL-5532 (April, 1956).

3. J. R. Dietrich, H. V. Lichtenberger, and W. H. Zinn, "Design and Operating Experience of a Prototype Boiling Water Power Reactor," Proceedings of the International Conference on the Peaceful Uses of Atomic Energy, (New York: United Nations, 1956), Vo1. 3, p. 56.

4. W. H. Zinn, et. al., "Operational Experience with the BORAX Power Plant," Nuc. Sci. Eng. 1 (No. 5) 420 (1956).

5. O. A. Schulze, "BORAX-IV: Preliminary Report on the Present Series of Experiments with Oxide Fuels," Paper presented at the Technical Briefing Session held at Argonne National Laboratory, May 27-28, 1957, TID-7535, p. 114.

6. J. H. Handwerk, C. L. Hoenig, and R. C. Lied, "Manufacture of the $\mathrm{ThO}_{2}-\mathrm{UO}_{2}$ Ceramic Fuel Pellets for BORAX-IV, "ANL-5678 (August, 1957).

7. J. H. Handwerk and R. A. Noland, "Oxide Fuel Elements for BORAX-IV," TID-7535, p. 140 .

8. F. Schroeder, et, al,, "Experimental Study of Transient Behavior in a Subcooled Water-Moderated Reactor," Nuc. Sci. Eng. 2, 96 (1957).

9. S. G. Forbes, F. Schroeder, and W. E. Nyer, "First Reports on Instability in SPERT-I," Nucleonics 15 (No. 1) 41 (1957).

10. J.A. Thie, "EBWR Physics Experiments," TID-7535, p. 40. 
11. H. A. Bethe, "Reactor Safety and Oscillator Tests," APDA-117 (October 15, 1956).

12. M. N. Moore, "The Determination of Reactor Transfer Functions from Measurements at Steady Operation, " NAA-SR-1972 (August 15, 1957).

13. R. Macklin and H. Pomerance, "Resonance Capture Integrals," Proceedings of the International Conference on the Peaceful Uses of Atomic Energy, (New York: United Nations, 1956) Vol 5, p. 96.

14. J. M. Harrer, et. al., "Nuclear Reactor Control," Nucleonics, 10, (No. 8) 32 (1952).

15. J. A. Thie, "Stability of Bubbling Reactors," Reactor Engineering Division Quarterly Report - Section II, ANL-5601, (December, 1956) p. 31 .

16. J. A. Thie, "Boiling Water Reactor Instability," Nucleonics, 16, (No. 3) 102 (1958). 